University of Louisville

ThinkIR: The University of Louisville's Institutional Repository

\title{
The relationship between staff nurse perception of nurse manager leadership behavior and staff nurse job satisfaction in a hospital applying for magnet recognition status.
}

Lorraine B. Bormann

University of Louisville

Follow this and additional works at: https://ir.library.louisville.edu/etd

\section{Recommended Citation}

Bormann, Lorraine B., "The relationship between staff nurse perception of nurse manager leadership behavior and staff nurse job satisfaction in a hospital applying for magnet recognition status." (2011). Electronic Theses and Dissertations. Paper 129.

https://doi.org/10.18297/etd/129

This Doctoral Dissertation is brought to you for free and open access by ThinkIR: The University of Louisville's Institutional Repository. It has been accepted for inclusion in Electronic Theses and Dissertations by an authorized administrator of ThinkIR: The University of Louisville's Institutional Repository. This title appears here courtesy of the author, who has retained all other copyrights. For more information, please contact thinkir@louisville.edu. 
THE RELATIONSHIP BETWEEN STAFF NURSE PERCEPTION OF NURSE MANAGER LEADERSHIP BEHAVIOR AND STAFF NURSE JOB SATISFACTION IN A HOSPITAL APPLYING FOR MAGNET RECOGNITION STATUS

By

Lorraine B. Bormann

A.S.N. Western Kentucky University, 1978

B.S. Western Kentucky University, 2001

M.H.A. Western Kentucky University, 2003

\author{
A Dissertation \\ Submitted to the Faculty of the \\ Graduate School of the University of Louisville \\ in Partial Fulfillment of the Requirements \\ for the Degree of
}

Doctor of Philosophy

Department of Leadership, Foundations, and Human Resource Education University of Louisville 
Copyright 2011 by Lorraine B. Bormann

All rights reserved 
THE RELATIONSHIP BETWEEN STAFF NURSE PERCEPTION OF NURSE MANAGER LEADERSHIP BEHAVIOR AND STAFF NURSE JOB SATISFACTION IN A HOSPITAL APPLYING FOR MAGNET RECOGNITION STATUS

By

Lorraine B. Bormann

A.S.N. Western Kentucky University, 1978

B.S. Western Kentucky University, 2001

M.S. Western Kentucky University, 2003

A Dissertation Approved on

July 21, 2011

by the following Dissertation Committee:

Dissertation Director (Joseph Petrosko)

Ann Herd

Brad Shuck

Beverly Siegrist 


\section{DEDICATION}

I would like to dedicate this dissertation to my husband and best friend, Hank, and to my children, Sara, Anna and Nick McCahill, and Lisa. Without their loving support and encouragement, this would not have been possible.

I also dedicate this dissertation with loving memory of my son, Adam Bormann. 


\section{ACKNOWLEDGMENTS}

I would like to thank Dr. Joseph Petrosko, chair of my dissertation committee, for his guidance and patience. Dr. Petrosko remained available to answer questions and provide expertise throughout this project. I would also like to thank the other committee members, Dr. Ann Herd, Dr. Brad Shuck, and Dr. Beverly Siegrist for their comments and feedback. I also acknowledge Dr. Susan Lasky for her guidance and support during the major revisions. She encouraged me and helped me stay focused. Many thanks to my wonderful sisters for understanding those times when I was unavailable for extended periods of time: Doris Hill, Ellen Munchbach, and Loretta Dalrymple.

Lastly, I would like to acknowledge that partial funding for this dissertation was received from the College of Health and Human Services at Western Kentucky University and the Kappa Theta Chapter of Sigma Theta Tau. 


\begin{abstract}
THE RELATIONSHIP BETWEEN STAFF NURSE PERCEPTION OF NURSE MANAGER LEADERSHIP BEHAVIOR AND STAFF NURSE JOB SATISFACTION IN A HOSPITAL APPLYING FOR MAGNET RECOGNITION STATUS
\end{abstract}

Lorraine B. Bormann

June 29, 2011

Hospitals are challenged to understand factors related to staff nurse retention in the context of the nursing shortage slowdown (Huselid, 1995; Mancino, 2008; Mancino, 2009). Leadership is a major factor in organizational success (Gandossy \& Guarnieri, 2008; Gettler, 2003; Wooten \& Crane, 2003) and nurse managers are the direct link between the executive nurse leaders and the registered nurses $(R N)$ in the staff position (Taunton, Boyle, Woods, Hansen, \& Bott, 1997).

Studies show that nurse manager leader behaviors influence staff nurse job satisfaction (Blegen, 1993; Irvine \& Evans, 1995; Lashinger \& Finegan, 2005). A primary role of the nurse leader is to plan strategies for recruiting nursing personnel and to prevent rapid and frequent turnover of nursing staff (American Nurses Association [ANA] Nursing Administration Scope and Standards of Practice, 2009). Nurse managers are in a position to influence staff nurses' job satisfaction and retention through their leader behaviors.

McGuire and Kennerly (2006) and Brown and Reilly (2009) conducted studies that show managers perceive their leadership behaviors different than those who reported 
to them. Bass and Avolio (2004) pointed out that leadership is in the 'eye of the beholder' and the leadership behavior ratings represented the people's perceptions of leaders (p. 9). Understanding the staff nurse perception of their nurse manager leadership behaviors that are related to staff nurse job satisfaction will contribute to improving staff nurse retention strategies.

The Magnet Recognition program is one approach to improving staff nurse job satisfaction and retention. The Magnet Recognition program (Magnet) considers that the nurse leaders are the key to nursing excellence (American Nurses Credentialing Center [ANCC], n.d.). The sample population for this study was staff nurses in an acute care hospital applying for Magnet Recognition status.

The purpose of this correlational research study was to describe the relationship between the staff nurse perception of their nurse manager leadership behaviors associated with both the facets of staff nurse job satisfaction (job satisfaction with: work on present job, pay, promotion, supervision, and co-workers) and staff nurse overall job satisfaction and the relationship between the facets of staff nurse job satisfaction and staff nurse overall job satisfaction in an acute care hospital applying for Magnet Recognition status (Magnet status). The intent to depart is conceptually and empirically shown to be a direct antecedent to actual turnover. Overall job satisfaction and turnover are inversely related. Brodke et al. (2009) reported overall job satisfaction was the best predictor of intent to quit. Many studies examined facets of staff nurse job satisfaction but the researcher identified that few if any studies examined nurse manager leadership behaviors related to facets of staff nurse job satisfaction and staff nurse overall job satisfaction in a hospital in the process of applying for Magnet status. 


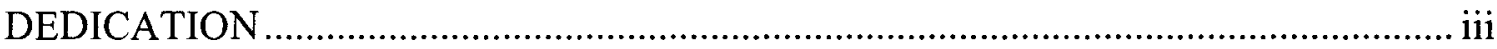

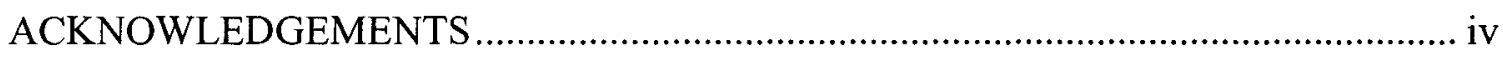

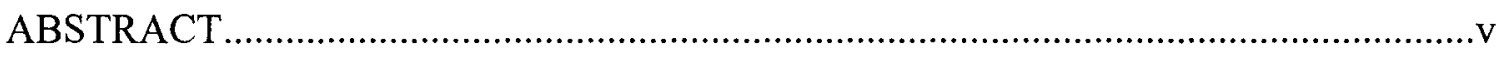

LIST OF TABLES

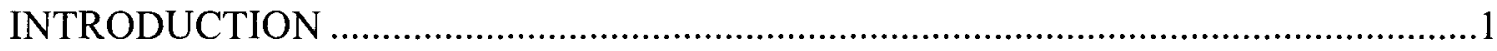

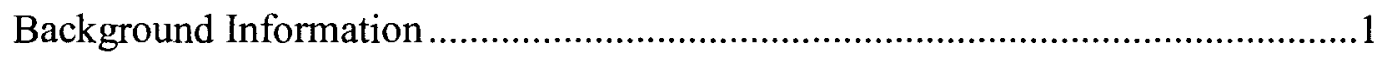

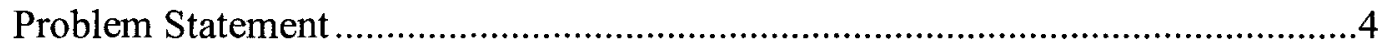

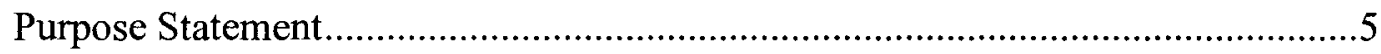

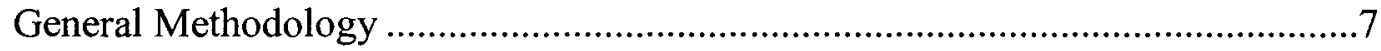

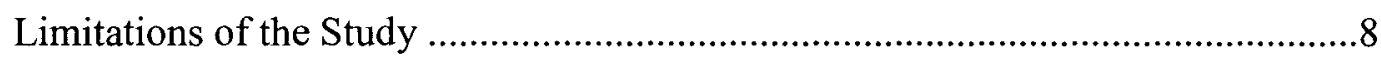

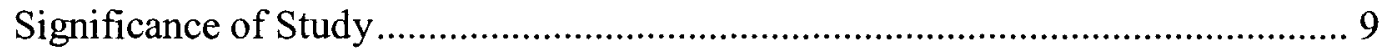

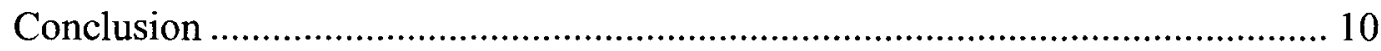

REVIEW OF LITERATURE

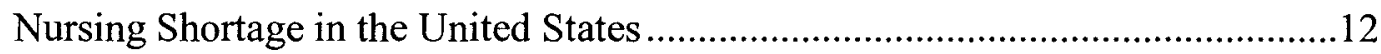

Recent History of Nursing Shortage .......................................................14

Influence of Retirement and Nurses .......................................................15

Influence of Faculty Shortage and Nursing Schools...................................16

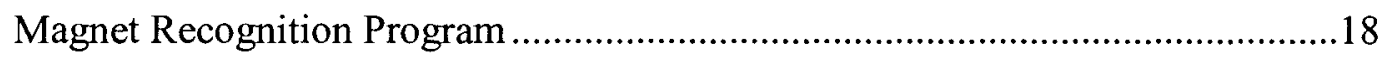

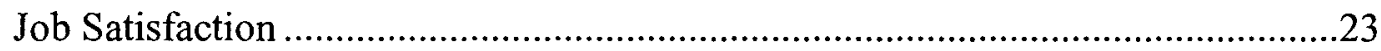

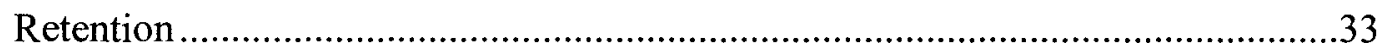

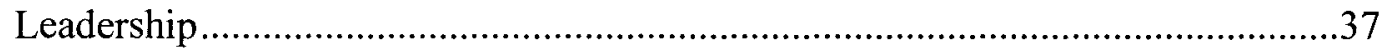

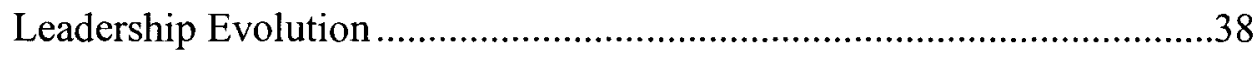

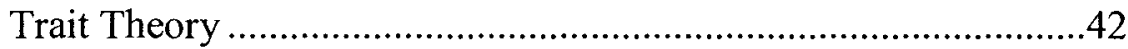

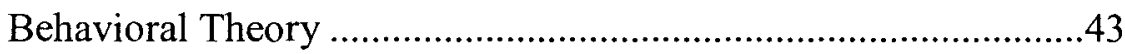

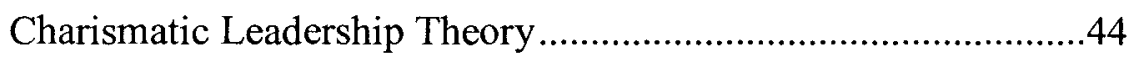

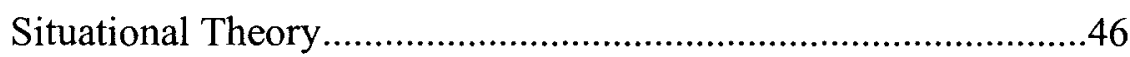

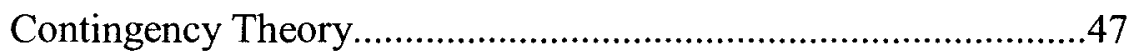

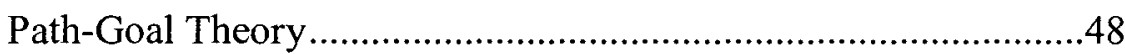

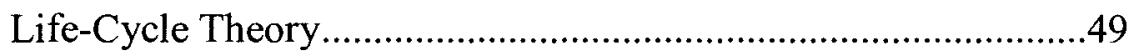

Transactional Leadership Theory …………………....................50

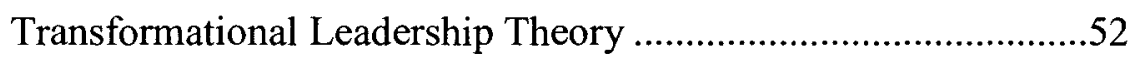

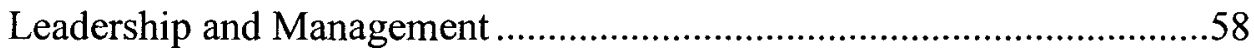

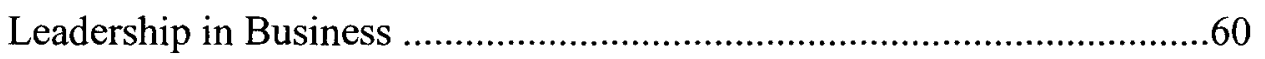


Leadership in Healthcare ......................................................................63

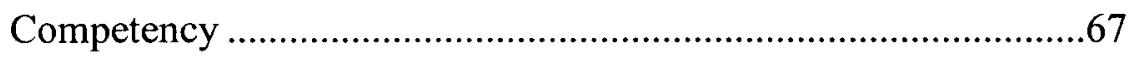

Best Practice..............................................................................

Leadership in Nursing........................................................................

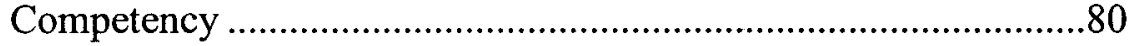

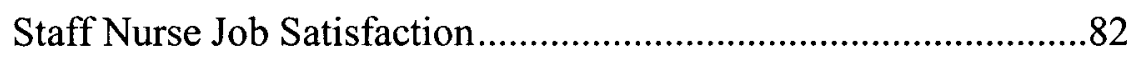

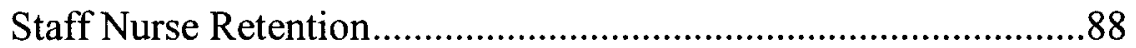

Summary and Research Problem ......................................................................

FRAMEWORK

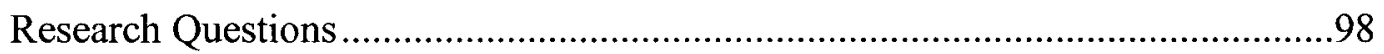

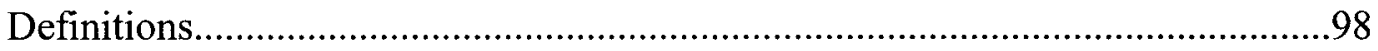

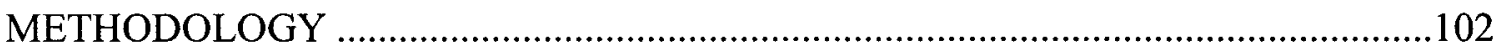

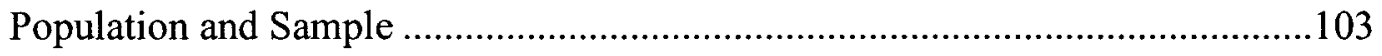

Sample Size and Power.........................................................................103

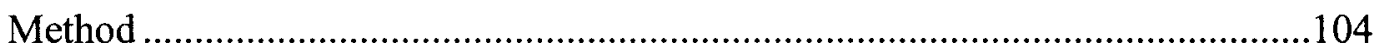

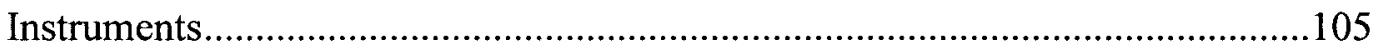

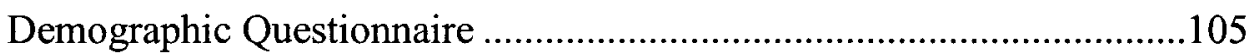

Multifactor Leadership Questionnaire ...................................................106

Abridged Job Descriptive Index/Abridged Job in General.......................109

Procedure

Data Management and Analysis ..................................................................

Statistical Analyses I Related to Research Questions................................114

Statistical Analyses II Related to Mediation Analysis Implied by the

Conceptual Framework .........................................................................115

Mediation Analysis .............................................................................116

Summary of Statistical Analyses .........................................................117

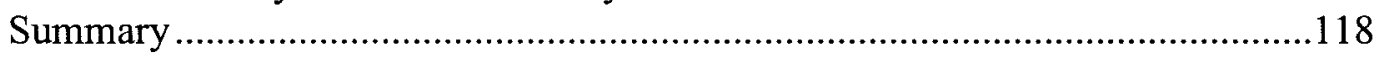

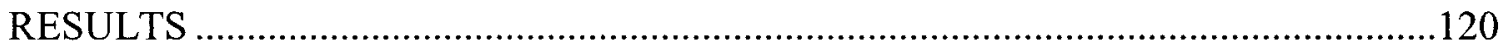

Procedures and Demographic Data.............................................................120

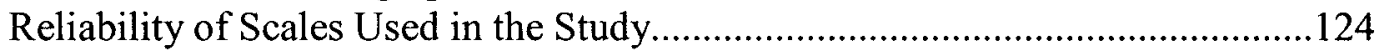

Results for Statistical Analyses Set I: Research Question 1 ............................125

Results for Statistical Analyses Set I: Research Question 2 ............................128

Results for Statistical Analyses Set I: Research Question 3 ............................130

Results for Statistical Analyses Set II: Mediation Analysis ...............................132

MLQ Transformational ....................................................................132

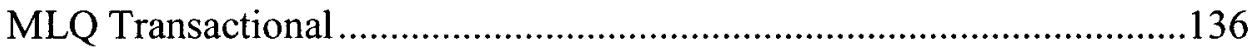

MLQ Passive-avoidant .........................................................................138

Summary of Results for Research Questions 1 through 3 and Mediation

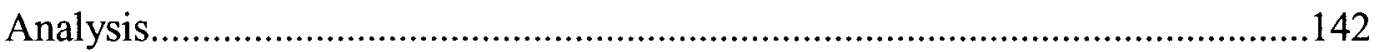

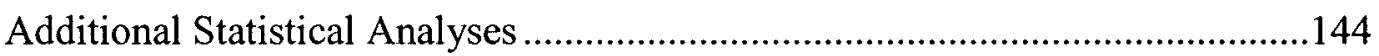




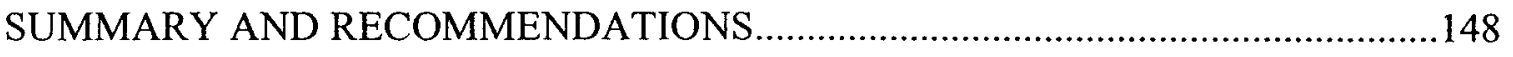

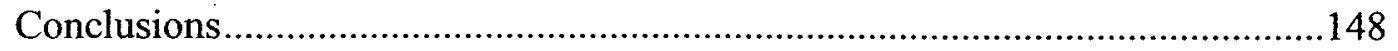

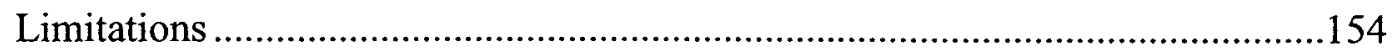

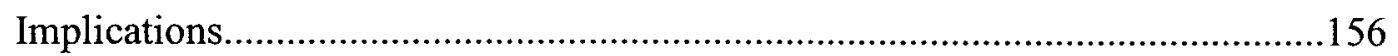

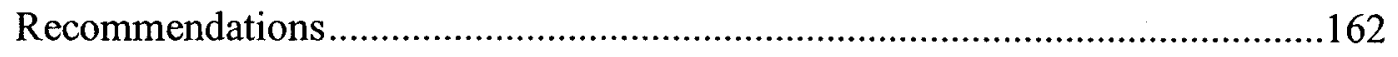

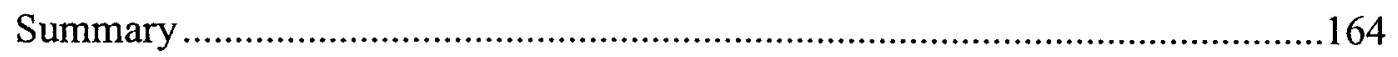

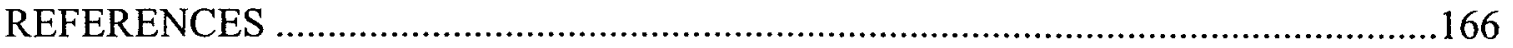

APPENDIX A - MULTIFACTOR LEADERSHIP QUESTIONNAIRE (MLQ), ABRIDGED JOB DESCRIPTIVE INDEX/ABRIDGED JOB IN GENERAL (AJDI/AJIG) SURVEY, AND DEMOGRAPHIC QUESTIONNAIRE .......................186

APPENDIX B - PERMISSION FOR USE OF THE MLQ QUESTIONNAIRE ...........190

APPENDIX C - PERMISSION TO USE ABRIDGED JOB DESCRIPTIVE INDEX/ ABRIDGED JOB IN GENERAL (AJDI - AJIG) ...................................................192

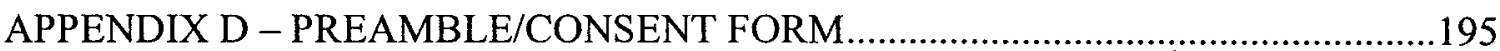

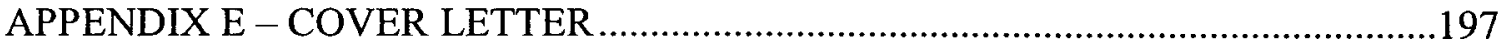

APPENDIX F - PERMISSION TO USE LEADERSHIP TABLE .............................199

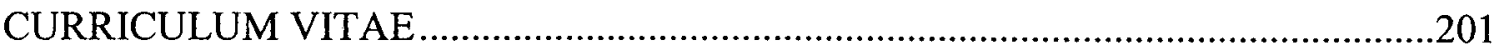




\section{LIST OF TABLES}

TABLE

PAGE

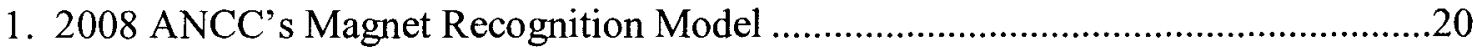

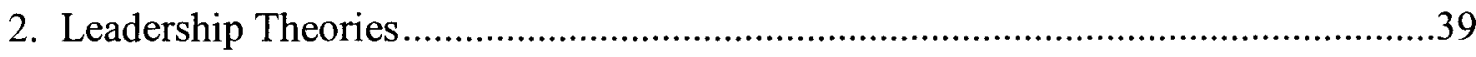

3. Cronbach's Coefficient Alpha among the MLQ subscales...................................108

4. Cronbach's Coefficient Alpha among the JDI facets and JIG.............................111

5. Variables Used in this Study for Mediation Analysis.......................................116

6. Source of Regression Coefficients for Mediation Analysis................................117

7. Summary of Proposed Statistical Analyses ..............................................118

8. Demographics including Age, Clinical Experience, and Academic Preparation .....121

9. Demographics including Length of Time in Current Hospital and Present

Position, Primary Work Shift, and Employment Status

10. Cronbach's Alpha Internal Consistency Reliability Coefficients for Scales Used in the Study

11. Results of Statistical Analyses Set I, Research Question I: Descriptive Statistics for Perceived Nurse Manager Leadership Behaviors and Facets of Staff Nurse Job Satisfaction.

12. Results of Statistical Analyses Set I, Research Question I: Correlations between Perceived Nurse Manager Leadership Behaviors and Facets of Staff Nurse Job Satisfaction

13. Results of Statistical Analyses Set I, Research Question 2: Descriptive Statistics 
for Perceived Nurse Manager Leadership Behaviors and Overall Nurse Job

Satisfaction.

14. Results of Statistical Analyses Set I, Research Question 2: Correlations between Perceived Nurse Manager Leadership Behaviors and Overall Staff Nurse Job Satisfaction.

15. Results of Statistical Analyses Set I, Research Question 3: Descriptive Statistics for Ratings of Five Job Facets and Overall Nurse Job Satisfaction

16. Results of Statistical Analyses Set I, Research Question 3: Correlations between Ratings of Five Job Facets and Overall Nurse Job Satisfaction

17. Regression Summaries for Mediation Analysis: MLQ Transformational and aJDI supervision Prediction JIG score

18. Regression Coefficients (Betas) Used to Test Mediation: MLQ Transformational and aJDI supervision Predicting JIG score

19. Regression Summaries for Mediation Analysis: MLQ Transactional and aJDI Supervision Predicting JIG score.

20. Regression Coefficients (Betas) Used to Test mediation: MLQ Transactional and aJDI supervision Predicting JIG score

21. Regression Summaries for Mediation Analysis: MLQ Passive-avoidant and aJDI Supervision Predicting JIG score.

22. Regression Coefficients (Betas) Used to Test Mediation: MLQ Passive-avoidant and aJDI supervision Predicting JIG score

23. Summary of Results for Research Questions 1 through 3 and Mediation Analysis .142

24. Summary of Results of Mediation Analyses 143 


\section{CHAPTER I}

\section{INTRODUCTION}

Chapter one provides an introduction to and an overview of the research study.

The chapter begins with the background of the study, followed by the problem statement, purpose statement, general methodology, limitations of the study, and significance of the study. The chapter concludes with a brief description of the organization of the dissertation.

\section{Background Information}

The current and projected nursing shortage in the United States has been widely reported in the literature and makes it essential for hospital organizations to understand the factors related to staff nurse retention. The Institute of Medicine (IOM), in collaboration with The Robert Wood Johnson Foundation (RWJF), released a report on October 5, 2010, The Future of Nursing: Leading Change, Advancing Health, calling for the transformation of the nursing profession. One of the key recommendations presented in the report calls for nurses to "take responsibility for their personal and professional growth by developing leadership competencies and exercising these competencies across all care settings" (Institute of Medicine [IOM], 2010, p. 3). A primary role of the nurse leader is to plan for retention strategies (ANA Nursing Administration Scope and Standards of Practice, 2009).

Previous studies identified nursing leadership as a factor influencing staff nurse satisfaction and retention. This study seeks to supplement these studies by identifying 
key behaviors of nurse managers as perceived by their staff nurses that influence facets of staff nurse job satisfaction and staff nurse overall job satisfaction. McGuire and Kennerly (2006) and Brown and Reilly (2009) conducted studies that showed nurse managers perceived themselves with different leadership behaviors than did those who reported to them. The goal of the study was to describe the relationship between staff nurse perception of their nurse manager leadership behavior and facets of staff nurse job satisfaction and staff nurse overall job satisfaction and to examine the relationship between the facets of staff nurse job satisfaction and staff nurse overall job satisfaction. The researcher used a descriptive correlational design to survey staff nurses in an acute care hospital applying for Magnet Recognition status.

Hospital executives face challenges to recruit and retain clinical nurses (Force, 2005) and continually seek ways to improve their organizations. The Magnet Recognition program was developed during the nursing shortage in the $1980 \mathrm{~s}$ in an effort to identify the characteristics of hospitals that were considered successful with improved staff nurse satisfaction and retention rates as compared to other hospitals (Lewis \& Matthews, 1998). The Magnet Recognition program is sponsored by the American Nurses Credentialing Center (ANCC) in Washington, DC and provides a designation for excellence in nursing services. Evidence suggests that the Magnet Recognition program demonstrates excellent outcomes in both patient care as well as the ability to attract and retain nurses (Brady-Schwartz, 2005; Hader, Saver \& Steltzer, 2006; Prater, 2009; Taylor, 2005; Upenieks, 2003a).

The shortage of nurses is expected to continue as the baby boomers age and the need for health care increases. Although the actual supply of nurses continues to grow, the growth has not kept up with the increase in demand for nurses. The projected 
shortage of nurses is driven by the large cohort of baby boom registered nurses that are expected to retire in the next decade. The smaller cohorts of RNs following the retiring baby boom RNs prevents the workforce from shrinking but is not large enough to meet the anticipated demand for nurses (American Association of Colleges of Nursing [AACN], 2010; American Hospital Association [AHA], 2002; Buerhaus, Auerbach \& Staiger, 2009). Aiken et al. (2001) reported two in ten nurses planned to leave their jobs within the next year and included a noticeable percentage of nurses under age thirty planned to leave their hospital jobs.

Nurse administrators find themselves with an ever-growing demand for nursing services, with limited staff to fill that need (ANA, 2009, p. 21). Nurse administrators respond to the increasing needs of the aging employee by improving workplace satisfaction with accommodations in scheduling and improving the physical nursing environment. Nurse administrators strategize to recruit nursing staff and prevent rapid and frequent turnover of nursing staff (ANA, 2009). Cullen (as cited in Force, 2005) explained nurse administrators learned from exit interviews how management's behaviors and leadership styles impacted staff nurse desire to leave or stay with their organization.

Providing leadership in human resource development and management is an expected role of the nurse administrator (ANA, 2009). The supply of nurses is impacted by the shortage of students in nursing programs and graduate nurses in practice. Sound management principles are necessary to recruit and retain nurses. The demand for nurses in some specialties and geographic areas exceeds supply and management processes require innovation to provide the environment for high morale, motivation, and productivity to meet this demand. Financial considerations have increasingly dominated 
the health care industry, making the job of managing costly human and material resources even more important (Roussel, 2006).

Nurse retention focuses on preventing nurse turnover and keeping nurses in an organization's employment (Jones \& Gates, 2007). Results from a survey of 3,266 new RNs found 13 percent of newly licensed RNs had changed jobs after one year and 37 percent reported they had a desire to change jobs. Healthcare organizations reported nurse retention was a key strategic tool to a successful organization but only 40 percent reported a formal retention plan (Kovner et al., 2007). Retention efforts are imperative to protect the investment in human capital (Nursing Solutions, Inc. [NSI], 2009). Taunton et al. (1997) identified manager leadership behaviors as the "target for intervention most likely to improve retention of hospital staff nurses" (p. 224).

In summary, a better understanding of the nurse manager leader behaviors that are perceived by staff nurses as related to staff nurse job satisfaction ultimately leads to improved professional and patient outcomes (Sherman, Bishop, Eggenberger \& Karden, 2007) as well as improved staff nurse retention (Taunton et al., 1997). Any shortage of nurses in the United States compromises good nursing care and "shortages lead to lack of care, missed treatments, low morale, high turnover, and ultimately high costs to consumers" (Malloch \& Porter-O'Grady, 2009, p. 165).

\section{Problem Statement}

The literature identified many factors that contributed to the nursing shortage but few, if any studies described the staff nurse perceptions of their nurse manager leader behaviors that were related to facets of staff nurse job satisfaction and staff nurse overall job satisfaction in a hospital applying for Magnet Recognition status. A strategy for reducing the nursing shortage in hospitals is to improve staff nurse recruitment and 
retention. Nursing is the largest employment sector in a healthcare facility. The nurse managers have responsibility for staff nurse effectiveness and quality of patient care outcomes, job satisfaction, organizational commitment (McNeese-Smith, 1997) and retention (Taunton et al., 1997). The behaviors and attitudes of the nurse managers can influence staff nurse job satisfaction and retention within the organization. Describing the nurse manager leader behaviors that are perceived to be related to facets of staff nurse job satisfaction and staff nurse overall job satisfaction provides valuable insight for the hospital administration and for human resource management and development, training and retention strategies.

The problem of concern to this study was the impact that nurse mangers have with their staff nurses' facets of job satisfaction and staff nurse overall job satisfaction that has not been well studied in a hospital in the process of applying for Magnet Recognition status. This study examined the nurse manager leader behaviors that were perceived by their staff nurses and how these leader behaviors were related to staff job satisfaction in an acute care hospital setting in the process of applying for Magnet Recognition status. The results of the study were expected to show a significant relationship between the nurse manager leadership behaviors perceived by their staff nurses and facets of staff nurse job satisfaction and staff nurse overall job satisfaction.

\section{Purpose Statement}

The effective nurse manager achieves a balance between leadership behaviors, thus creating a leadership style that matches the needs of the followers (McGuire \& Kennerly, 2006). The purpose of this study was to describe the relationship between perceived leadership behaviors of nurse managers by their staff nurses and the job satisfaction of registered nurses at the staff level in an acute care hospital in the southern 
United States that was applying for Magnet Recognition status. Each nurse manager's perceived predominant leadership style was identified by their staff nurses and then examined in relationship to facets of staff nurse job satisfaction and to staff nurse overall job satisfaction.

A better understanding of nurse manager leader behaviors and the relationship to staff nurse job satisfaction is crucial to improving staff nurse retention in a hospital applying for Magnet Recognition status. Magnet status hospitals demonstrate nursing excellence through improved job satisfaction and retention rates. Some studies of job satisfaction and nurse managers have been conducted in the hospital setting but few studies, if any, have taken place with a hospital applying for Magnet Recognition status. Job satisfaction was crucial to retaining and attracting well-qualified personnel and was especially an issue in medical institutions such as hospitals due to the high skills that were required (Kleinman, 2004b).

Staff nurse satisfaction and retention are critical due to the increased cost of recruitment and training new nurses. Although not all types of voluntary turnover are negative, voluntary turnover that is avoidable can be very costly in terms of recruitment, selection, and training of nurses. Costs associated with the average per-RN cost of turnover stem from vacancy, orientation and training, newly hired-RN productivity, and recruiting costs. The cost estimate of per-RN turnover is 1.2 to 1.3 times the annual salaries of registered nurses. The costs range from $\$ 82,000$, if experienced nurses fill the open staff nurse vacancies, to $\$ 88,000$ when hiring newer nurses who require longer orientation and greater training (Jones, 2004, 2008).

Research in the social sciences indicated that leadership styles and behaviors can have an influence on performance and outcomes. It is important to describe the 
relationship between the effects of leadership in the health care environment and how that affects outcomes such as job satisfaction and retention (Kleinman, 2004a, 2004b; Rad \& Yarmohammadian, 2006). Nurses reported increased stress and dissatisfaction and turnover rates were increasing at a time when demand for nurses was also increasing (Vahey, Aiken, Sloane, Clarke, \& Vargas, 2004). The focus of this research pertained specifically to the registered nurse working at the staff level in the acute care hospital setting and their perception of their nurse manager leadership behaviors that were related to the facets of staff nurse job satisfaction and staff nurse overall job satisfaction.

\section{General Methodology}

The quantitative study utilized a descriptive survey research design. The focus of the survey was to describe the relationship between the leadership behaviors of nurse managers as perceived by their staff nurses that were associated with facets of staff nurse job satisfaction and to staff nurse overall job satisfaction and to compare facets of staff nurse job satisfaction and staff nurse overall job satisfaction.

Permission was obtained from the institutional review boards at both the University of Louisville and the hospital where the research was conducted. The data collection began during the hospital's shared governance meetings when the staff nurses attended the sessions. The survey packets included a brief description of the study, a consent form, a questionnaire that included the Multifactor Leadership Questionnaire (MLQ), the Abridged Job Descriptive Index/Abridged Job in General (aJDI/aJIG) survey and the demographic questionnaire. The returns were tracked and opportunities to collect additional surveys were available at the shared governance meetings the following two months. 
The research questions for the study were:

1. What is the relationship between staff nurse perception of the nurse manager leadership behavior and the facets of staff nurse job satisfaction?

2. What is the relationship between the staff nurse perception of the nurse manager leadership behavior and the staff nurse overall job satisfaction?

3. What is the relationship between facets of staff nurse job satisfaction and staff nurse overall job satisfaction?

The independent variables were the perceived nurse manager leader behaviors perceived by their staff nurses as measured by the demographic variables and the MLQ. The dependent variables were the facets of staff nurse job satisfaction measured by the aJDI and staff nurse overall job satisfaction measured by the aJIG. The MLQ was used to address the first and second research questions regarding the staff nurse perception of their nurse manager leadership behavior. The aJDI was used to address the first and third research questions regarding facets of staff nurse job satisfaction. The aJIG was used to address the second and third research questions regarding staff nurse overall job satisfaction.

\section{Limitations of the Study}

Limitations of the study which may affect the ability to generalize findings included the following: the study design, the use of distributed surveys, the use of reported data related to nurse manager leader behaviors based on perception of the staff nurse and not actual leadership behaviors; the sample population was limited to staff nurses at a non-profit acute care hospital in the southern United States applying for Magnet status and may not apply to for-profit or hospitals in other geographical 
locations; and the study criteria excluded private hospitals, home care agencies, and urgent care facilities.

\section{Significance of the Study}

Describing the relationship between nurse manager leader behaviors as perceived by their staff nurses to facets of staff nurse job satisfaction and staff nurse overall job satisfaction contributes to the existing knowledge in nursing research related to staff nurse retention specifically in hospitals applying for Magnet Recognition status. Many of the complex demands faced by executives in the acute care hospitals are also realized at the nurse manager and staff nurse level. The staff nurse relies on the nurse manager's clinical and leadership abilities to have a smooth running unit that results in satisfied nurses and quality patient care.

The staff nurse perception of their nurse manager leadership behavior as it relates to facets of staff nurse job satisfaction and staff nurse overall job satisfaction is of interest because nurse managers have a responsibility to the organization to support staff nurse job satisfaction and staff nurse retention strategies. This study revealed important information about staff nurse perceptions of nurse manager leader behaviors, facets of staff nurse job satisfaction and staff nurse overall job satisfaction.

The research was particularly important to hospitals applying for Magnet Recognition status in their efforts to improve nurse satisfaction scores and retention rates. The research proved useful to the study site and gave insight into potential strategies related to leadership training and retention. Ultimately, the results of the study were expected to have a positive influence on understanding nurse manager leader behaviors that positively influence staff nurse job satisfaction and retention in a hospital applying for Magnet Recognition status. 


\section{Conclusion}

The characteristics and skills of effective leaders and managers and their influence on successful organizations and outcomes has been a topic in the literature for over thirty years and needed further study in the health care environment. Research on leadership that was reported in the healthcare literature was primarily descriptive but did show that it had substantial effects on people and organizational outcomes (Bass, 1990; Luthans, 2005; Sellgren, Ekvall, \& Tomson, 2006; Vance \& Larson, 2002).

Sellgren et al. (2006) found leadership behaviors that were suitable for health care organizations had been poorly explored. Recent studies demonstrated deficiencies in the quality of health care and organizations were challenged to implement quality improvement programs and include the structure of the organization (Glickman, Baggett, Krubert, Peterson, \& Schulman, 2007). Describing the perception of registered nurses of their nurse manager leader behaviors in this study gave additional insight into how nurse manager leader behavior affected facets of staff nurse job satisfaction and staff nurse overall job satisfaction within the organization.

The current and projected shortage of nurses in the United States requires that healthcare organizations investigate opportunities to improve staff nurse job satisfaction and retention. Healthcare organizations have an increased incentive to improve staff nurse retention due to the high financial costs related to nursing turnover and associated adverse patient outcomes. The literature supported the assertion that nurse manager leader behaviors impacted staff nurse job satisfaction which showed a relationship to staff nurse intent to depart and turnover. Understanding the leader behaviors of the nurse managers that influence staff nurse job satisfaction provides guidance in the hiring and training process of nurse managers, thus ultimately influencing retention. 
Chapter 1 provided an overview of the study. The background information described the nursing shortage and laid the foundation for understanding the relationship between nurse manager leadership behavior as perceived by their staff nurses and staff nurse job satisfaction. Detailed rationale for the study was presented followed by an overview of pertinent nursing literature. The methodology subsection describes the study design, the independent and dependent variables, and measurement tools. Limitations of the study identified the scope and potential weaknesses of the study and the significance of the study described rationale for the study and how it contributes to professional nursing knowledge and practice.

Chapter 2 contained a comprehensive review of the literature related to the major constructs of the research project including job satisfaction, retention, and leadership. The literature review included leadership theories; leadership and management; leadership in business; leadership in healthcare including competency and best practice; and leadership in nursing including competency, staff nurse job satisfaction, and staff nurse retention. The nursing shortage and Magnet Recognition program were reviewed as contextual elements of the project. Chapter 3 explained the conceptual framework for the research project and the research questions. Definitions of key terms were provided to provide clarity in following chapters. Chapter 4 outlined the study design for collecting survey data, the research setting, and sample. The measurement tools and the data management and analyses were explained. Chapter 5 presented the data results. Chapter 6 summarized the findings and provided a discussion of the findings with recommendations for further study. 


\section{CHAPTER II \\ REVIEW OF LITERATURE}

Chapter two gives empirical evidence for the major constructs of this project and the impact that nurse manager leader behaviors have with staff nurse job satisfaction. The Magnet Recognition Program is presented followed by the major construct of leadership and extensive literature surrounding nurse managers and staff nurse job satisfaction, and staff nurse retention.

Chapter two begins with information regarding the nursing shortage in the United States. This is followed by a discussion of literature regarding the foundations of job satisfaction, leadership evolution; leadership and management; and leadership in business, healthcare and nursing. Also included is information about healthcare related competencies and best practices. Leadership in nursing is broken down into nurse leader competencies, staff nurse job satisfaction and staff nurse retention.

\section{Nursing Shortage in the United States}

Hospitals are challenged to understand factors related to staff nurse retention in the context of the nursing shortage slowdown (Huselid, 1995; Mancino, 2008; Mancino, 2009). The 2001 Institute of Medicine (IOM, 2001) report, Crossing the Quality Chasm: A New Health System for the 21st Century, recognized the complexity of health care systems and organizations. Today's health care environment is dynamic and ever changing and requires organizations to continually adapt and improve (Lasky, Datnow, Stringfield, \& Sundell, 2007; Senge, 1990). The complexity of hospitals is intensified by 
the nursing workforce shortage (Blendon et al., 2001; Buerhaus et al., 2009; IOM, 2010) and brings challenges to hospital and nursing administrators regarding staff nurse job satisfaction and retention.

The Magnet Recognition program originated as a policy study that was commissioned by the American Academy of Nursing (AAN) in 1981 during a time of severe nursing shortages. The study examined nursing practices in 41 out of 165 hospitals and focused on the factors influencing the attraction and retention of registered nurses and those features that were shared by the successful hospitals. The 41 selected hospitals were part of a nomination process by the Fellows of the American Academy of Nursing. The Fellows considered the following criteria for nomination of the hospitals: 1) the hospital was considered a good place to work by nurses, 2) the hospital had a relatively low turnover rate of nurses, and 3) the hospital was in a competitive market and was not the single source of nurse employment in a labor market (Buchan, 1999). The findings from the policy study determined that nurse leaders were the key to creating and sustaining an environment that supported nursing excellence (Lewis \& Matthews, 1998).

The supply and demand for staff nurses in the United States continues to change over time. The nursing shortage in the U.S. was projected to grow to 260,000 RNs by 2025 (Buerhaus et al., 2009). There were approximately 3,063,163 licensed RNs in the U.S. in 2008 , a 5.3 percent increase from 2004. Not all licensed RNs are employed in nursing positions (U.S. Department of Health and Human Services, Health Resources and Services Administration [HRSA], 2010). Buerhaus et al. (2009) reported that the supply of full time equivalent (FTE) RNs in the workforce in the U.S. was 2.5 million and was expected to reach nearly 2.8 million FTE RNs by. HRSA (2010) data revealed the U.S. had a ratio of 854 RNs per 100,000 people. Utah had the fewest RNs per 100,000 with 
598 for each 100,000 people and the District of Columbia had the most, 1,868 RNs per 100,000 people. Kentucky had a ratio of 973 RNs per 100,000 people (HRSA, 2010).

\section{Recent history of nursing shortage.}

The nursing shortage in the U.S. developed more than ten years ago. The U.S. has experienced two recessions during the current nursing shortage. The first recession in 2001 resulted in the national unemployment rates peaking at 6.3 percent. The second recession began in 2007 with unemployment rates at 7.2 percent in December 2008 (Buerhaus et al., 2009). U.S. annual unemployment rates averaged 9.3 percent in 2009. Kentucky unemployment rates averaged 6.6 percent in 2008 and 10.5 percent in 2009 (U.S. Department of Labor, Bureau of Labor Statistics [BLS], 2010). According to a report by the American Hospital Association (AHA) in July 2007, more than 135,000 RN vacancies existed in the U.S. and translated into a national RN vacancy rate of 8.1 percent (AACN, 2010; American Hospital Association [AHA], 2007).

The national hospital nurse turnover in 2001 averaged 20 percent (Force, 2005). The Bernard Hodes Group (as cited in AACN, 2010) conducted a national poll of 138 health care recruiters and found the average RN turnover rate was $13.9 \%$ in 2005 . In 2009, 123 U.S. hospitals responded to the "National Healthcare and RN Retention" survey. The results of the survey indicated the average national hospital $\mathrm{RN}$ turnover rate in 2009 was 14.2 percent (Nursing Solutions, Inc [NSI], 2009).

Nurses perceived the RN shortage impacted patient care and quality initiatives (Buerhaus, Donelan, Ulrich, Norman, \& Dittus, 2006). A Commonwealth Fund International Health Policy survey of physicians in five countries including the United States, Australia, Canada, New Zealand, and the United Kingdom indicated that doctors ranked nurse staffing levels at hospitals as a major concern in providing top-quality 
health care. The survey also found physicians in all five countries reported a serious nursing shortage (Blendon et al., 2001).

The U.S. Bureau of Labor Statistics (2009), estimated 581,500 new RN positions would be created through 2018 , a growth of 22.2 percent and the largest increase for any occupation during the recession. The most common job for RNs in the U.S. was the position "staff nurse" with 66.3 percent of employed RNs working as staff nurse in 2008 compared to 64.1 percent working as staff nurse in 2004. Hospitals were the most common employment setting for RNs in the U.S. with 62.2 percent of employed RNs working in hospitals in 2008. The number of RNs working in hospitals in 2004 was 56.2 percent (HRSA, 2010). Hospital RN employment increased by 184,000 FTE RNs during 2002 - 2003 and 243,000 FTEs during 2007 - 2008. New RN positions were expected to be created as the economy improved and the baby-boom nurse generations retired in great numbers. Buerhaus et al. (2009) explained a recent increase in employment for RNs increased the percentages of RNs in the workplace, yet large shortages of nurses were expected through the next decade.

\section{Influence of retirement and nurses.}

More recent literature finds that nurses are aging and statistics suggested that a large percentage of nurses will retire in the next decade (AACN, 2010; Buerhaus et al, 2009). In addition to retiring nurses, the percentage of nurses under age thirty was found to be quite low and impacted those nurses with the potential for extended careers in nursing (Aiken et al., 2001). The HRSA (2010) national survey data of registered nurses reported the average age of all RNs increased to 47.0 years in 2008 from 46.8 years of age in 2004 and represented stabilization after many years of continuing large increases in average age. HRSA (2010) reported nearly 45 percent of RNs were 50 years of age or 
older in 2008, a dramatic increase from 33 percent in 2000 and 25 percent in 1980. Results from Nursing Management's Aging Workforce Survey of nearly 1,000 registered nurses reported 55 percent of surveyed nurses plan to retire between 2011 and 2020 (Hader et al., 2006). A shortage of nurse managers in the health care profession is threatening as nurses currently in these positions approach retirement and fewer nurses are seeking nursing management positions. Hader et al. (2006) reported the largest majority of nurses who planned to retire were nurse managers followed by a large percentage of staff nurse employees.

\section{Influence of faculty shortage and nursing schools.}

New nurse graduates are not expected to replace retiring nurses due to nursing schools being unable to attract and retain the adequate nursing faculty and clinical staff that are necessary to train the increasing numbers of nurse applicants (American Association of Colleges of Nursing [AACN], 2010, 2005, 1999; Atencio, Cohen, \& Gorenberg, 2003; Buerhaus et al., 2009). The AACN completed an "Annual Survey of Institutions with Baccalaureate and Higher Degree Nursing Programs" representing 640 member schools of nursing at public and private institutions. U.S. nursing schools turned away 32,797 qualified applicants from baccalaureate and graduate nursing programs in 2004 and turned away 54, 991 qualified applicants from baccalaureate and graduate nursing programs in 2009. U.S. nursing schools turned away 42,981 qualified applicants from baccalaureate nursing programs in 2009 compared to 3,600 qualified applicants in 2002. The reasons qualified applicants were turned away from nursing schools were due to a shortage of faculty, clinical sites, classroom space, clinical preceptors, and budget constraints (AACN, 2010, 2005, 1999; Buerhaus et al., 2009). 
Fang and Tracy (2010) analyzed data from the $2009-2010$ Enrollment and Graduations in Baccalaureate and Graduate Programs in Nursing AACN survey and reported 56 percent of the 554 responding schools with vacancies and the need for additional faculty. Schools reported no faculty vacancies but reported the need for additional faculty to increase nursing programs was 21.1 percent. The major reasons reported for preventing schools of nursing from hiring additional full time faculty for $2009-2010$ were: insufficient funds to hire additional faculty, unwillingness of administration to commit to additional full-time positions, inability to recruit qualified faculty related to competition, and geographical unavailability of qualified faculty applicants. The major issues related to faculty recruitment and retention included: noncompetitive faculty salaries, limited pool faculty with doctoral degree, and high faculty workload (AACN, 2010).

Student enrollment increased into baccalaureate nursing programs by 3.5 percent from 2008 to 2009 . The number of graduates from entry level baccalaureate nursing programs increased by 3.2 percent from 2008 to 2009 . The rise in graduation from baccalaureate degree nursing programs continued an upward trend from 2001 to 2009 . The upward trend in baccalaureate nursing graduates from 2001 to 2009 was preceded by a six-year decline in baccalaureate nursing graduates from 1996 through 2001. The growth of RNs with master's or doctoral degree in nursing or a related field increased 46.9 percent from 2000 to 2008 . The increased enrollment in graduate programs addresses future needs for nurses to serve in teaching and leadership roles (AACN, 2010; HRSA, 2010).

Many nursing graduates are staying in school or returning to school to increase their education, which should increase their employability (Randolph, 2010). The most 
common initial RN education is the associate degree. The number of RNs with diploma degree education is declining and is a trend that continued since 1980. The number of RNs with an initial bachelor's degree in nursing continues a steady increase from 17.6 percent in 1980 to 34.2 percent in 2008. Nursing schools indicated in the AACN survey that a shortage of faculty, insufficient clinical education sites, and budget cuts were barriers to future growth (AACN, 2010).

Nationally, 50 percent of RNs have achieved a baccalaureate degree or higher in 2008 compared to 27.5 percent in 1980 (HRSA, 2010). The National Student Nurses Association (NSNA) conducted studies among new nurse graduates in 2008 and again in 2009 and found new graduates are experiencing a delay in obtaining employment and cited reasons related to the recent U.S. economic slowdown (Mancino, 2008; Mancino, 2009). "The nursing shortage will be compounded once the health of the U.S. economy is restored by the sudden exodus of retiring nurses and the increased hospital census. We will have to compensate for the nurses lost to other fields and for the possible decline in nursing school applications and enrollments" (Mancino, 2009, p. 2).

\section{Magnet Recognition Program}

In the context of the nursing shortage, the American Nurses Association (ANA), through the American Nurses Credentialing Center (ANCC), established the formal Magnet Nursing Services Recognition Program in 1994. The ANCC is a subsidiary of the American Nurses Association (ANA) and provides support resources to the nursing profession required to achieve excellence (ANCC Magnet Recognition Program, n.d.). The designation as a Magnet hospital acknowledges excellence in nursing services. Healthcare organizations with Magnet status were recognized as having cultures that 
valued excellence in nursing care and professional practice and demonstrated an ability to attract and retain professional nurses (Aiken, Havens, \& Sloan, 2000).

Buchan (1999) examined the research base for Magnet hospitals - those that had a good reputation for recruitment and retention of registered nurses. Previous research was reviewed, trends in nursing employment were examined, and 14 case studies were revisited. The results of the study found that some of the original 14 Magnet hospitals no longer exhibited the core characteristics of 'magnetism' while others retained the characteristics despite organizational change over time. The conclusion of the study recommended the need to monitor Magnet hospitals for changes in light of significant changes in the U.S. health system.

Almost 20 years after the launching of the ANCC Magnet hospital application and designation program only 16 Magnet hospitals had been identified of the original 41 hospitals selected in the original nomination process (Aiken et al., 2000). The American Hospital Association 2008 annual survey reported there were 5,815 hospitals in the United States and resulted in the 6.3 percent of hospitals in the United States with Magnet designation (American Hospital Association [AHA], 2010). Presently, there are 372 Magnet hospitals worldwide. There are 367 Magnet hospitals in the United States, two Magnet hospitals in Australia, one Magnet hospital in Lebanon, one Magnet hospital in New Zealand, and one Magnet hospital in Singapore. Kentucky currently has five hospitals that have been designated as Magnet hospitals. These hospitals are Baptist Hospital East, Louisville (2008); Central Baptist Hospital, Lexington (2005); Kosair Children's Hospital, Louisville (2007); St. Elizabeth Medical Center, Edgewood (2006); and University of Kentucky Hospital, Lexington (2001) (American Nurses Credentialing Center [ANCC], 2010). 
The 2008 ANCC's Magnet Recognition program configured the foundational 14 Forces of Magnetism into 5 Model Components noted in Table 1.

Table 1

2008 ANCC's Magnet Recognition Model

The 14 Forces of Magnetism include:

1. Quality of nursing leadership

2. Organizational structure

3. Management style

4. Personnel policies and programs

5. Professional models of care

6. Quality of care

7. Quality improvement

8. Consultation and resources

9. Autonomy

10. Community and the hospital

11. Nurses as teachers

12. Image of nursing

13. Interdisciplinary relationships

14. Professional development

The 5 Model Components include:

1. Transformational leadership

2. Structural empowerment

3. Exemplary professional practice

4. New knowledge, innovation, and improvements

5. Empirical quality results

(ANCC Magnet Recognition Program, n.d.) 
Magnet hospitals have been successful in recruiting and retaining nurses and research studies show that organizations with Magnet status have high levels of nursing satisfaction (Brady-Schwartz, 2005; Hader et al., 2006; Prater, 2009; Taylor, 2005; Upenieks, 2003a). The success of the health care organization depends on how well they incorporate the characteristics of the Magnet program into the health care organizational culture and requires ongoing commitment from leadership in the organization (Kramer \& Schmalenberg, 2005). The hospital site for this research study is in the process of applying for the Magnet Recognition designation. The results of the study can provide important data to the chief nursing officer as they proceed with the application process. The data related to staff nurse job satisfaction and staff nurse intent to depart and the relationship to nurse manager leadership behaviors allows for strategic planning and training opportunities to target staff nurse retention strategies.

A series of studies were conducted in the late 1980s to compare Magnet hospital characteristics with a sample of 'control' hospitals in similar environments (Kramer \& Schmalenberg, 1988a, 1988b, 1991; Kramer, 1990). These studies examined characteristics of a sample of 939 nurses in 14 Magnet hospitals and compared them with a sample of 808 nurses in the non Magnet hospitals. The Magnet hospitals consistently had significantly lower nurse turnover and staff nurses reported higher job satisfaction than the non Magnet hospitals. These findings supported the conclusions made by the authors of the original study in 1983, that there were "links between Magnet hospital characteristics, higher than average reported nurse job satisfaction, and lower rates of turnover" (Buchan, 1999, p. 102).

A comparative multisite observational design incorporating two subsamples of Magnet status hospitals was studied in 2000 to compare the original AAN Magnet 
hospitals with ones that met criteria for accreditation as Magnet hospitals by the American Nurses Credentialing Center (ANCC). The study found that nurses at ANCC recognized Magnet hospitals had lower burnout rates and higher levels of job satisfaction than did nurses at the AAN Magnet hospitals. The research indicated that "ANCC Magnet hospital designation is a valid marker of good nursing care" (Aiken et al., 2000, p. 34).

Upenieks (2003a) examined whether Magnet hospitals provided higher levels of job satisfaction and empowerment among nurses when compared with non Magnet hospitals in a quantitative study using several measurement tools. Job satisfaction was measured with the NWI-R and empowerment was measured with the revised Conditions of Work Effectiveness Questionnaire (CWEQ-II). Also included in the study at both types of hospitals was whether job satisfaction discrepancy was interlinked with leadership effectiveness and support of professional nursing practice. The population consisted of a convenience sample of 305 clinical nurses and 16 nurse leaders from two Magnet hospitals and two comparison non Magnet hospitals. The results of the study found that nurses employed at Magnet hospitals experienced higher levels of empowerment and job satisfaction. Nursing leadership was confirmed to be the most essential organizational characteristic of the Magnet hospitals.

Similar results were identified by Taylor (2005) from a national nursing research study that demonstrated Magnet hospitals minimize staffing shortages by improving RN autonomy, nurse/doctor relationships, and $\mathrm{RN}$ control over nursing practice. Additionally, staff nurses scored the highest in expecting both leadership and management activities from their nurse managers. 
The Nursing Management Aging Workforce Survey, in partnership with Bernard Hodes Group, surveyed nearly 1000 nurses and the results demonstrated the lack of comprehensive strategies designed to retain aging nurses. The study included a comparison of Magnet versus non-Magnet facility support for nursing that indicated Magnet hospitals offered more services and benefits for employees (Hader et al., 2006). Hader found the results consistent with other research findings that Magnet hospitals have lower staff nurse turnover and greater job satisfaction.

\section{Job Satisfaction}

Job satisfaction had an undeniable influence on employee well-being and on their behavior (Hellman, 1997). Literature well documented the significant negative relationship between staff nurse job satisfaction and intent to depart. Literature also documented a primary connection between intention to turnover being a greater predictor of retention than job satisfaction and retention (Steel, 2002).

Human resource development (HRD) was defined as "a process for developing and unleashing human expertise through organization development and personnel training and development for the purpose of improving performance" and involved engaging others in the organization to support and carry out the functions of HRD responsibilities (Swanson \& Holton, 2001, p. 4). The two major components of HRD were: 1) training and development and 2) organization development (Swanson \& Holton, 2001). HRD has important functions in the hospital related to hiring new nurses and providing appropriate orientation, competency training, and ongoing education. Nurses must maintain skills as well as demonstrate ongoing competence with the rapidly changing health care environment and technology. 
Organization development is a component of HRD with a human relations perspective that is traced back to the Training within Industry (TWI) Service established by the War Manpower Commission during World War II (Dooley, 1945). The objectives of the TWI were to help contractors produce efficiently with lower costs and higher qualities. The TWI's Program Development Method (PDM) introduced a four-step improvement process: 1) spot a production problem, 2) develop a specific plan, 3) get the plan into action, and 4) check results. The PDM is similar to the "plan-do-study-checkact cycle" that Edward Deming (1993) is well known as the leading quality guru. The TWI project developed systematic performance-based training, improvement of work processes, and the improvement of human relations in the workplace. Those core quality improvement principles provided a basis for contemporary HRD and organization development and training processes (Swanson \& Holton, 2001).

The field of human resource management (HRM) focuses mainly on the human resource functions of hiring, compensation, and personnel issues (Bernardin, 2010; Swanson \& Holton, 2001). HRM practices impact employees through recruiting procedures, development of an organization's human capital and through the provision of organizational structures that allow employees to participate with and improve how their jobs are performed (Huselid, 1995). Empirical studies consistently found that the use of effective HRM practices enhanced organizational performance. The policies and procedures related to the valued firm-level outcomes were labeled High Performance Work Practices by U.S. Department of Labor (1993) (as cited in Huselid, 1995).

An understanding of the early theorists gave foundational knowledge and understanding for managers to focus on strategies related to employee satisfaction, reduced intent to depart and increased retention (Tietjen \& Myers, 1998). Abraham 
Maslow, an American psychologist, was considered one of the leaders of humanist approach to management (Swanson \& Holton, 2001). Maslow presented the needs hierarchy in his 1943 paper, A Theory of Human Motivation. Maslow formulated a "positive theory of motivation" model that was identified by the widely known pyramid shape represented the hierarchical nature of the five most widely discussed needs. The lower levels of the pyramid represent the more basic fundamental human needs that Maslow referred to as deficiency needs: physiological, safety, belonging, and esteem. The higher level needs were abandoned until the lower level needs were met and mastered. The highest level of the pyramid, self-actualization, was only accomplished when the lower needs were met. The highest level of self-actualization was "achieving individual potential" (Maslow, 1943).

Maslow published his book Towards a Psychology of Being in 1962 and established a theory of quality of life. Maslow added three more needs to his hierarchy of needs. Between esteem and self-actualization needs was added: the need for knowledge and understanding; and the needs for creativity and aesthetics. Self-actualization was divided into the need for self-actualization and the need for self-transcendence (KoltkoRivera, 2006). Transcendence, which was helping others to achieve their potential, was the need to become an "integrated and valuable part of the world" (Ventegodt, Merrick, \& Anderson, 2003, p. 1052).

Ventegodt et al. (2003) discussed Maslow's hierarchy of needs and the quality of life aspect to empower patients dealing with chronic illness and as a tool for the physician who wished to help their patient "be the best they could be". Benson and Dundis (2003) evaluated Maslow's Hierarchy of Needs model with the challenges of the rapidly changing health care industry. They concluded that Maslow's model brought an essential 
element that deserved attention in the health care environment and as health care reforms were implemented and demand for quality outcomes were expected to rise.

Social exchange theory, presented by George Caspar Homans in 1958, gave a frame of reference (Emerson, 1976) for understanding workplace behavior. Theorists generally agreed that social exchange involved interactions that generated obligations and provided for mutually and rewarding transactions and relationships over time. Social exchange theory was applied to survey research design when small token incentives were provided with the request to complete the survey to significantly increase response rates (Dillman, Smyth, \& Christian, 2009). The social exchange relationship in the workplace involved the differences in the parties involved in the relationship and predicted that, given certain conditions, people sought to reciprocate those who benefited them (Bateman \& Organ, 1983). The presumption with the social exchange was that workers formed different and distinguishing relationships with their supervisor (Cropanzano \& Mitchell, 2005).

Frederick Herzberg introduced job enrichment and the Theory of Motivation referred to as the Motivator-Hygiene theory, or Two-Factor theory of job satisfaction. In 1959, Herzberg, Mausner and Snyderman (as cited in House \& Wigdor, 1967) reported research findings from interviews of 203 accountants and engineers in Pittsburg in the 1950 s and advanced the "dual factor" theory of motivation. The theory proposed that people are influenced by two sets of factors: motivator factors (achievement, recognition, work itself, responsibility, promotion, growth) and hygiene factors (pay and benefits; company policy and administration; relationships with co-workers; supervision; status; job security; working conditions; and personal life). He explained that an employee's motivation to work was best understood when the employee's attitude was understood 
and that both hygiene issues and motivator factors must be addressed to improve job satisfaction. Herzberg posited that job satisfaction was related to intrinsic factors (motivator factors) and job dissatisfaction came from extrinsic conditions (hygiene factors). Herzberg explained how managers could better understand employee motivation when they examined employee's attitudes and their feelings toward their work (Herzberg, 1987).

The Herzberg theory was criticized as "oversimplication of the relationships between motivation and satisfaction" (House \& Wigdor, 1967, p. 387), that values were not addressed (Locke, 1976 as cited in Tietjen \& Myers, 1998, p. 228) and implied that job satisfaction would lead to increased productivity; however this was not always the case (Bateman \& Organ, 1983; Tietjen \& Myers, 1998). Schwab and Cummings (1970) credited the work of Herzberg and his colleagues with providing "the best illustration of current theory and research formulated on the view that satisfaction leads to performance" (p. 410). They further explained that the early work of Herzberg contained alternative explanations of the findings that were not included in subsequent versions of the findings and resulted in misinterpretations and criticism instead of further theory development and refinement.

Douglas M. McGregor's book, The Human Side of Enterprise, was published in the 1960s at MIT Sloan School of Management. McGregor presented two models, Theory $\mathrm{X}$ and Theory $\mathrm{Y}$, based on the premise that the role of management was to coordinate the factors of production, including people, for the economic benefit of the company. The theories described two different attitudes about motivation in the workforce. Theory X assumed that "all people dislike work and will avoid it unless they are controlled and threatened" and Theory Y assumed that "if workers are respected and 
involved in decision-making, they will be highly motivated" (McGregor, 1960/1985, p. 32). These theories of human motivation are used in human resource management and organizational development today. McGregor explained that delegation was not an effective management tool and that management could only be successful grasping Theory Y if they had confidence in human capacities. These theories influenced human resource management, organizational personnel policies, and performance reviews (McGregor, 1960; Swanson \& Holton, 2001).

Theory $\mathrm{X}$ was the precursor of transactional leadership with the focus on corrective management behaviors. Theory $\mathrm{Y}$ was the basis for transformational leadership theory whereby the leader transformed their followers through the four components of transformational leadership: idealized influence, inspirational motivation, intellectual stimulation, and individualized consideration (Bass \& Avolio, 2004).

The Managerial Grid was developed by Robert R. Blake and Jane Mouton in the early 1960 s to assist with training managers how to lead their organizations (Northouse, 2010). The managerial grid was later changed to the Leadership Grid. The grid identified various types of managerial leadership based on concern for production and concern for people. The grid used the concern for production (task) versus the concern for people (person) as dimensions of how much attention to pay to one or the other. The low task and low person dimension resulted in "impoverished management" which was minimum effort to get the work completed and avoided as much work as possible. The ideal, high task and high person dimension resulted in the "team management" style of leadership. Effective managers were concerned with both production and people and managers worked to motivate followers to achieve their highest potential (Northouse, 2010). For example, nurse managers seek to create a team approach among the staff 
nurses in their unit. One of the five model components of the Magnet Recognition Program is structural empowerment and creates an environment for team management (ANCC Magnet Recognition Program, n.d.).

Resource-based theory (RBT) was a popular perspective related to understanding the determinants of organizational performance and for guiding strategic management research and had been the topic of research during the past two decades. RBT was closely associated with a sustained competitive advantage. A meta-analysis of $125 \mathrm{RTB}$ studies was conducted that encompassed over 29,000 organizations to determine how strongly strategic resources related to performance. The conservative estimate found robust support for the evolving RBT and recommended additional RBT studies to clearly define the performance effects of utilizing the strategic resources (Crook, Ketchen, Combs, \& Todd, 2008).

In the field of human resources, several studies examined the relationship between job satisfaction and intent to depart. Turnover process models were found in organizational literature since the early 1950s. Job satisfaction-turnover research was conducted by Porter and Steers (1973) (as cited in Steel, 2002, p. 346) and concluded that affect, expressed in the form of job satisfaction or organizational commitment was a centerpiece of turnover theory. More recent contributions to turnover research looked at behavioral intentions as an extension of the original turnover model by Mobley (1977) (as cited in Steel, 2002, p. 346). The behavioral intentions were notably the intention to quit/stay. Employee satisfaction and commitment were reported in the literature to be negatively related to intent to leave and positively correlated with one another. Hellman (1997) reported that the relationship between job satisfaction and intent to leave was thought to be negative but found the magnitude of the relationship was not consistent 
within the literature. Using the strength of effect size offered by Cohen for the correlation coefficient, small $=.10 ;$ medium $=.30$ and large $=.50$, Hellman cited studies of job satisfaction and intent to leave with effect sizes between $r=.59$ to $r=-.10$.

The relations among age, tenure, and job satisfaction by gender were studied by Bedeian, Ferris and Kacmar (1992) from a sample of 764 (males, $n=172$ and females, $n=592$ ) nonacademic employees working in a large land-grant university located in the southwestern United States. Both overall and facet-specific job satisfaction were assessed using the Job Descriptive Index (JDI), which measured five dimensions of job satisfaction: work, supervision, pay, promotions, and co-workers; and the Job in General (JIG), which measured global or overall job satisfaction. Bedeian et al. (1992) explained it was inappropriate to use facet satisfaction scales to compute an overall job satisfaction index because different individuals used different frames of reference when responding to measures of job satisfaction. Coefficient $\alpha$ internal consistency reliability estimates on the six JDU/JIG scales for males and females (in parentheses) were: Satisfaction with Work $=.83(.83)$, Satisfaction with Supervision $=.91(.89)$, Satisfaction with Pay $=.75$ (.78), Satisfaction with Promotions $=.84(.86)$, Satisfaction with Co-workers $=.90(.89)$, and Satisfaction in General $=.94(.93)$.

Bedeian et al. (1992) performed two parallel analyses using hierarchical polynomial regression analysis to determine whether age or tenure was the strongest demographic predictor of job satisfaction and to compare the stability of the relations as suggested by job experience and career stage models. The results of the study found that age and tenure were natural dependent, time-related variables which co-varied with one another, but were distinct variables leading to different outcomes. Tenure was found to be a stronger predictor of job satisfaction than chronological age. 
A meta-analytic study was conducted by Hellman (1997) to examine the relationship between job satisfaction and intent to leave and possible moderating effects of age, tenure, and the employing organization on the job satisfaction-intent to leave relationship. Hellman noted there were few published reports of effect sizes for the relationship between job satisfaction and intent to leave (p. 678). Hellman explained that employee investments may moderate the relationship between job satisfaction and turnover intentions. The investments examined in the study included age, tenure and the employing organization. Data included a total of 50 studies and a total sample size of 18,239 correlations. Correlations were examined between job satisfaction and intent to leave from 38 studies and from 12 studies representing 12 separate organizations of a large federal agency across the United States. The studies were divided into groups of federal employees and public-sector employees. The results of the study revealed job satisfaction consistently predicted turnover intentions $(r=-.47, p<.05)$. Across levels of job satisfaction, federal employees were less likely than the private-sector employees to leave the organization. Employee age and tenure moderated the association between job satisfaction and intent to leave among the federal employees. Hellman recommended that researchers should exercise caution in generalizing the turnover models to all populations due to the difference in mean correlations between this and other studies.

Tett and Meyer (1993) used path analysis on correlations from meta-analyses to examine the magnitude of effect that job satisfaction and organizational commitment (affective variables) and turnover intentions (cognitive variables) had on actual turnover. They analyzed correlations from 178 independent samples from 155 studies to look at the cross-study differences in the contributions of work attitudes to the turnover process. The results showed that satisfaction $(r=-.58, p<.05)$ and commitment $(r=-.54, p<.05)$ were 
independent and unique predictors of intention. Turnover intentions mediated the relationship between job satisfaction and organizational commitment and actual turnover. Turnover intention was the strongest predictor of turnover $(r=.45, p<.05)$. The modest strength of the relation (Spearman's rank correlation coefficient $=.65$ ) indicated there were limits regarding intent to quit as a precursor of turnover. The predictors of actual turnover were organizational commitment $(r=-.33, p<.05)$ and job satisfaction $(r=-.25, p<.05)$

Employees satisfied with their jobs were committed to understanding their job characteristics and the role they played with improving organizational outcomes. It seemed logical that employees that were more satisfied with their jobs were more productive and more engaged within the organization they work (Yang, 2009). Tietjen and Myers (1998) explained that instilling satisfaction within workers was a crucial task of management and that employee satisfaction created confidence, loyalty, and ultimately improved quality in productivity.

Babin and Boles (1996) investigated the relationship between employee perceptions of co-worker involvement and supervisory support and the effect on reducing stress and increasing job satisfaction in the retail food service environment. The sample population was 261 respondents in a major southern metropolitan area. The direct effect of supervisory support on increasing job satisfaction was strongly supported. The path estimate between supervisor support and job satisfaction was significant and positive $(.41, p<.05)$

Employee dissatisfaction produced thoughts in which employees began to examine the costs and benefits associated with staying or leaving their jobs and was the premise of the original turnover model incorporating behavior intentions by W. Mobley 
in 1977. Ultimately, the decision making process regarding turnover intention resulted in the employee's departure from the organization (Hellman, 1997).

Yang (2009, p. 1261) explained how satisfied employees "contribute greater work reliability, responsiveness, and quality to an organization". The resource based theory (RBT) perspective for understanding the relationship between human resource management and organizational leadership was used to investigate the effect of transformational leadership on employee intrinsic and extrinsic job satisfaction. Participants in the survey were from four life insurance firms and included 369 sales employees and 177 sales managers. Yang examined whether employee group interaction behaviors acted as mediators in the transformational leadership process. The results of the study advanced previous RBT studies by demonstrating that transformational leadership had a significant influence on both interaction behaviors and employee job satisfaction, interaction behaviors had a significant influence on satisfaction, and the interaction behaviors acted as mediators to enhance the effect of transformational leadership on satisfaction. The nurse managers that practice transformational leadership actively participate with the nursing staff and can improve job satisfaction and retention.

\section{Retention}

Turnover theory was a topic of much research from 1977 to 1981 . The Theory of Reasoned Action (TRA) was developed by Martin Fishbein and Icek Ajzen in 1975. The TRA assumed that self-reported intentions or plans were the best predictors of behavior. Sheppard, Hartwick and Warshaw (1988) conducted two meta-analyses to investigate the effectiveness of the Fishbein and Ajzen model and found "strong overall evidence for the predictive utility of the model across conditions" (p. 325). The TRA marked the 
beginning for important empirical and theoretical work in the field of attitudes that followed (Sheppard et al., 1988).

Many researchers studying turnover used turnover intentions as the most immediate and most accurate predictor of actual employee turnover (Van Bruekelen, Van Der Vlist, \& Steensma, 2004; Cotton \& Tuttle, 1986). A meta-analysis statistically summarized the information found in a literature review. Cotton and Tuttle (1986) conducted a meta-analysis of over 120 studies of turnover and studies of the turnover process. Data was collected from articles, book chapters, and other publications from 1979 to mid-1984. The requirements for inclusion in the study report were quantifiable data with statistical analyses and were from a published source. The authors preferred using correlations (or effect sizes in some studies) rather than probability statistics but many studies did not report them. The results of the meta-analysis confirmed many conclusions from earlier qualitative reviews. The reliable correlates with turnover included age, tenure, pay, overall job satisfaction, and employment perceptions. Of interest from the meta-analyses was the explanation of the reliability of behavioral intentions as predictor of turnover that had not been tested in earlier turnover reviews.

Drawing on the Theory of Reasoned Action, Bedeian, Kemery and Pizzolatto (1991) investigated the employee withdrawal process as related to career commitment and the expected current job utility for attaining the desired career outcome. They collected data pertaining to career commitment, expected utility of present job, turnover intentions, and actual turnover of 244 employees in two medium-size general hospitals. The results of their study found that career commitment interacted with utility of present job to predict turnover intentions and turnover intentions had a direct effect on turnover but concluded that the individual career factors affected turnover through turnover 
intentions. Of interest was the relation between expected utility of present job and turnover intent was negative for subjects with high career commitment but positive for participants with low career commitment. This suggests that nurses with higher levels of career commitment and anticipated career growth opportunities within the organization are less likely to express turnover intentions.

Individual employee performance had implications for organizational outcomes and research was increasing from the perspective that, collectively, a firm's employees could also provide a unique competitive advantage for the organization. The impact of human resource management practices and policies on firm performance was evaluated from a national sample of nearly one thousand firms from a wide range of industries. The purpose of the study was to evaluate the links between systems of high performance work practices and firm performance from a strategic perspective. The results from the survey study found an economically and statistically significant impact on employee outcomes related to turnover and productivity. There was considerable support for organizations that invested in high performance work practices (Huselid, 1995).

Griffeth, Hom, and Gaertner (2000) updated and refined the previous metaanalysis data base by Hom \& Griffeth (1995) (as cited in Griffeth et al., 2000 p. 464) to include correlations of the predictive strength of turnover antecedents. They contributed to the earlier analysis and identified various moderators of antecedent-turnover relationships. The studies were from the 1990 s and the conditions for inclusion were actual turnover assessments, a predictive design that collects predictor measures before turnover occurrence, and turnover was measured at the individual level of analysis. They investigated the moderators identified by earlier meta-analyses by first conducting correlational analysis to screen for significant correlations between moderators and effect 
sizes; then ran subgroup analyses on those moderators that significantly correlated with effect sizes. With the exception of tenure and number of children, the results of the updated meta-analyses confirmed and replicated previous findings that most demographic attributes did not predict turnover (e.g., no correlation between cognitive ability and turnover; women and men had similar quit rates; and no relationship between race and turnover).

The updated meta-analysis by Griffeth et al. (2000) yielded similar predictive validity as the Hom and Griffeth (1995) meta-analysis. Overall job satisfaction and facet satisfaction with overall job satisfaction were the best predictors with work satisfaction displaying the highest relationship to turnover among the satisfaction facets. The updated meta-analysis found quit intentions to be the best predictor of turnover. Moderators were tested with studies appearing in the 1990s and only for predictor-quit correlations from 10 or more samples and included age, organizational tenure, overall satisfaction, pay, perceived job alternatives, performance, commitment, and quit intentions. Of interest to this study, employee age moderated the tenure-turnover correlation; performanceturnover correlation is negative when reward contingencies exist, but positive when contingencies are absent indicating that when high performers are not rewarded, they leave.

Westlund and Hannon (2008) conducted a quantitative correlational design study of 124 software developers from 24 organizations representing higher education, consulting, defense contracting, and local government using survey questionnaires. The purpose of the study was to understand the relationships among the facets of job satisfaction and turnover intentions and to measure which job satisfaction facets were most significantly related to turnover. The measuring instruments were Spector's job 
satisfaction survey and Jackofsky and Slocum's measure of turnover intentions and a demographic data questionnaire. The facets of satisfaction included: contingent rewards, promotion, supervision, pay, operating conditions, coworkers, benefits, communication, and the nature of work. The Multifactor Leadership Questionnaire (MLQ) 5X rater form was administered but not included in the study. The results of the study reported the following Pearson correlation coefficients for the variables in the study: contingent rewards and communications (.725), contingent rewards and pay (.717), contingent rewards and supervision (.704), benefits and supervision (.147), benefits and coworkers (.185), and the nature of work and pay (.194). The hypotheses were tested using multiple linear regression and tests for assumptions were met for a) linear relationships, b) equal variances, c) normality, and d) independent observations. The coefficient of determination $=0.395$ and indicates that $39.5 \%$ of turnover intentions were attributed to the variables in the model.

\section{Leadership}

Leadership was a topic of great interest and one of the most frequently studied topics in the organizational sciences. The precise nature of leadership and its relationship to key criterion variables such as subordinate satisfaction, commitment, and performance was uncertain. Luthans (2005) explained that leadership remained a 'black box' or unexplainable concept.

Leadership behaviors and styles had effects on people and organizational outcomes. James (2003) described how leaders needed to devise better ways of meeting customer needs, changing organizational structures, and responding to the demands of talented employees. Employees were more interested in having meaningful work and the opportunity to make a difference in the organization (Kouzes \& Posner, 2002). 
Leadership behaviors resulted in different outcomes. Leadership at the executive level had middle managers with positive outcomes while other managers had negative outcomes resulting in a missed opportunity for the executive leadership to utilize the demonstrated best practice performance in their own organization. The best practices could then translate into better outcomes in other areas of the organization (Kleinman, 2004b).

Scientific research studies of leadership did not begin until the early twentieth century. Early behavior scientists explored what behaviors, abilities, traits, sources of power, and or/aspects of the situation determine the leader's ability to influence others and to accomplish group objectives (Marriner-Tomey, 1993). Leadership researchers in recent decades viewed leadership as part of role differentiation or as derived from social interaction processes (Bass, 1981).

Bass and Avolio (2004) described how leadership could increase the maturity level of both the leaders and meet the followers' needs. The primary concern for individual needs shifted to concern for both the individual and the group with respect to performance and development. The individual's needs were met during the exchange process, or transactional relationship, and shifted to a higher order exchange process, or transformational relationship, that had longer-term implications and impacted both process and outcomes (p. 19).

\section{Leadership evolution.}

This section reviews the early leadership theories and leadership styles that are the basis for understanding transactional and transformational leadership and Bass's Full Range Leadership model. Employees, subordinates, and followers are referred to as "follower" for consistency in understanding the relationship to the "leader". 
Studies of leadership passed through distinct phases, from the "trait" theories of the 1930-1940s, through the "behavioral" theories of the 1950-1960s; and the "situational" and "contingency" theories of the 1960-1970s; to the models of "heroic" leadership - based on being "visionary", "charismatic" or "transformational" of the 19801990s (Alimo-Metcalfe, Alban-Metcalfe, Bradley, Mariathasan, \& Semele, 2008;

Marriner-Tomey, 1993; Popper, 2004); and the contemporary models of "quantum", "servant", and "shared or distributive" leadership. Many leadership studies and theories developed over time and are listed below (Changing Minds, 2009).

Table 2

\section{Leadership Theories}

\begin{tabular}{|c|c|c|}
\hline Theory: & Assumptions: & Discussion and tools: \\
\hline Trait Theory & $\begin{array}{l}\text { People were born with inherited traits, } \\
\text { some traits were suited to leadership, } \\
\text { and good leaders have right } \\
\text { combination of traits. }\end{array}$ & $\begin{array}{l}\text { Minnesota Multiphasic } \\
\text { Personality Inventory, } \\
\text { Myers-Briggs Type } \\
\text { Indicator (MBTI), } \\
\text { Leadership Trait } \\
\text { Questionnaire (LTQ) } \\
\end{array}$ \\
\hline $\begin{array}{l}\text { Behavioral Theory } \\
\text { (Blake \& Mouton, } \\
\text { 1960s) } \\
\text { Charismatic Leadership } \\
\text { Theory } \\
\text { (Weber, 1947) }\end{array}$ & $\begin{array}{l}\text { Leaders could be made, rather than } \\
\text { were born and leadership was based in } \\
\text { definable, learnable behavior. }\end{array}$ & $\begin{array}{l}\text { Ohio State Studies - } \\
\text { Leader Behavior } \\
\text { Description } \\
\text { Questionnaire (LBDQ), } \\
\text { University of Michigan } \\
\text { Studies, Blake \& } \\
\text { Mouton's Managerial } \\
\text { Grid, Douglas } \\
\text { McGregor's Theory X } \\
\text { and Theory Y } \\
\end{array}$ \\
\hline $\begin{array}{l}\text { Situational Theory } \\
\text { (Stogdill, 1948) }\end{array}$ & $\begin{array}{l}\text { Leader action depended on a range of } \\
\text { situational factors and effective leader } \\
\text { did not rely on a single preferred style } \\
\text { of leadership. }\end{array}$ & $\begin{array}{l}\text { Leaders focused on } \\
\text { behaviors that the } \\
\text { leader should adopt } \\
\text { with external } \\
\text { relationships, } \\
\text { acquisition to }\end{array}$ \\
\hline
\end{tabular}




\begin{tabular}{|c|c|c|}
\hline & & $\begin{array}{l}\text { resources, managing } \\
\text { demands, and group } \\
\text { structure. }\end{array}$ \\
\hline $\begin{array}{l}\text { Contingency Theories } \\
\text { (Fiedler, 1967) }\end{array}$ & $\begin{array}{l}\text { Leader ability was contingent upon } \\
\text { various situational factors including } \\
\text { leader's preferred style, capabilities } \\
\text { and behaviors of follows and no one } \\
\text { best way of leading. }\end{array}$ & $\begin{array}{l}\text { Fiedler's Least } \\
\text { Preferred Co-worker } \\
\text { scale (LPC), Cognitive } \\
\text { Resource Theory, } \\
\text { Strategic Contingencies } \\
\text { Theory }\end{array}$ \\
\hline $\begin{array}{l}\text { Path-Goal Theory } \\
\text { (House, 1971) } \\
\text { Participative } \\
\text { Leadership }\end{array}$ & $\begin{array}{l}\text { Leaders motivated followers to } \\
\text { perform by achieving satisfaction } \\
\text { from task to be accomplished and } \\
\text { leaders clarified goals and paths to } \\
\text { those goals. }\end{array}$ & $\begin{array}{l}\text { Path-goal Leadership } \\
\text { Questionnaire }\end{array}$ \\
\hline $\begin{array}{l}\text { Life-Cycle Theory } \\
\text { Situational Leadership } \\
\text { Vroom \& Yetton } \\
\text { Normative Model } \\
\text { (1973) } \\
\text { (Hersey \& Blanchard, } \\
\text { 1982) }\end{array}$ & $\begin{array}{l}\text { Maturity of followers related to leader } \\
\text { behavior. There should be an eventual } \\
\text { decrease in consideration as maturity } \\
\text { increased and the person consequently } \\
\text { needed less support. }\end{array}$ & $\begin{array}{l}\text { Situational Leadership } \\
\text { II (SLI) (SLII) }\end{array}$ \\
\hline $\begin{array}{l}\text { Transactional } \\
\text { Leadership } \\
\text { (Burns, 1978) } \\
\text { (Bass, 1981) }\end{array}$ & $\begin{array}{l}\text { People were motivated by reward and } \\
\text { punishment, social systems had clear } \\
\text { chain of command, and subordinate } \\
\text { did what manager told them. }\end{array}$ & $\begin{array}{l}\text { Leader-Member } \\
\text { Exchange (LMX) } \\
\text { Theory }\end{array}$ \\
\hline $\begin{array}{l}\text { Transformational } \\
\text { Leadership Theory } \\
\text { (Burns, 1978) } \\
\text { (Bass, 1985) } \\
\text { (Bennis \& Nanus, 1985) }\end{array}$ & $\begin{array}{l}\text { People followed a person who } \\
\text { inspired them, a person with vision } \\
\text { and passion could achieve great } \\
\text { things, and enthusiasm and energy got } \\
\text { things done. }\end{array}$ & $\begin{array}{l}\text { Burns' } \\
\text { Transformational } \\
\text { Leadership Theory } \\
\text { (1978), } \\
\text { Bass' Transformational } \\
\text { Leadership Theory } \\
\text { (1985), } \\
\text { Avolio \& Bass (1987) } \\
\text { Multifactor Leadership } \\
\text { Questionnaire (MLQ), } \\
\text { Kouzes \& Posner's } \\
\text { (2002) Leadership } \\
\text { Practices Inventory }\end{array}$ \\
\hline
\end{tabular}




\begin{tabular}{|c|c|c|}
\hline $\begin{array}{l}\text { Servant Leadership } \\
\text { (Robert K. Greenleaf, } \\
1970 \text { s) }\end{array}$ & $\begin{array}{l}\text { Emphasized leader attentiveness to } \\
\text { followers, leaders empathized with } \\
\text { followers, and leaders took care of and } \\
\text { nurtured followers. }\end{array}$ & $\begin{array}{l}\text { Greenleaf's essay was } \\
\text { published in The } \\
\text { Servant as Leader }\end{array}$ \\
\hline $\begin{array}{l}\text { Quantum leadership } \\
\text { (Porter-O'Grady \& } \\
\text { Malloch, 2004) }\end{array}$ & $\begin{array}{l}\text { Considered the whole, integration, } \\
\text { synthesis, relatedness, and team } \\
\text { action; incorporated transformation, a } \\
\text { dynamic flow that integrated } \\
\text { transitions from work, rules, scripts, } \\
\text { chaos, and loss; and quantum leader } \\
\text { characteristics included fluid, flexible, } \\
\text { mobile, reflected synthesis, worked } \\
\text { from the whole, and coordinated the } \\
\text { intersection. }\end{array}$ & $\begin{array}{l}\text { Leader skills worked } \\
\text { within the reality of } \\
\text { "potentials" rather than } \\
\text { "actualities" } \\
\text { (Porter-O'Grady, 1999) }\end{array}$ \\
\hline $\begin{array}{l}\text { Shared Leadership or } \\
\text { Distributive Leadership }\end{array}$ & $\begin{array}{l}\text { An approach to team leadership, } \\
\text { encompassed leadership of the entire } \\
\text { team, and leaders and followers } \\
\text { worked together for team } \\
\text { effectiveness. Assumed the leader } \\
\text { knew about group processes and team } \\
\text { dynamics. }\end{array}$ & $\begin{array}{l}\text { The complex model } \\
\text { was not completely } \\
\text { supported or tested } \\
\text { (Northouse, } 2010 \text { ) }\end{array}$ \\
\hline
\end{tabular}

(Adapted with permission - Changing Minds, 2009)

Debate continued as to whether leadership was a learned skill or an innate quality from birth (Pfeffer, 1977). According to Taylor (2003), leaders were made, not born. Jay Conger asserted that leaders were born and made (O'Reilly, 2007). He explained how chaotic and complex the world was and how leaders needed to embrace the new social paradigm and new practice models.

The healthcare environment is certainly chaotic, complex and rapidly changing due to many internal and external forces that impact leadership's ability to become and remain effective. The nursing profession, being the largest segment of the nation's health care workforce with over three million in number, is called to assume leadership roles in 
advancing the objectives set forth in the 2010 Affordable Care Act. "Efforts to cultivate and promote leaders within the nursing profession - from the front lines of care to the boardroom - prepares nurses with the skills needed to help improve health care and advance their profession" (IOM, 2010).

\section{Trait theory.}

The trait theory of the 1930-1940s was one of the first systematic attempts to study leadership (Northouse, 2010). The trait theory was closely related to the great man theory and made assumptions that people were born with inherited traits and some of these traits were well suited to leadership. The early theorists believed that if leaders inherited certain qualities that made them great leaders then those traits should be singled out and studied (Marriner-Tomey, 1993).

Trait and behavioral theories of leadership attempted to identify the types of behavior and personality characteristics associated with effective leadership. In an attempt to describe the basic factors of personality, Goldberg (as cited in Judge, Bono, Ilies, and Gerhardt, 2002) found that a consensus had emerged among researchers. Goldberg explained that a five-factor model of personality could be used to describe the basic factors of personality. The five factors that made up the model were commonly referred to as the Big Five and included Neuroticism, Extraversion, Openness, Agreeableness, and Conscientiousness (Northouse, 2010). Griffeth et al. (2000) conducted a follow up meta-analysis to extend the Hom and Griffeth (1995) (as cited in Griffeth et al. 2000, p. 464) meta-analysis data base and included the antecedents and correlates of employee turnover. They acknowledged that several of the Big Five personality factors could predict turnover or tenure but omitted them from their metaanalyses because of the small number of studies that used personality predictors. 
Judge et al. (2002) conducted a major meta-analysis of 78 leadership and personality studies (73 independent samples) containing 222 correlations that were classified into one or more of the five-factor traits. The results of the analysis identified extraversion as the factor most strongly associated with leadership $(r=.31)$, followed by conscientiousness $(r=.28)$, openness to experience $(r=.24)$, neuroticism $(r=-.24)$, and agreeableness $(r=.08)$. Overall, Judge et al. (2002) reported a multiple correlation of .48 with leadership, and supported the leader trait perspective in the study.

The leadership instruments to measure individuals' unique personality attributes for leadership included standard personality measures such as the Minnesota Multiphasic Personality Inventory, the Leadership Trait Questionnaire (LTQ) and the Myers-Briggs Type Indicator (MBTI). The Leadership Trait Questionnaire (LTQ) measured personal leadership characteristics by quantifying the perceptions of the individual leader and selected observers such as subordinates or peers (Northouse, 2010). Brown and Reilly (2009) conducted a study of over 2,000 followers and 148 managers to determine if the Myers-Briggs type indicator and transformational leadership, as measured by the Multifactor Leadership Questionnaire (MLQ), were related. The results of their study found no relationship between the elements of personality as measured by the MBTI and those measured by the MLQ. The researchers indicated that the MBTI did not predict or explain transformational leadership behaviors.

\section{Behavioral theory.}

The behavioral theories of leadership examined how leaders act and what leaders do rather than examining inborn traits or capabilities. The earlier trait theories involved examining the individual traits or personalities that made great leaders. In the late 1940s, behavioral theorists shifted to the study of the behaviors of leaders and followers in 
relation to situations (Northouse, 2010). "Leadership was viewed as an observable process or activity rather than an inherent, often unobservable, personal characteristic or trait" (Jago, 1982, p. 319). The behavioral theorists advanced the understanding of leadership to assume that leadership capability can be learned. The study of behavioral theory assessed leadership success and the actions of leaders as well as the behaviors that contributed to failure (Burke, 2006). Popper (2004) described how a shift occurred from the individual traits to the relationship perspective in later theory development.

\section{Charismatic leadership theory.}

Charismatic leadership theory was first described by Max Weber (1947) (as cited in Marriner-Tomey, 1993) in the book The Theory of Social and Economic Organization. Weber's work provided an explanation for the influence of one individual to exert control over others in a social system, including work groups. Weber perceived charisma as a personality characteristic and recognized the role that followers played in validating charisma in the leader. Charismatic authority was bestowed on the leader by the followers as an obligation to obey that came from a moral perspective and not from a set of rules.

Weber described "pure" charisma as certain individuals with extraordinary abilities who communicated a vision of a new social institution. However, the charismatic authority may be transformed into an organizational phenomenon and become "routinized" charisma when it is no longer a bond with a specific charismatic individual. Charismatic authority could be routinized when charisma was transferred to another leader through succession or from the person to the office or leadership position (Marriner-Tomey, 1993; Popper, 2004). Studies examined charisma in association with famous political leaders such as Hitler and Ghandi and described the 'dark side of 
charisma' when charismatic leaders demanded unquestioning obedience with power and privilege (Northouse, 2010).

Shamir, House, and Arthur (1993) advanced leadership theory to explain the process by which charismatic leader behaviors brought forth transformational effects on followers. The outcome of their analysis suggested that charismatic leaders achieved transformational effects by increasing the intrinsic value of the follower's self-concepts (self-expression, self-consistency, and self-esteem) and linked the identity of the follower to the identity of the organization.

Studies were conducted at Ohio State University in the late 1940s. The researchers were interested in how individuals acted when they were leading a group or organization. The results of the Ohio State University studies found that leadership behaviors changed from leader to leader. Some leaders exhibited rigid structure behaviors in terms of task accomplishments while other leaders focused more on building and maintaining personal relationships. The research was based on questionnaires received from both leaders and subordinates. The Leader Behavior Description Questionnaire (LBDQ) was constructed and later revised by Stogdill (1963) (as cited in Northouse, 2010) to a shortened version called the LBDQ-XII. Results of the Ohio State University studies indicated that initiating structure and consideration were the two dominant dimensions in leadership. The initiating structure behaviors were the task behaviors and the consideration behaviors were the relationship behaviors that included trust and respect. The Ohio State University studies viewed the initiating structure leader behaviors and the consideration leader behaviors as distinct and independent of each other (Northouse, 2010). 
The University of Michigan studies began in the 1950s and gave special attention to leadership behavior and small group performance. Two types of leadership behaviors were classified: employee orientation and production orientation. Employee orientation was the behavior of leaders with a strong human relations emphasis and was comparable to the consideration behaviors in the Ohio State University studies. The production orientation was the behavior of leaders that focused on the technical and production aspects of the job and was similar to the initiating structure found in the Ohio State University studies. The University of Michigan studies identified three characteristics of effective leaders: task oriented behavior, relationship oriented behavior, and participative leadership. Similar to the Ohio State University studies, the University of Michigan studies also considered their employee and production constructs as independent orientations (Northouse, 2010). The University of Michigan findings "represented early empirical evidence offering little reason for optimism about the association between satisfaction and performance" (Schwab \& Cummings, 1970, p. 413).

Studies continued during the 1950-1960s to determine how leaders could combine the task and relationship behaviors to optimize the satisfaction and performance of the followers. The results were mostly contradictory and inconclusive and did not meet the goal of identifying one best style of leadership (Northouse, 2010).

\section{Situational theory.}

Stogdill (1948) (as cited in Northouse, 2010), in a major review, analyzed more than 124 trait studies conducted between 1904 and 1947 and identified a group of eight traits that were related to how individuals became leaders. Stogdill concluded that individuals that were great leaders in one situation may not be great leaders in another situation. Stogdill found leaders possessed traits that included intelligence, alertness, 
insight, responsibility, initiative, persistence, self-confidence, and sociability. Stogdill's research initiated a new approach to leadership research that focused on leadership behaviors and leadership situations referred to as situational leadership.

In 1974, Stogdill published a second survey from an analysis of 163 new trait studies and determined that both personality factors and situational factors were characteristics of leadership. The study validated the 1947 study that a leader's characteristics were part of leadership. The 10 characteristics from Stogdill's second survey that were positively associated with leadership included: 1) drive for responsibility and task completion, 2) vigor and persistence in pursuit of goals, 3) risk taking and originality in problem solving, 4) drive to exercise initiative in social situations, 5) self-confidence and sense of personal identity, 7) readiness to absorb interpersonal stress, 8) willingness to tolerate frustration and delay, 9) ability to influence other people's behavior, and 10) capacity to structure social interaction systems to the purpose at hand (Northouse, 2010). Effective leaders were those that adapted their leadership style to match the needs of the follower depending on the situation (MarrinerTomey, 1993).

\section{Contingency theory.}

Situational and contingency theories of leadership examined the environmental and situational influences on leader behavior. The basis for Fred Fiedler's contingency model (1967) was that "effective leadership was contingent on matching a leader's style

to the right setting" (Northouse, 2010, p. 111) and that no best leadership theory existed. Bass (1999) explained that leaders exhibited varying degrees of both transactional and transformational leader behaviors depending on the situation. Fiedler developed the Least Preferred Coworker (LPC) scale to measure a person's leadership style and to 
determine those leaders described as relationship motivated and those identified as task motivated. Fiedler studied the styles of many different leaders and the organizational context in which they worked. He analyzed the styles of hundreds of leaders and determined which styles of leadership were best and which were worst for a given organizational context.

The pattern of leader behavior was considered effective if it met the challenges of the situation. Contingency theory was concerned with the personality of the leader and the challenges of the situation and for placing leaders in the situations for which they were best suited (Marriner-Tomey, 1993; Northouse, 2010). Bass and Avolio (2004, p.6) explained the benefits to placing managers in positions for which they were best suited to a particular kind of organizational culture, department, work group, project, or situation. Fieldler explained the three important dimensions that influenced the leader's effectiveness were: 1) leader-member relations, 2) task structure, and 3) position power. The leader-member relations were the degree of confidence the follower had in the leader and included loyalty to the leader. Task structure was the degree to which the follower's job was considered routine as contrasted with nonroutine. Position power was the power inherent to the leadership position and included rewards, punishments, and the leader's formal authority.

\section{Path-goal theory.}

The path-goal theory of leadership described how leaders motivated followers to perform and accomplish goals or succeed in the path to high performance. Robert House developed the path-goal theory in 1971 in an attempt to reconcile the prior empirical investigations of the effects of leader task orientation and leader person orientation on subordinate satisfaction and performance. In contrast to the contingency theory which 
emphasized the leader style and the situation, path-goal theory examined the relationship between the leader's style, characteristics of the followers, and the work setting. Leaders motivated followers by providing rewards and clear goals and removing barriers to attaining the goals. The path-goal leadership questionnaire provided information about four leadership styles: directive, supportive, participative, and achievement oriented (Northouse, 2010).

In 1996, House presented a reformulated path-goal theory of work unit leadership that specified leader behaviors that enhanced follower empowerment and satisfaction and work unit and follower effectiveness (House, 1996). Participative leadership was one approach to the path-goal theory and involved the participation of the followers with the leaders in shared decision making and gave greater clarity to how certain paths led to certain goals. Participative leadership emphasizes shared decision making and created an environment for nurse executives to exhibit greater transformational qualities and resulted in better staff satisfaction and work effectiveness (Dunham-Taylor, 2000).

\section{Life-cycle theory/situational leadership.}

The original Hersey-Blanchard Situational Leadership Model was developed in 1969 and posited that the maturity of followers related to leader behavior (Northouse, 2010). The life-style theory attempted to provide the leader with some understanding of the relationship between the leader and the maturity level of the followers. Leaders adapted their style to the readiness level of the follower in a specific situation so the follower became the focus and not the leader. In other words, as the maturity of followers increased, leader behavior reflected a decreased emphasis on task structure and a greater emphasis on consideration. 
The life-cycle theory of leadership was further developed by Hersey and Blanchard in 1982 (as cited in Marriner-Tomey, 1993) and was known as situational leadership. The Situational Leadership II (SLII) model consisted of two parts: leadership style and development level of subordinates. The leadership styles were classified into four categories of directive and supportive behaviors and the development levels described various combinations of commitment and competence for employees on a specific task (Northouse, 2010). The situational leadership theory had received criticism due to the lack of strong published research and raised questions about the theoretical basis of the approach (Graeff, 1997).

The Vroom and Yetton (1973) Normative Model of leadership focused on the situational determinants of the participative decision making process. The model described the different ways leaders could make decisions and how the followers could participate in decision making.

\section{Transactional leadership theory.}

Transactional leadership was an exchange style of leadership that focused on a contingency reward of the followers (Bass \& Avolio, 2004). The transactional leader motivated employee behaviors by setting goals, giving directions and using rewards to reinforce behaviors associated with meeting or exceeding goals. Burns (1978) viewed leadership as involving power and created the relationship between leader and follower for the short-term desired outcomes of the leader (Marriner-Tomey, 1993). Bass and Avolio (2004) contended that the transactional leadership process was viewed as an appropriate component of the full range of effective leadership when the leader clarified what the followers needed to do in exchange for a reward. The follower's development 
and performance suffered under transactional leadership if focusing on mistakes was all the leader did.

Prior to the Leader Member Exchange (LMX) theory, researchers viewed leadership as something leaders do to followers. LMX theory challenged that assumption and viewed leadership as interactions between leaders and followers. The vertical dyadic linkage (VDL) theory was the precursor of leader member exchange and focused on the vertical linkages leaders form with their followers. The exchanges between the leader and the subordinate defined the unique dyadic relationship. Researchers found two types of relationship categories that leaders place followers. The in-group relationship was based on expanded and negotiated role responsibilities and the out-group relationship was based on the formal employment contract. The VDL theory assumed leaders did not have the same exchange relationship with each follower. Subordinates could negotiate and move from the out-group to the in-group if they were willing to do more for the group than was required in their formal job descriptions and how well they worked with their leader and the leader worked with them (Northouse, 2010).

LMX theory attempted to view leadership in terms of relationships that were purposeful and important to both the leader and the followers (Popper, 2004). Leadermember exchange theory was described in the works of Dansereau, Graen, and Haga (1975) (as cited in Northouse, 2010, p. 148) and conceptualizes leadership as a process that was centered on the dyadic relationship between leaders and followers. The LMX was initially considered transactional leadership but was subsequently seen as a transactional and transformational leadership process.

The development process of the leader member exchange included trust, loyalty, and respect ranging from the transactional first stage to the final transformational stage 
(Bass, 1999). The LMX 7 was a seven-item questionnaire developed by Graen \& UhlBien (1995) (as cited in Northouse, 2010, p. 164) that provided a reliable and valid measure of the quality of leader-member exchanges through three dimensions of respect, trust, and obligation. The quality of the leader-member exchange had been linked to job satisfaction, commitment and job performance (Laschinger, Finegan, \& Wilk, 2009; Laschinger, Purdy \& Almost, 2007).

\section{Transformational leadership theory.}

Transactional and transformational leadership has received extensive theoretical, empirical, and practitioner attention (Sosik, Potosky, \& Jung, 2002). Many figures described in the literature were viewed more as rulers than leaders. Popper (2004) viewed leadership more from the perspectives of the follower. Interest in the concepts of transformational and transactional leadership and the relationship between leader and follower was developed by Burns (1978) in his seminal piece entitled, Leadership. Burns analyzed political leaders and introduced the term Transformational Leadership. The basic concepts of transactional and transformational leadership were communicated in Burns' conclusions about the differences between management and leadership and proposed that transactional and transforming were two separate forms of leadership (Marriner-Tomey, 1993; McNeese-Smith, 1995).

Bernard M. Bass extended Burns' theory on leadership in 1985 to include complex organizational settings and incorporates elements of both transactional and transformational leadership. In the early 1990s, Bass and Bruce Avolio identified the most common leadership approaches of managers and military leaders through empirical study and further defined the stages of leadership on a continuum between transactional leadership and transformational leadership. This model was called "The Full Range of 
Leadership" and utilized the Multifactor Leadership Questionnaire (MLQ). The full range model of leadership was developed to broaden the range of leadership styles being studied from the paradigms of initiation of structure and consideration (Bass \& Avolio, 2004) to the new paradigm of leader impact on followers' effort and performance as well as on group and organizational performance (p. 17). The leadership styles ranged from the higher order maturity of the inspirational leader to the lower order of maturity of the avoidant laissez-faire leader.

The theory of transformational and transactional leadership offers a framework for nurse managers to develop their own knowledge and abilities about leading others and can result in improved staff nurse job satisfaction and retention. Bass \& Avolio (2004) contended that both transformational and transactional leadership behaviors were positive forms of leadership and that good managers exhibited both types of behaviors just in varying degrees. The nurse managers need to have strengths in both task-oriented and relationship-focused behaviors. Too often, nurse managers tend to have strength in one area and have under-developed skills in the other area (McNeese-Smith, 1997).

Transformational leadership sharply contrasts with the more transactional, operational view of work (ANA, 2009). Transformational leadership was a more active leadership style characterized by motivating employees to do more than was required and gaining commitment through their vision and confidence toward improvements or transformations in the organization. As originally described in the seminal work by Burns (1978), transformational leadership provided a framework for leaders and managers in dealing with those who worked for them. Burns described how the motives of both the leader and the follower were identical through a transforming process. 
Transformational leaders fostered open communication horizontally and vertically, provided inspiration and enthusiasm, and created harmony among staff. They sought to improve communication, staff satisfaction, and output (Robbins \& Davidhizar, 2007). Within this framework, nurse managers defined and projected shared vision, demonstrated dedication and continued commitment on the journey toward a vision, motivated and contributed to positive change, gave individualized attention to staff, and allowed for shared decision-making (Rearick, 2007).

The key components of transformational leadership were considered higher order change processes and included: 1) idealized influence, 2) inspirational motivation, 3) intellectual stimulation and, 4) individualized consideration. Bass (1999, p. 12) explained how Maslow's hierarchy of needs moved a step beyond the "ultimate in maturity of development" or self-actualization to a stage of idealization.

Transformational leaders moved followers beyond one's self interests and toward the greater good for group, organization, or society.

Idealized influence was often referred to as charismatic leadership but Bass and Avolio (2004) substituted the term idealized influence for charisma to show the influence about ideals. Transformational leaders utilizing idealized influence exhibited role model behavior and earned respect, admiration and trust from followers and in turn followers wanted to emulate the leader. Charismatic leadership was often described in ways that made it similar to transformational leadership (Northouse, 2010).

Leaders who exhibited inspirational motivation were those transformational leaders who motivated or inspired others with enthusiasm and optimism. Such leaders provided meaning and challenge to the work at hand. Leaders with idealized influence and inspirational motivation demonstrated an ability to create an atmosphere of 
commitment to goals and shared vision (Bass, 1999). This type of leadership enhanced team spirit and encouraged followers to achieve more than they would in their own selfinterest (Northouse, 2010).

Through intellectual stimulation, transformational leaders helped followers learn to solve future problems by encouraging new ways of thinking about old problems. This type of leadership "stimulates followers to be creative and to challenge their own beliefs and values as well as those of the leader and the organization" (Northouse, 2010, p. 179). A key measure of the leader's effectiveness was how capable the followers were in the absence of the leader (Bass \& Avolio, 2004).

Individualized consideration was a key component of transformational leadership where followers were valued as individuals with unique concerns and developmental needs. Leaders created an environment that was supportive and stimulated individual growth to maximum potential. Bass (1999) found that individualized consideration could have detrimental effects in certain situations after post-hoc interviews were conducted with operating room nurses and revealed that a head nurse who was individually considerate was perceived as showing favoritism and demonstrated inequity.

The key components of transactional leadership included: 1) contingent reward, 2) management-by-exception active, 3) management-by-exception passive, and 4) laissez-faire as passive/avoidant leadership. The transactional leader did not focus on the individual needs of followers or their personal development but rather exchanged things of value to advance the leader or organization agenda (Northouse, 2010). The Ohio State University studies' consideration factor of personal relationship could substitute for transactional leadership but not for transformational leadership (Bass, 1999). 
Contingent reward was based on an exchange relationship between transactional leaders and followers. The leader tried to get agreement from the followers and used rewards in exchange for satisfactory performance (Northouse, 2010). Contingent reward was often included with transformational components in conjunction with motivating others to achieve organizational outcomes (Bass \& Avolio, 2004). An example of transactional leadership was the dean who negotiated with the faculty member about the number and quality of publications required for tenure and promotion while the transformational leader inspired and motivated the faculty member to go beyond what was expected.

Management-by-exception transactional leaders exhibited exchange behaviors that focused on identifying mistakes and had two forms. The active form of management-byexception involved close monitoring for the occurrence of mistakes or rule violations and then took corrective action. The passive form of management-by-exception involved waiting for mistakes to occur and problems had arisen before taking action (Bass \& Avolio, 2004; Northouse, 2010).

Laissez faire was the most passive leadership behavior style and was characterized by indifference and resulted in nothing happening and represented the absence of leadership. Leaders with laissez faire behaviors did not make decisions, actions were not carried out and responsibilities were ignored (Bass, 1990; Northouse, 2010).

Bennis and Nanus (1985) analyzed the open-ended, semi-structured questionnaires and interviews from 90 leaders and constructed a model of transformational leadership. Their findings identified four common strategies used by leaders to transform organizations and included: 1) transforming leaders had a clear 
vision for the future of the organization, 2) transforming leaders were social architects to "motivate and create a culture of respect, caring, and trust" (p. xii), 3) transforming leaders created trust in their organizations by being predictable or reliable, and 4) transforming leaders had a positive self-regard in themselves and created a reciprocal impact on followers (Northouse, 2010).

James Kouzes and Barry Posner in The Leadership Challenge (2003), developed a transformational leadership model and described five fundamental practices of an effective leadership style that included: 1) model the way, 2) inspire a shared vision, 3) challenge the process, 4) enable others to act, and 5) encourage the heart. Kouzes and Posner interviewed more than 1,300 middle and senior level managers in both public and private organizations and asked them to describe their "personal best" experiences as leaders (Northouse, 2010). They developed the Leadership Practices Inventory and conceptual framework through a triangulation of qualitative and quantitative research methods and studies that include interviews and written case studies from their personalbest leadership experiences (Kouzes \& Posner, 2002). The fundamental practices and behaviors could be used to lead health care systems into the future along with a transformational leadership style (Jooste, 2004).

Servant leadership was discussed in nursing management literature and was effective when implementing a team approach. Servant leadership was developed by Robert Greenleaf in the early 1970s and had leader behaviors that were altruistic or seeking to serve others (Northouse, 2010). It was the caring aspect of servant leadership that resonated with the nursing profession. Anthony et al. (2005) referred to servant leadership as the new paradigm of nursing leadership following their study of voluntary participants in focus groups. Neill and Saunders (2008) described a model of servant 
leadership that encouraged professional development of nurses and at the same time promoted the improved delivery of healthcare services through "a combination of interdisciplinary teamwork, shared decision making, and ethical behavior" (p. 395).

\section{Leadership and management.}

Leadership and management were different concepts that overlapped how they both involved influencing a group of individuals in goal attainment (Kotter, 1988; Northouse, 2010; Yukl, 1989). In 1911, Frederick Taylor published The Principles of

Scientific Management and was widely regarded as the father of American management thought and was the first to apply scientific principles to the practice of management. Management theory turned away from Taylor's theory following the series of experiments conducted at Western Electric's Hawthorne plant. The Hawthorne studies were conducted between 1924 into the early 1930 s to examine the effect of various illumination levels and worker productivity. The results of the studies showed an increase in productivity of both the experimental and control groups with light intensity and only a decrease in productivity with the experimental group when the light intensity was reduced to that of moonlight. The researchers concluded that light intensity was not related to employee productivity but could not explain the increase in worker productivity behavior (Swanson \& Holton, 2001).

In 1927, Elton Mayo, a Harvard professor, and his associates joined the Hawthorne studies as consultants. Mayo and his associates conducted a series of experiments and concluded that the Hawthorne effect of paying attention to workers was a likely explanation of increased productivity by the workers. The results showed that technical skill was not enough; human behavior and interpersonal skills were also needed (Swanson \& Holton, 2001). The results of Mayo's studies have relevance to the nursing 
profession. Nurses deal directly with people at various levels in the organization and both technical and interpersonal skills are critical to quality nursing care and optimum patient outcomes.

Taylor (2003) explained how the leadership in an organization involved communicating a vision while management was the implementation of another's vision. Management traditionally focused on the human resource functions of planning, organizing, staffing, and controlling, whereas leadership emphasized the general influence process. Leadership could occur any time the behavior of followers was influenced, whether it was for the leader's goals or those of others (Marriner-Tomey, 1993).

There were distinctions between leaders and managers. Effective leaders had the ability to envision what the future of the organization should look like and then communicate that vision to their colleagues. This brought a sense of excitement and motivation in the workplace as everyone worked toward achieving a common goal. Cullen (1999) contended that good management skills were important but leadership impacted retention.

Leaders surrounded themselves with people who had high potential and understood the most important skills were to lead the way, remove barriers, and empower others to become successful leaders. Managers created order and stability and leadership was about adaptation and constructive change (Northouse, 2010). Leadership expert, Jay Conger described the difference between leadership and managers and explained "managing has a lot more to do with operational focus" and "leadership has a lot more to do with the longer-range focus and is more strategic" (as cited in Gettler, 2003). 
The management personnel in an organization were involved with the planning, organizing, staffing, directing, and controlling that occurred on an organization-wide basis. The manager was someone who was responsible to delegate and perform those functions. Persons in leadership roles primarily dealt with influencing others. Leaders and managers had power and authority as a result of their position in the organization. A manager may or may not have been an effective leader. A leader's ability to influence others may be based on many factors other than position (Northouse, 2010).

Jay Conger was recognized throughout the world as an expert on leadership through his extensive training and development of leaders and managers and organizational change. Conger asserted that leaders were born and made (O'Reilly, 2007). Conger explained how chaotic and complex the world was and how leaders needed to embrace the new social paradigm and new practice models. The healthcare environment is certainly chaotic, complex and rapidly changing due to many internal and external forces that impact leadership's ability to become and remain effective (IOM, 2001).

\section{Leadership in business.}

The business sector has conducted research related to leadership styles and behaviors. Interviews and survey research were conducted by the Conference Board, a well-respected United States business forum. The Conference Board nominated 10 broad skills of the successful leader that include: (Barrett \& Beeson, 2002).

1. Intellectual firepower and mental agility

2. Strategic thinking skills, especially in regard to global competition and technology 
3. Analytical ability and the savvy to sort through a tsunami of information sources and select the most relevant parts

4. Solid decision-making in the face of uncertainty

5. Personal and organizational communication skills

6. The ability to influence and persuade not only within the organization but also outside, involving customers, suppliers, strategic partners, external constituents, and investors

7. Managing a diverse workplace and employing several styles for dealing with many cultures, generations, and points of view

8. Knowing how to delegate tasks and responsibilities but at the same time managing risk and having sound controls in place

9. The ability to recognize, attract, develop, and retain talent

10. Personal adaptability

Longitudinal multisource field data were used to examine the linkages between self-monitoring, discrepancy in manager match-to-position, 5 measures of leadership, and manager performance. The survey included 98 managers and 294 subordinates in a large business firm in the United States. The results of the study revealed that discrepancy in manager match-to-position was associated with a decrease in laissez faire and passive management-by-exception leadership behaviors. Self-monitoring was positively associated with all 5 leadership behaviors and performance was related positively to transformational leadership behavior and negatively to passive management-by-exception and contingent-reward behaviors (Sosik et al., 2002).

Another research study examined the leader-member exchange (LMX) theory from both supervisor and subordinate perceptions. Previous studies had been completed 
but they typically ignored the perspective of the supervisor. This multidimensional study involved a wide range of settings including the service industry (27.7\%), human services (14.7\%), and government (11.4\%). The results of the study supported a multidimensional factor structure for both supervisor and subordinate LMX scales with four distinct dimensions: affect, loyalty, contribution, and professional respect (Greguras \& Ford, 2006).

Albrecht (2005) conducted qualitative research in the public sector to better understand how generalized perceptions of leadership might influence organizational outcomes. The results of the study suggested that both affectively and cognitively based perceptions of leadership influenced organizational commitment and cynicism toward change. Their findings may be useful to human resource practitioners that are interested in the transformational leadership climate in public sector organizations.

One study focused on 105 institutions in the Council for Christian Colleges and Universities. The study examined the impact of leader behaviors on motivation levels of employees. Leaders were administered the Multifactor Leadership Questionnaire (MLQrater version). The results of the study created a four-factor leadership model that identified the significant predictive leadership variables that correlated with motivation for extra effort among the workers in the study. The study provided empirical data to support the concept that a combination of charisma, intellectual stimulation, personal consideration, and a reward system can significantly increase the motivation of workers in an organization (Webb, 2007).

The association between employee empowerment and interpersonal trust in managers was explored from a random sample of 2,000 salaried employees at a Fortune 500 manufacturing organization in the U.S. The results of the online survey indicated 
that employees who felt empowered in their work environments tended to have higher levels of interpersonal trust in their managers. "Managers can engage in behaviors that promote trust and demonstrate consistency, integrity, concern, and a willingness to share control" (Moye \& Henkin, 2006 p. 113).

\section{Leadership in healthcare.}

Many changes in society over the past few decades required that a change occur in the focus of leadership research in the healthcare environment. Indicators for the need for change included the growing demand for leaders in the health and social service fields; the increased gender and cultural diversity in the workplace; the globalization of organizations; rapidly changing work environments; and the information and technology

revolution (Vance \& Larson, 2002). Leadership was one of the main factors that affected employee engagement and retention. The structure and culture of hospitals influence leadership behaviors and additional research is needed that includes both the external and internal environmental factors and results in measurable outcomes.

The corporate world realized for many years that the culture of the organization could determine its success and be a competitive advantage. Quality initiatives and performance improvement projects were common in the business sector. The health care industry has lagged behind the business sector in their understanding of how the culture of the organization can impact quality initiatives and other performance improvements. An effective organizational culture was found to be critical for health care organizations as they faced issues such as managed health care structures and systems, competitive labor markets, and declining patient satisfaction (Graber \& Kilpatrick, 2008; Wooten \& Crane, 2003). 
Research on leadership that was reported in the healthcare literature was primarily descriptive but did show that it had substantial effects on people and organizational outcomes (Bass, 1990). The relationship between leadership in the health care environment affected outcomes such as job satisfaction. Dunham-Taylor (2000) concluded that participative leadership created an environment for nurse executives to exhibit greater transformational qualities and staff satisfaction. Work group effectiveness decreased as nurse executives exhibited more transactional leader behaviors. Leadership styles had a major influence on performance and outcomes but there was minimal transfer of this work to the health care environment (Vance \& Larson, 2002).

The Institute of Medicine (IOM) was established in 1970 and serves as an independent, nonprofit organization to provide informative and authoritative advice to the nation and policymakers to improve the nation's health. The IOM has a decade of quality reports mandating change. To Err Is Human: Building a Safer Health System was released by the IOM on November 1, 1999 and looked at systems and processes as the catalyst versus individual responsibility for reducing avoidable medical errors (IOM, 1999). Crossing the Quality Chasm: A New Health System for the 21st Century was released March 1, 2001 and recommended a redesign of the American health care system. The IOM report recognized the complexity of health care systems and organizations and offered four levels for intervening in the delivery of health care including 1) experience of patients, 2) the functioning of small units of health care delivery systems, 3) functioning of the organization that comprise the small units of health care delivery systems, and 4) external factors that affect the environment in which health care organizations deliver health care (IOM, 1999, 2001). 
The IOM reports in 2003 looked at the clinical education competencies for all health care professionals and specifically at the work environment of nurses. Included in the April 18, 2003 IOM report, Health Professions Education: A Bridge to Quality, over 150 health care leaders and experts attended the Health Professions Education Summit to strategize and provide recommendations for restructuring clinical education. The recommendations were based on findings that health care professionals were not adequately prepared to provide high quality care and there was insufficient evidence of ongoing proficiency. The report called for educators and accreditation, licensing and certification organizations to assure competence and proficiency in five core areas and included: 1) patient centered care, 2) work as an interdisciplinary team, 3) employ evidence-based practice, 4) applying quality improvement methods, and 5) utilize informatics (IOM, 2003).

The November 2, 2003 IOM report, Keeping Patients Safe: Transforming the Work Environment of Nurses, built on the earlier IOM reports and focused primarily on the work environment of nurses. The report urged attention to be paid to all organizational components regarding 1) transformational leadership and evidence-based management, 2) maximize workforce capability, and 3) create and sustain a culture of safety (IOM, 2004).

Vance and Larson (2002) found that the majority of the research in the health care and business literature was descriptive and included demographic characteristics on personality traits of leaders. Only 15 (5.2\%) of 290 research articles included correlations of qualities or styles of leadership with measurable outcomes on individuals or changes in the organizations. There were more citations related to leadership in the business literature than in the health care literature. The recommendations from the study 
concluded that leadership research should extend beyond the interaction between leadership and employees but also include identification of specific outcomes for clients, the delivery of care to clients, and organizational change (Vance \& Larson, 2002).

The measurable improvement outcomes of quality improvement programs were directly related to the management's commitment and dedication to ongoing improvements within the organization. A strong mission statement that was supported by the leadership and employees set a foundation for teamwork and a defined sense of purpose to guide behaviors. The recruitment process acquainted new employees with the culture of the organization and identified individuals whose values were consistent with the organization. The employee training could be structured to instill the values of the organization and the first year could be used to reinforce and model those values and expected behaviors in the workplace (Wooten \& Crane, 2003).

A descriptive retrospective design study examined the reasons why 32 nurse managers left their positions. The study site was two hospitals that resulted from a merger of five hospitals over a five year period in Sweden. Data was gathered from questionnaires and letters and qualitative content analysis was used to analyze the data. The results indicated that nurse managers resigned their jobs for personal and organizational reasons, and concluded that the relation to the head of the department influenced the nurse managers' overall work situation. The nurses identified important support factors as personal, organizational, practical and the desire to have opportunities for development and education (Skytt, Ljunggren, \& Carlsson, 2007).

A study of 43,000 nurses from more than 700 hospitals in the United States, Canada, England, Scotland, and Germany found fewer than half of the nurses in each country reported having management that was responsive to their concerns, opportunities 
for shared decision making, or recognizing nurses' contributions to patient care. The nurses in North America indicated that nurse manager positions and executive level nursing positions had been cut and resulted in a concern that staff nurses had to assume managerial duties as well as provide patient care. The results of the study found more than two in ten nurses planned to leave their nursing job within the next year and more that 40 percent of nurses working in hospitals reported dissatisfaction with their jobs. Job dissatisfaction was higher among nurses than in other groups of workers (Aiken et al., 2001). A longitudinal empirical investigation using quantitative methods found a predictive relationship between leadership quality and organizational performance in the healthcare study. The study found leadership quality "engaging with others" to be a significant predictor of organizational performance (Alimo-Metcalfe et al., 2008).

\section{Competency.}

The ANA Scope and Standards of Practice $(2009$, p. 3) stated that nurses "need to understand and embrace the competencies of nursing leadership" and "be aware of and exemplify leadership skills and traits". Nurse managers coordinate activities between their areas of responsibility and provide both clinical and administrative direction and expertise. Nurse managers are in leadership positions and have responsibility for staff nurse recruitment and retention. The scope of practice of the nurse manager includes the critical ability to enhance the work environment to recruit and retain nurses. The nurse manager attains knowledge and competency and maintains professional records that provide evidence of competency and lifelong learning.

The Healthcare Leadership Alliance (HLA) is a consortium of six major professional membership organizations including 1) American College of Healthcare Executives (ACHE), 2) American College of Physician Executives (ACPE), 3) American 
Organization of Nurse Executives (AONE), 4) Healthcare Financial Management Association (HFMA), 5) Healthcare Information and Management Systems Society (HIMSS), and 6) Medical Group Management (MGMA). The HLA developed five competency domains that were common among the membership of all six membership organizations to address the increased complexity of the healthcare environment and assure talented and capable leaders. The competency domains for all practicing managers were: 1) communication and relationship management 2) professionalism, 3) leadership, 4) knowledge of the healthcare system, and 5) business skills and knowledge. The result of the collaboration is a model or a foundation for future interprofessional teamwork among the associations, within the practice setting, and within educational or academic programs (Stefl, 2008).

The Health Leadership Competency Model (HLCM) is an interprofessional competency model for healthcare leadership that was developed as an evidence-based and behaviorally focused approach for evaluating leadership skills across the professions, including health management, medicine, and nursing, and across career stages.

Additional research and hypotheses testing was recommended by Calhoun (2008) to further validate the HLCM model for use by healthcare leaders.

The health care environment is rapidly changing and may well benefit from various leadership approaches depending on the situation. The ability of healthcare leaders to adapt to the complex environment is critical in order to provide the level of quality care and excellent outcomes that is expected. Different skills are becoming more important for leading in dynamic world and meeting current demands than the previous leadership styles and theories that have been practiced in the past (Porter-O'Grady \& Malloch, 2007). 
The leadership personnel in healthcare organizations are responsible for solving problems effectively. They often use the same techniques over and over and wonder why the outcomes are not improved. Problem-solving skills must be learned, refined and practiced in order to become effective tools for continual improvement. Problems must first be identified and then steps taken to identify the root causes of the problems in order to make improvements or eliminate the problem. Northouse (2010) described how effective problem solving and performance were the outcomes of leadership and were influenced by the leader's competencies (i.e., problem-solving skills, social judgment skills, and knowledge). "Leaders must develop themselves in order to effectively develop others" (Bass \& Avolio, 2004).

The IOM report, The Future of Nursing: Leading Change, Advancing Health, was released On October 5, 2010 after a two-year initiative with the Robert Wood Johnson Foundation (RWJF) in response to the need to assess the barriers that prevent nurses from leading change and advancing health in the United States. The committee recommended an action plan and key messages for the future of nursing.

The four key messages were:

1. Nurses should practice to the full extent of their education and training.

2. Nurses should achieve higher levels of education and training through an improved education system that promotes seamless academic progression.

3. Nurses should be full partners, with physicians and other health care professionals, in redesigning health care in the United States.

4. Effective workforce planning and policy making require better data collection and information infrastructure (IOM, 2010). 


\section{Best practice.}

Best practices in the health care world demonstrated how effective leadership could have positive results for their organization related to satisfaction and retention. The Magnet Recognition program was one approach to improving staff nurse job satisfaction and retention. The Magnet Recognition program (Magnet) considered that the nurse leaders were the key to nursing excellence (ANCC, n.d.). The Magnet Recognition program is one of the constructs of this research and the sample population for this study will be staff nurses in an acute care hospital applying for Magnet Recognition status.

The chief executive officer and leaders at Baptist Hospital in Pensacola, Florida crafted a vision to become the best healthcare system in America. Their mission, values, and patient care philosophy reflected their commitment to empower their employees and create an organization that engaged their staff and listened to their patients. They changed their organizational environment to an open leadership system where the employees were not just encouraged, but they were expected to contact anyone in the organization at any time to discuss work issues and improvement opportunities. The open leadership philosophy resulted in improvements in satisfaction for their patients, positive morale for the hospital staff and senior leaders serving as role models. They have adopted a "no excuses" policy where leaders were held accountable for organizational performance. The result of their organizational improvements was acknowledged by the prestigious 2003 Malcolm Baldrige National Quality Award presented by the President of the United States (Baldrige National Quality Program, 2003).

Healthcare organizations can utilize various models to improve their performance improvement outcomes. The Planetree philosophy offered a model as one approach that 
hospitals used to improve quality outcomes. The Griffin Hospital in Derby, Connecticut had been recognized with many awards since adopting the Planetree care philosophy and commitment to continuously improve the health of the community, the quality of life and well being of residents, and to provide leadership to achieve the vision of making their community a better place in which to live, work, raise a family and enjoy life. The hospital celebrated its seventh year on Fortune Magazine's 100 Best Companies to Work for in America and was the only hospital in the country to be named to the list for seven consecutive years (Charmel, 2009).

Six Sigma is an approach for continuous performance improvement within organizations. The methodology was introduced by Motorola in 1987 and further developed by General Electric in the late 1990s. The Six sigma methodology for process improvement is based around: 1) define, 2) measure, 3) analyze, 4) improve, and 5) control - often referred to as DMAIC. The Six Sigma methodology has many of the same elements found in other continuous process improvement techniques. Although the Six Sigma methodology began in the business sector, it is becoming part of the performance improvement process in some health care organizations (National Association Healthcare Quality [NAHQ], 2006). Of interest to this study; the hospital cite for the research utilizes Six Sigma methodology as their approach to quality improvement projects.

\section{Leadership in nursing.}

The research focus for nursing leadership had gone from a broad scope to a more narrow focus and from the individual to the process. Valuable information was obtained to understand leadership; however, "research regarding nursing leadership should continue so that knowledge can be provided to fill in the gaps, settle controversy, and 
define effective leadership" (Marriner-Tomey, 1993, p. 13). Marriner-Tomey (1993) reported that leadership practices in nursing should be based upon empirical processes that can serve as guides for practice and behavior. Thus, this study examined the relationship between registered staff nurses' perception of the leadership behaviors of their nurse managers and staff nurse job satisfaction at a hospital in South Central Kentucky that is applying for Magnet Recognition status. Facets of staff nurse job satisfaction and the relation to staff nurse overall job satisfaction was also analyzed.

The American Nurses Association Scope and Standards of Practice stated that providing leadership in human resource development and management is an expected role of the nurse administrator. The ability of nurse managers to enhance the practice environment and professional development of nurses is critical to the recruitment and retention of registered nurses with diverse backgrounds and appropriate education and experience (ANA, 2009).

In mid 2001, The American Nurses Foundation awarded a grant to help fund a Call to the Nursing Profession Summit. Over 100 participants from 60 national nursing organizations convened with the primary focus on achieving nursing's desired future state by 2010 . The steering committee identified 10 distinct domains to bring about positive change for the nursing profession and health care system. Following the work that was done by the IOM report, Crossing the Quality Chasm: A New Health System for the 21st Century, the domains were narrowed to common themes and included:

1) collaboration within all levels of nursing, 2) developing nurses' leadership and public communication skills, 3) improving the professional image of nursing, and 4) nursing partnership with policy-makers and business leaders to assure that nursing's voice is heard and helps shape the future (ANA, 2002). 
Dunham-Taylor (2000) examined a national sample of 396 randomly selected hospital nurse executives and 1,115 staff nurses in the United States. The study participants rated the nurse executives' leadership style, staff nurse extra effort, staff nurse job satisfaction, and work group effectiveness using Bass and Avolio's Multifactor Leadership Questionnaire (MLQ). The results from the study found as nurse executives were more transformational, they achieved higher staff nurse job satisfaction and higher work group effectiveness. The study also suggested that effective leaders exhibited characteristics of both transformational and transactional management styles.

The IOM (2004), Keeping Patients Safe: Transforming the Work Environment of Nurses, identified creating and sustaining trust throughout the organization as a critically important leader quality. Laschinger and Finegan (2005) explained that nursing management had to regain and maintain the trust of their employees to meet the impending nurse shortage. They conducted a non experimental predictive design to test the proposed model linking nurses' empowerment to organizational justice, respect, and trust in management and the link to job satisfaction and organizational commitment. The sample consisted of a random sample of 273 staff nurses in urban teaching hospitals across Canada. The results of the study identified that staff nurse empowerment had an impact on their perceptions of fair management practices. Job satisfaction had a statistically significant effect on organizational commitment $(\beta=0.54)$. The staff nurses reported structural empowerment meant their managers were concerned for their wellbeing in regards to decision making and provided them with explanations of their decisions. Trust in management was increased when nurses reported receiving the respect they felt they deserved. These conditions resulted in greater job satisfaction and 
commitment to the organization and concluded that nurses were more likely to believe in the goals of the organization, exert extra effort, and have lower turnover intentions.

Laschinger et al. (2007) tested a theoretical model linking nurse managers' perceptions with their supervisors and empowerment to job satisfaction in a sample of 141 hospital-based nurse managers. They hypothesized that a higher quality leadermember exchange (LMX) would result in higher levels of nurse manager job satisfaction. The results of the study indicated that higher quality relationship between nurse manager and supervisor resulted in greater sense of empowerment both environmentally and psychologically and as a result, nurse managers were more likely to be satisfied with their job. The results of the study indicated that nurse managers had a reduced intent to leave the job because of their job satisfaction.

The Current Population Survey (CPS) is a nationally representative survey administered monthly by the U.S. Census Bureau and contains data of more than 3,000 RNs employed in nursing each year. CPS data reported employment of foreign-born RNs in the U.S. increased from 9 percent of the total RN workforce in 1994 to 16.3 percent in 2008. Men and Hispanics were underrepresented in nursing relative to their proportion in the population and the workforce. The total RN workforce was approximately 9 percent male and 5 percent Hispanic. African American and Asian RNs in the workplace were proportional to the population (Buerhaus et al., 2009).

The leadership at the executive level considered unit managers responsible for productivity, motivation, and retention (Buckingham \& Coffman, 1999). The nurse managers performed their duties at many levels in the health care organization. The different levels included first-line patient care management at the unit level, middle management at the department level, and top management at the executive level 
(Roussel, 2006). Although nurse managers represented a small portion of the current nursing population, their performance was critical due to their impact on their respective nursing units. Martin (2004) explained the role of 'chief retention officer' and how nurse leaders were in a pivotal position to influence recruitment and retention initiatives.

The relationships that nurse leaders developed with their staff could influence staff satisfaction and retention. Anderson, Manno, O'Connor, and Gallagher (2010) used a national database of nursing quality indicators to analyze the characteristics of exemplary nurse managers as identified by their staff that supports staff nurse job satisfaction and retention. The recommendations from the study included a focus on leadership techniques of servant leadership and to incorporate elements of nurse leader visibility and communication with the values of respect and empathy.

Neill and Saunders (2008) conducted a study to describe the experience of the nurse leaders that implemented servant leadership at the George E. Wahlen Veterans Affairs Medical Center in Salt Lake City, Utah and consistently earned exceptional rankings in quality patient care and increased professional satisfaction in nursing practice. Ten principles of servant leadership that could be applied in nursing practice included listening, empathy, healing, awareness, persuasion, conceptualization, foresight, stewardship, committed to the growth of people or 'people builders', and building community.

Research had shown that nurse leaders had a measurable effect on the morale and job satisfaction of nurses (Anthony et al., 2005; Foong-Loke, 2001; Irvine \& Evans, 1995; Rad \& Yarmohammadian, 2006). A study conducted by Foong-Loke (2001) found that nurse leader behaviors and employee outcomes for job satisfaction, degree of productivity and organizational commitment were significantly correlated. The study 
explored the relationships between five leadership behaviors identified by Kouzes and Posner (2002). The regression results indicated that $29 \%$ of job satisfaction, $22 \%$ of organizational commitment and $9 \%$ of productivity were explained by the use of leadership behaviors.

The results of a study of 3,266 newly licensed RNs reported 13 percent had changed jobs after one year and 37 percent had desire to change jobs. Respondents indicated general satisfaction with their job but inadequate support from supervisors, inadequate supplies and equipment, and negative responses to attitudes about work. RNs with associate degrees reported greater desire to leave the job than RNs with baccalaureate degrees (Kovner et al., 2007).

A longitudinal research project was conducted by Atencio, Cohen, and Gorenberg to measure RN's perceptions of their work environments (Atencio, 2003). Their analyses found that positive perceptions were important in improving job satisfaction, retaining experienced nurses, and decreasing turnover and allowed nurse administrators to develop strategies to enhance work morale and performance. Another longitudinal empirical investigation used quantitative methods and found a predictive relationship between leadership quality and organizational performance (Alimo-Metcalfe et al., 2008). The study found leadership quality "engaging with others" to be a significant predictor of organizational performance.

To further evaluate how RNs view the work environment, Ulrich, Buerhaus, Donelan, Norman, and Dittus (2005) conducted a follow-up survey to the 2002 Nurse Week Publishing and the American Organization of Nurse Executives national survey on the views of registered nurses on the nursing shortage, workplace environments, and their future career intentions. The results of 1,783 completed surveys indicated there had been 
improvements in a number of aspects of the work environment of nurses but other areas had little or no progress and concluded with the need for continued improvement efforts. Only $42 \%$ of the RNs in the study reported the relationship between nurses and nurse managers as excellent or very good and $64 \%$ of the respondents said that more respect from nurse managers would cause them to reconsider leaving their current position. Of interest in the study was the fact that staff nurses reported they did not feel the organization had increased efforts at nurse recognition in an attempt to reduce turnover.

Magnet hospitals were recognized for their ability to attract and retain nurses. Research related to staff nurse satisfaction and retention was statistically significant for Magnet hospitals and Magnet versus non Magnet hospitals. Research on the Magnet nurse leader effectiveness had been limited (Upenieks, 2003b).

Interviews were conducted with 279 staff nurses working in 14 Magnet hospitals and the results indicated major implications for chief nurse executives and nurse managers. Results of the qualitative study suggested that the "single most important role activity of chief nurse executives is to engage nurse managers who understand that control model of leadership is no longer appropriate" followed by the need to "guide and teach nurse managers to empower their staff' (Kramer \& Schmalenberg, 2003 p. 449).

A study was conducted for the purpose of using peer recognition for potential nursing leaders in two study hospitals with 1600 staff nurses. The premise of the study was that nurses in individual units could better identify potential leaders and assist in the next generation of nursing leaders. The purpose of the study was to develop a model for identifying leadership potential. The researchers developed a three-tiered selection process consisting of: confidential peer voting, head nurse recommendations, and a personal interview. Differences were found between the staffs' and the managers' 
perceptions of appropriate potential candidates (Picker-Rotem, Schneider, Wasserzug, \& Zelker, 2008). As noted by Upenieks (2003a), differences in job satisfaction scores could be explained by the gap between the nurse leader's actual behaviors within the organization and his or her statement of the importance of these leader traits.

Nursing management is a difficult and challenging task. Leadership style in nursing management was the research study conducted by Sellgren, Ekvall, and Tomson in 2006. Questionnaires were sent to nurse managers and their subordinates to assess the preferred leadership behavior in three areas: change, production and employee/relation orientations. The questionnaire was also used to assess the subordinates' perceptions of their manager's leadership behavior. The conclusion of the study found that subordinates preferred managers with more clearly expressed leadership behavior than the managers preferred or demonstrated (Sellgren et al., 2006).

A field study conducted by Purvanova, Bono, and Dzieweczynski (2006) linked transformational leadership behaviors to employees' perceptions of their jobs. The employees' perceptions included the significance, meaningfulness, and importance of their work. The managers rated job perceptions to employees' citizenship performance. The results of the study indicated a positive link between managers' transformational leadership behaviors and followers' citizenship performance. Employees who report to managers that engage in transformational leadership behaviors rated their jobs as more challenging, meaningful, and significant (Purvanova et al., 2006).

A descriptive correlational study conducted by McGuire and Kennerly (2006) examined the relationship between the key variables: leadership style of nurse managers and the organizational commitment of staff nurses working on their respective unit(s). Nurse leaders that demonstrated transformational leader characteristics promoted a higher 
sense of commitment in their followers. The measurement instruments included a demographic form, the Multifactor Leadership Questionnaire (MLQ) Form 5X (Bass \& Avolio, 2004) to measure transformational and transactional leadership characteristics, and the Porter and Smith (as cited in McGuire \& Kennerly, 2006) Organizational Commitment Questionnaire (OCQ) to measure organizational commitment.

The research questions included:

1. "What is the relationship between the nurse manager's self-assessment and the RNs' assessment of the manager as it relates to transformational and transactional leadership characteristics?

2. What is the relationship between the RNs' perception of the nurse manager's transformational and transactional leadership characteristics and the degree of organizational commitment demonstrated by the same RNs?

3. What is the relationship between the self-assessed transformational and transactional leadership characteristics of the nurse manager and the degree of organizational commitment demonstrated by the RNs reporting to that nurse manager?" (McGuire \& Kennerly, 2006, p. 182)

The sample population was drawn from eleven hospitals and included 63 nurse managers and 500 staff registered nurses. The research question 1 found that nurse managers rated themselves higher on transformational leadership than did their staff nurses. The research question 2 demonstrated statistically significant correlations between the staff nurses' scores on the MLQ and the OCQ except for the transactional subscale labeled management-by-exception. The strongest positive correlation was 'idealized influence' also called charismatic leadership. Research question 3 revealed no 
significant correlation between the nurse managers' self-assessed leadership

characteristics and the degree of organizational commitment demonstrated by their staff nurses.

The research work by Anthony et al. (2005) recognized the successful nurse managers held the same principles found in servant leadership and considers servant leadership as the new paradigm of nursing leadership. Neill and Saunders (2008) described servant leadership as a powerful skill set that was particularly effective in regard to nursing leadership. Servant leadership was often applied to nursing management and was founded on the belief that nurse leaders are motivated to serve his/her employees who in turn served others (Anderson et al., 2010; Anthony et al., 2005; Neill \& Saunders, 2008; Northouse, 2010). Northouse (2010) explained there had been an increased interest in servant leadership since its development by Robert Greenleaf in the early 1970 s. The approach had not been uniformly defined, resulting in different measures of the construct. A common theme running through the different servant leader perspectives was related to the importance of leaders' attention to the needs of their followers.

\section{Competency.}

The literature review included discussion about leadership competency and how important it was to develop, retain and attract healthcare leadership. Leadership research showed that many nurses were promoted into leadership positions without adequate leadership training (Advisory Board Company, 2002). Most nurse managers had little formal leadership training and had learned on the job mostly through trial and error (Sherman et al., 2007). Nurses who had exemplary clinical expertise may not have had the necessary leadership skills for promotion to a leadership role. Thus, it is important to 
determine whether nurse managers need leadership education and training. Surveying subordinates perceptions of their nurse leader behaviors may identify if leadership training is needed.

A qualitative study of 94 nurse leader participants was conducted by Sullivan, Bretschneider, and McCausland to look at the educational needs of both new and experienced nurse leaders (Sullivan, Bretschneider, \& McCausland, 2003). Their findings recommended a structured, competency-based orientation for new managers. They also supported implementation of a national curriculum for leadership development and a more collaborative approach toward multidisciplinary leadership development. Sherman et al. (2007) explored the viewpoints of 120 nurse managers through a grounded theory methodology to gain perspectives related to the critical leadership skills and competencies. They confirmed that there is a need to formally develop future nurse leaders. The research findings led to development of a nursing leadership competency model.

Leadership development programs need to include the skills that are necessary to address the complexities within the healthcare environment and not just address the technical skills. Some critical skills for effective leadership mandate excellent communication, team-building and the ability to pull together competent, creative managers who possess the talents to work with all levels of personnel within the organization. The importance of values in organizations was considered to be a key quality of successful leaders and the importance of the topic was found in management literature. Healthcare organizations in the United States have unique structures that contribute to greater challenges for healthcare managers (Graber \& Kilpatrick, 2008; Wooten \& Crane, 2003). 
Nurses have a pivotal role in health care organizations and possess a strong desire to be actively involved with their patients, families, physicians, and leaders in the organization to make a difference. These are the same desires that cause nurses to leave an organization if they do not have a clear understanding of the organization's culture and how it operates. The disconnect between staff nurses and those in leadership positions could be improved upon once health care organizations understood and developed systems that clearly conveyed to the nursing staff the group's culture values (Graber \& Kilpatrick, 2008).

The American Nurses Credentialing Center (ANCC) provided guidelines for the Magnet Recognition Program (Roussell, 2006). The ANCC guidelines focused on recruiting and retaining quality staff, providing quality care or healthcare products, and valuing and enhancing the nursing profession. Many nurse administrators embraced the concepts reflected in the Five Model Components associated with the Magnet Recognition Program: Transformational Leadership; Structural Empowerment; Exemplary Professional Practice; New Knowledge, Innovation, and Improvements; and Empirical Quality Results. They sought to provide the nurses and others in their facilities, organizations, schools, or agencies with the tools and skills necessary to achieve quality work (ANCC, n.d.).

\section{Staff nurse job satisfaction.}

Employee job satisfaction and retention is critical due to the increased cost of recruitment and training new employees. Job satisfaction was a major element that was critical to retaining and attracting well-qualified personnel and was especially an issue in medical institutions such as hospitals where specialist training and retention were highly important (Rad \& Yarmohammadian, 2006). Nurses reported increased stress and 
dissatisfaction in the acute care nursing environment and some reports stated that one in five nurses planned to leave the profession within the next 5 years (Atencio et al., 2003) and more than 40 percent of nurses working in hospitals reported being dissatisfied with their staff nurse job (Aiken et al., 2001). The research conducted regarding job satisfaction among nurses had primarily been concerned with the satisfaction of nurses between different demographic groups and not related to nurse manager behavior.

A meta-analysis of 48 studies and a total of 15,048 nurses examined the variables most associated with nurses' job satisfaction. The two most important predictors of job satisfaction were related to stress and organizational commitment. Job satisfaction positively correlated with organizational commitment, communication with supervisor, and recognition and negatively correlated with stress, routinization, personal locus of control, and education (Blegen, 1993; Lashinger \& Finegan, 2005). Irvine and Evans (1995) found similar results in a meta-analytic study to investigate the causal relationships among job satisfaction, behavioral intentions, and nurse turnover behavior. The results of the study found a strong positive relationship between behavioral intentions and turnover; a strong negative relationship between job satisfaction and behavioral intentions, and a small negative relationship between job satisfaction and turnover. Work content and work environment had a stronger relationship with job satisfaction than economic variables.

The literature found leadership as important for creating conditions that resulted in an engaged and committed workforce. The meta-analysis conducted by Irvine and Evans (1995) concluded that health care administrators had control over many factors related to job satisfaction. The nurse manager could impact staff nurse job satisfaction by 
ensuring that nurses were empowered to practice according to professional nursing standards (Laschinger et al., 2009; Irvine \& Evans, 1995).

A literature review of 25 studies found that organizational commitment was not routinely studied in nursing turnover research and had not consistently produced strong correlations (Wagner, 2007). Explanations included the impact of moderating variables on organizational commitment and turnover. The moderating variables included tenure as a nurse, interval of measure between measurement of organizational commitment and turnover, and job satisfaction. Studies, even by the same researchers, found varying analyses and results. The studies of whether organizational commitment or job satisfaction was more strongly predictive of turnover behavior "remained puzzling" (p. 245).

McNeese-Smith (1997) found nurse managers that used the leadership behaviors identified by Kouzes and Posner in guiding their departments had staff nurses that reported higher job satisfaction, productivity and organizational commitment than those managers that did not use those leadership behaviors. Nurses attributed both positive and negative feelings about their job were related to the managers' behaviors. The leadership behaviors identified by Kouzes and Posner (2003) tested in the study included:

1) challenging the process, 2) inspiring a shared vision, 3) enabling others to act, 4) modeling the way, and 5) encouraging the heart.

McNeese-Smith (1997) sampled thirty nurses in a university-based Los Angeles hospital using a descriptive design and semi-structured interviews. The sample purposely included nurses from units with the highest job satisfaction scores and those units with the lowest job satisfaction scores to raise the probability of obtaining those nurses with more clearly identified feelings about their job. Forty-three percent of the nurses reported 
that recognition, praise and thanks from the manager most influenced their job satisfaction. Other behaviors that influenced job satisfaction were meeting nurses' personal needs (27\%), helping or guiding the nurse (23\%), using leadership skills, meeting unit needs, and supporting the team $(7 \%)$. The research concluded that nurses perceived the positive comments from their manager as affecting their job satisfaction and productivity but not necessarily their commitment to the organization.

Corser (1995) conducted a study to identify the activities and responsibilities that staff nurses expect from first-line managers. The questionnaire data from 192 registered nurses researched the first-line manager's role through the view of different staff nurse groups and tested for correlations between specific manager activities preference ratings and three staff nurse group demographics (the predominate work shift; full or part-time status; and type of work unit and specific work activities). The most notable results showed a wide response to the survey items suggesting that the activities that staff nurses feel should constitute first-line nurse managers' work vary greatly from nurse to nurse. Corser recommended further studies were needed to investigate whether or how work behaviors of first-line nurse managers affected staff job satisfaction levels, work productivity, and patient outcomes.

Medley and Larochelle (1995) conducted a research study of the relationship of head nurse leadership style to staff nurse job satisfaction using the Multifactor Leadership Questionnaire and the Index of Work Satisfaction. The participants in the study were 122 staff nurses in acute care community hospitals in north-central Florida. The results of the study indicated that the staff nurses identified transformational and transactional leadership styles in the head nurses and staff nurse job satisfaction correlated positively 
with the transformational leadership style of head nurses but not with transactional leadership style.

A cross-sectional mailed national survey, "Factors Associated with Work Satisfaction of Registered Nurses", was conducted consisting of 1,538 randomly selected RNs in a variety of nursing positions and healthcare organizations to examine the factors that influence work satisfaction. (Kovner, Brewer, Wu, Cheng, \& Suzuki, 2006) found 40 percent of the variance in satisfaction was explained by: supervisor support, workgroup cohesion, variety of work, autonomy, organizational constraint, promotional opportunities, work and family conflict, and distributive justice. "The amount of wage was not a significant factor but the fairness of the wage was important" (p. 78).

Brewer and Kovner (as cited in Robert Wood Johnson Foundation [RWJF], 2007) followed the "Factors Associated with Work Satisfaction of Registered Nurses" study (Kovner et al., 2006) to explain the factors related to work satisfaction for registered nurses in the hospital setting. The results from a nationally representative sample of 553 staff RNs who work in hospitals found 38 percent of variability in satisfaction was explained by the working conditions. Supervisory support was a significant variable related to job satisfaction of the hospital staff nurses. Wages and benefits were not found to be a significant factor related to job satisfaction in the study.

Leader-empowering behaviors significantly influenced staff nurse perceptions and access to empowerment structures and predicted lower levels of job tension and increased work effectiveness. The study highlighted the importance of nurse leadership behaviors within chaotic healthcare organizations (Laschinger, Wong, McMahon, \& Kaufmann, 1999). Laschinger et al. (2009), in their article entitled "Context Matters: The Impact of Unit Leadership and Empowerment on Nurses' Organizational Commitment," tested a 
multilevel model linking unit-level leader-member exchange (LMX) quality and structural empowerment and its link to nurses' psychological empowerment and organizational commitment at the individual level. The study was prompted by the nursing shortage in Canada and the projected shortage of 78,000 registered nurses by 2011. They found that few studies have examined the effects of nurse leaders at the unit level and individual nurse outcomes related to staff nurse commitment and retention. They completed a survey of 3,156 staff nurses in 217 hospital units and found unit-level leader-member exchange quality had a significant effect on staff nurse empowerment and job commitment. They concluded that positive supervisor relationships create conditions that result in a committed nursing workforce.

Atencio et al. (2003) studied the perceptions of staff nurses regarding autonomy, task orientation, and work pressure in the acute care hospital work environment. The results of the study explained staff nurse intent to stay or leave the workplace as dependent on the social climate of the workplace. The researchers also found job dissatisfaction as a predictor of nurses' intent to leave their jobs.

Staff nurse employees that were engaged in the healthcare organization had a higher sense of job satisfaction and were less likely to leave. As leaders focused on people and encouraged employees to become more engaged, satisfaction rose and retention increased. High employee retention was a key indicator of employee and organization well-being. Lower employee turnover rates reduced overtime and use of temporary personnel, reduced recruitment and new employee training costs. Greater employee satisfaction correlated with greater patient satisfaction as well (Studer, 2004).

Nurse autonomy and control over practice were linked to increased job satisfaction and decreased burnout. Magnet hospitals had management practices that 
fostered autonomy and demonstrated positive outcomes and a shared leadership model. Shared governance was a model that was ideally based on the principles of accountability, partnership, ownership, and equity that could benefit patients, staff, and leadership in an organization. The nurse leaders who created environments for increased nursing autonomy should result in improved staff nurse job satisfaction and reduced intent to leave the organization (Watters, 2009).

\section{Staff nurse retention.}

Staff nurse retention was important from an organizational point of view as well as from the staff nurse perspective. The retention of nursing staff provided the experience necessary to provide the quality patient care in a rapidly changing health care environment (Anderson et al., 2010). Staff nurse retention became important during times of nurse shortages and involved a wide array of individuals, from staff nurses to nurse managers and executives. The concerns related to staff nurse retention had both noneconomic and economic origins. The non-economic issues were: retaining adequate numbers of RNs to provide safe care to patients; increased workloads resulting in overburdening existing nursing staff that may increase turnover; and recruiting quality RNs to fill vacancies. The economic issues were costs related to turnover, the loss of nursing human capital, and the potential effects on quality of care (Jones \& Gates, 2007; Roussel, 2006).

Nurse leaders played an important role not only in the recruitment of nurses, but also in the retention of qualified, professional clinical nurses (Kettering-Murray, 2002). Results from a study of the literature finds leadership behaviors of the nurse leader in healthcare organizations influenced nurse employee satisfaction and retention in the acute care setting (hospital) (Kleinman, 2004a). One of the most important responsibilities of a 
nurse leader was the ability to recruit and retain qualified nurses. Kerfoot (2000), "The Leader as a Retention Specialist", explained how the public was demanding higher levels of safety, lower costs, and higher levels of customer service at a time when the healthcare industry was experiencing financial constraints that impacted the ability to attract and retain nurses. The nurse manager had opportunities and influence with his/her nursing staff at the unit level (Cullen, 1999). Staff nurse satisfaction and retention was especially important to understand in the rapidly changing healthcare environment $(\operatorname{Rad} \&$ Yarmohammadian, 2006).

The literature reported that leadership behaviors influenced performance and outcomes but there was minimal transfer of this research work to the health care environment (Bass, 1990; Luthans, 2005; Marriner-Tomey, 1993; Sellgren et al., 2006; Vance \& Larson, 2002). There was a relationship between leadership in the health care environment and outcomes such as job satisfaction and employee retention. Nurse leader behaviors had an impact on their staff nurse subordinates and needed further research and not just speculation. The health care field would benefit from a better understanding of organizational attributes as primary determinants of process change (Glickman et al., 2007).

One of the key factors related to employee retention was related to the leaders in the organization. Leaders were an important factor in why people stayed with an organization. "People generally do not quit their job or the organization, they quit their leaders" (Kouzes \& Posner, 2002, p. 283-284). The company did not do anything negative to the employees, people did. Sometimes coworkers caused the problems that prompted people to leave the organization but it was often the leaders who alienated the employees. Another important reason the majority of people stayed with an organization 
was because they liked the work they were doing and found it challenging, meaningful, and purposeful. People wanted to be tested, to take part in a social experiment, to do something well and good and a chance to make a difference (Kouzes \& Posner, 2002, p. 151; Thomas, 2000).

Organizations relied on their leaders for solving problems and improving performance to maintain a competitive advantage (McGuire \& Kennerly, 2006). The nurse managers were in a unique position to be involved with their nursing staff and also be involved at the administrative level. Managers serve as a link between nursing personnel and other ancillary departments by creating a trusting environment and being involved at many levels within the organization (Moye \& Henkin, 2006).

The nurse leader's role was essential to recruiting, retaining, and motivating staff and ensuring patient safety. The nurse managers had many responsibilities including coordinating activities that involved staffing and employee issues, physician and ancillary relationships, patients and their family demands. They were also expected to demonstrate clinical, administrative, and leadership expertise in handling the day-to-day operations and provided input at the executive level and kept their staff informed of executive level activities. The nurse managers carried forth the vision, mission and standards of the organization for their nursing departments to meet the goals of the organization (ANA, 2009).

The leadership skills and abilities of nurse managers were recognized as important determinants to the efficient operation of acute care hospitals. Their leadership roles were gaining more attention in relation to staff satisfaction and organizational commitment. The way nurse leaders implemented their leadership role could have a significant impact on their staff satisfaction and retention (Kettering-Murray, 2002; 
McGuire \& Kennerly, 2006). Nurse managers' leadership skills enhanced the practice environment and provided for the professional development of nurses and were critical to the recruitment and retention of registered nurses with diverse backgrounds and appropriate education and experience (ANA, 2009).

Understanding the perception of registered nurses on the roles and responsibility of nurse manager leadership could give additional insight into how that affects their job satisfaction and retention with the organization. Sellgren et al. (2006) found leadership behaviors that were suitable for health care organizations had been poorly explored. The health care industry was complex and would remain that way in the future. Changes in the workplace related to diversity and technology brought both challenges and rewards. Costs were rising while resources, including human capital, were diminishing (Swenson, 2008).

Four large acute care hospitals in a midwestern metropolitan area participated in a prospective correlational research study of manager leadership characteristics on registered nurse retention over a six month period. The retention indicators measured turnover, unit separation, and retention. The effects of manager characteristics were linked to retention through work characteristics, job stress, job satisfaction, commitment, and intent to stay. The participants in the study included 95 nurse managers and 1171 staff nurses. The manager's leadership behavior more directly affected unit separation than turnover. Manager leader behaviors that had a direct impact on retention included consideration of staff in terms of concern, valuing their input, and support for personal development. Job satisfaction was a predictor of unit separation but not turnover (Taunton et al., 1997). 
Anthony et al. (2005, p. 146) considered "nurse managers the link between executives and bedside nurses who assume roles that bridge both organizational and professional goals". Nurse retention was recognized as one of the responsibilities of the nurse manager. The researchers conducted focus groups of 32 voluntary nurse managers and were asked questions about what characteristics and behaviors attributed to successful nurse managers and to promote retention. The respondents were asked questions that included the following: What are the key roles of the nurse manager? What skills do nurse managers need to retain staff? To what extent do you believe most managers have those skills? The results of the study were divided by structure (professional area expertise), process (interpersonal skill), and outcome (quality indicators). The primary characteristics and behaviors identified from the study included communication, advocating for nurses, providing a supportive organizational culture, autonomous practice environment, scheduling, staffing, continuing education, and collaborative relationships (Anderson et al., 2010).

Nursing leaders of the next generation workforce need to be open to the rapidly changing workplace and to the wide range of diversity and experiences of its employees. Flexibility and the ability to adapt are skills of effective leaders as they create work environments to attract new employees and meet the needs of the employees to improve retention. Developing effective leaders requires commitment, time, and money. Nursing leaders need to be receptive to analyzing their leadership behaviors in the context of the staff nurse job satisfaction and staff nurse retention.

Many CEOs considered the lack of qualified leadership talent as the most significant constraint on growth (Gandossy \& Guarnieri, 2008). Attention to the long term organizational goals related to nursing retention and not just the short term reward 
structures and metrics that organizations readily use benefited the health care organization and the staff nurse employees. Short term solutions often discouraged people from having the learning experiences they needed for leadership development (Gettler, 2003). Effective nursing leadership empowered its staff and held all employees responsible for the organizational success. Empowerment also generated support for organizational goals and the momentum necessary for change initiatives (Wooten \& Crane, 2003).

\section{Summary and Research Problem}

The nursing shortage had abated temporarily but was expected to recur in the next decade (Buerhaus et al., 2009). Hospitals desire to recruit qualified staff nurses and retain them within their organization. The link between the nursing shortage and staff nurse retention is significant because staff nurses have more opportunity to seek other employment during times of nursing shortage with their increased demand. The work of Anthony et al., (2005); Irvine \& Evans (1995); and Rad \& Yarmohammadian (2006) validated the significant role that nurse managers have on the staff nurse job satisfaction and Kettering-Murray (2002), Kleinman (2004a), and McGuire \& Kennerly (2006) identified direct links between leader behavior and staff nurse retention. The gap in the literature related to the relationship between the staff nurse perceptions of their nurse leader behaviors and facets of staff nurse job satisfaction and staff nurse overall job satisfaction in an acute care hospital applying for Magnet status has not been well studied in the literature.

The purpose of this research was to describe the relationship between staff nurses perception of their manager leader behaviors and facets of staff nurse job satisfaction and staff nurse overall job satisfaction and the relationship between the facets of staff nurse 
job satisfaction and staff nurse overall job satisfaction in a hospital applying for Magnet status. This research identified nurse manager leader behaviors that were related to facets of staff nurse job satisfaction and identified nurse manager leader behaviors that were related to staff nurse overall job satisfaction. Identifying nurse manager leader behaviors that were related to staff nurse overall job satisfaction may be a greater indicator of actual staff nurse turnover than identifying nurse manager leader behaviors that are related to facets of staff nurse job satisfaction (Brodke et al., 2009). 


\section{CHAPTER III}

\section{FRAMEWORK}

The current and projected nursing shortage in the United States (Huselid, 1995; Mancino, 2008; Mancino, 2009) makes it imperative to more fully understand how nurse manager leadership behaviors are related to facets of staff nurse job satisfaction and staff nurse retention (Gandossy \& Guarnieri, 2008; Gettler, 2003; Wooten \& Crane, 2003). Hospitals are open systems (Senge, 1990) that are impacted by economic, structural, and psychological factors (Irvine \& Evans, 1995). The staff nurse participants in the research study worked in a hospital in the process of applying for Magnet status. The research was studied in the context of the nursing shortage and a hospital in the process of applying for Magnet recognition status.

The conceptual framework for the research study explains the interrelationship between nurse leader behaviors as perceived by their staff nurses and the facets of staff nurse job satisfaction and staff nurse overall job satisfaction in a hospital applying for Magnet status. Studies show that hospitals with Magnet Recognition status have improved staff nurse job satisfaction and retention (Brady-Schwartz, 2005; Hader et al., 2006; Prater, 2009; Taylor, 2005; Upenieks, 2003a). Studies show that nurse manager leader behaviors influence staff nurse job satisfaction (Blegen, 1993; Irvine \& Evans, 1995; Lashinger \& Finegan, 2005). Hospitals accredited with Magnet status identify transformational leadership as one of the five model components for success related to a 
positive environment for nurses that includes job satisfaction, retention and shared governance (ANCC, n.d.).

Figure 1. Conceptual Framework

$$
\text { Nursing Shortage }
$$

Hospital Applying for Magnet Recognition Status

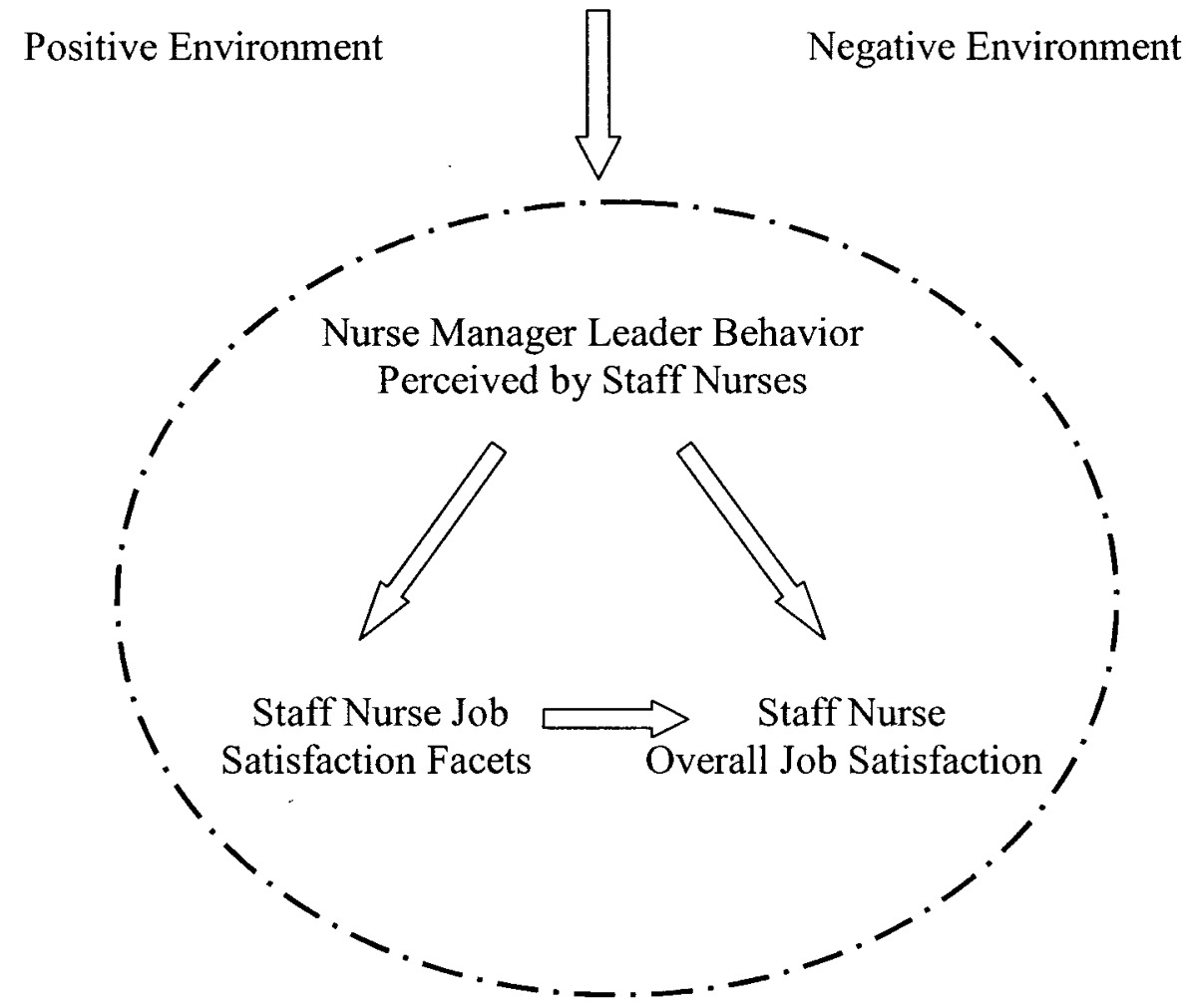

The conceptual framework that anchored this study was: nurse manager leadership behaviors as perceived by their staff nurses, staff nurse job satisfaction facets and staff nurse overall job satisfaction. These constructs provided valuable insight into describing nurse manager leadership behaviors that were related to the facets of staff nurse job satisfaction and staff nurse overall job satisfaction as perceived the nurse managers' staff nurses. These constructs were influenced by the hospital in the context of the nursing shortage and in the process of applying for Magnet Recognition status. 
This research studied the leader behaviors of nurse managers as perceived by their staff nurses in a hospital applying for Magnet status and the relationship to the facets of staff nurse job satisfaction and staff nurse overall job satisfaction. Staff nurses completed the aJDI/aJIG survey to measure their satisfaction with five facets (work, pay, promotion, supervision, and co-workers) and their overall job satisfaction, the MLQ 5X Short form to rate their perception of their nurse manager leader behaviors, and demographic variables to describe the characteristics of the subjects in the study.

Bass \& Avolio (2004) contended that both transformational and transactional leadership behaviors were positive forms of leadership and that good managers exhibited both types of behaviors just in varying degrees. Nurse managers may exhibit leadership strengths in both the transformational task-oriented and transformational relationshipfocused behaviors to carry out their day to day operation of their units. Too often, nurse managers tend to have strength in one area and have under-developed skills in the other area (McNeese-Smith, 1997).

Nurse managers demonstrate a range of leadership behaviors in the day to day operation of their unit. Bass and Avolio (2004) developed the Full Range of Leadership model to provide the framework for assessing a broad range of leadership behaviors. The Full Range of Leadership model provided a comprehensive approach to identifying leadership behaviors of the nurse manager as perceived by their staff nurses.

The Full Range of Leadership behaviors are measured by the Multifactor Leadership Questionnaire (MLQ). Staff nurses evaluated how frequently, or to what degree, they observed their nurse leader engage in specific behaviors or attributes. Bass and Avolio's theory of transformational leadership offers a framework for nurse managers to develop their own knowledge and abilities about leading others and can 
result in improved staff nurse job satisfaction and retention. Transformational leadership is one of the five model components of the 2008 ANCC's Magnet Recognition program to create a positive Magnet environment for recruitment and retention of staff nurses.

\section{Research Questions}

The focus of the study was the relationship between the self-reported staff nurse perception of their nurse manager leader behaviors to facets of staff nurse job satisfaction, staff nurse overall job satisfaction, and the relationship between the facets of staff nurse job satisfaction and staff nurse overall job satisfaction. The goal of the study was to identify nurse manager leader behaviors that were perceived to be related to facets of staff nurse job satisfaction and staff nurse overall job satisfaction. The relationship between facets of staff nurse job satisfaction and staff nurse overall job satisfaction was also examined.

The study was designed to answer the following research questions:

1. What is the relationship between staff nurse perception of the nurse manager leadership behavior and the facets of staff nurse job satisfaction?

2. What is the relationship between staff nurse perception of the nurse manager leadership behavior and the staff nurse overall job satisfaction?

3. What is the relationship between facets of staff nurse job satisfaction and staff nurse overall job satisfaction?

\section{Definitions}

The following definitions were provided for common understanding of terms used in the research project.

Abridged Job Descriptive Index/Abridged Job in General (aJDI/aJIG) - a multifaceted assessment of job satisfaction that has been used extensively in research and 
applied settings for over 40 years. The aJDI contained 25 items and the aJIG contained 8 items (Brodke et al., 2009).

Job satisfaction - the job satisfaction specified in the Abridged Job Descriptive Index/Abridged Job in General (aJDI/aJIG). Job satisfaction is one's affective attachment to the job viewed either in its entirety overall job satisfaction as measured by aJIG) or with regard to particular aspects (facets of job satisfaction: work, pay, promotion, supervision, and coworkers as measured by aJDI) (Tett\& Meyer, 1993). Leadership - a "process whereby an individual influences a group of individuals to achieve a common goal" (Northouse, 2010, p. 3). The following components were central to the concept of leadership: leadership as a process, leadership involved influence, leadership occurred in groups, and leadership involved common goals (Northouse, 2010). “There are almost as many definitions of leadership as there are persons who have attempted to define the concept" (Stogdill, 1974, p. 7).

Leadership behaviors - the behaviors specified in Multifactor Leadership Questionnaire (MLQ). The Full Range of Leadership (Bass \& Avolio, 2004) behaviors were identified in a continuum found in 4 dimensions and 12 subscales: 1 ) transformational leadership (idealized attributes, idealized behaviors, inspirational motivation, intellectual stimulation, individual consideration, 2) transactional leadership (contingency reward, active management-by-exception, 3) passive avoidant (passive management-by-exception, laissez-faire), and 4) outcomes of leadership (extra effort, effectiveness, and satisfaction).

Magnet hospitals - recognized for their excellence in nursing care and the high degree of satisfaction and retention of their nurses. Magnet hospitals met the 14 standards or forces of magnetism: 1) quality of nursing leadership, 2) organizational 
structure, 3) management style, 4) personnel policies and programs, 5) professional models of care, 6) qualify of care, 7) quality improvement, 8) consultation and resources, 9) autonomy, 10) community and the hospital 11) nurses as teachers, 12) image of nursing, 13) interdisciplinary relationships, and 14) professional development. The 2008 Magnet Recognition program configured the foundational 14 Forces of Magnetism into 5 model components: 1) transformational leadership, 2) structural empowerment, 3) exemplary professional practice, 4) new knowledge, innovation, and improvements, and 5) empirical quality results (ANCC Magnet Recognition Program, n.d.). Multifactor Leadership Questionnaire (MLQ) - a 45-item self-report questionnaire that measured a Full Range of Leadership (Bass \& Avolio, 2004) behaviors through 4 dimensions and 12 subscales including 1) transformational leadership (idealized attributes, idealized behaviors, inspirational motivation, intellectual stimulation, individual consideration, 2) transactional leadership (contingency reward, active management-by-exception, 3) passive avoidant (passive management-byexception, laissez-faire), and 4) outcomes of leadership (extra effort, effectiveness, and satisfaction).

Nurse administrator - is a registered nurse who orchestrated and influenced the work of others in a defined environment to enhance the shared vision of the organization or institution. The metrics often used to determine the success of the nurse administrator included employee satisfaction, successful recruitment and retention efforts, quality outcomes, and elevation of the image of nursing practice. Functions of the nurse administrators was to serve as an organizational development resource and required understanding of human resources theories and how to best utilize the talents and abilities of the people that make up the organization's workforce (ANA, 2009). 
Nurse manager - a registered nurse who had 24-hour responsibility for the operation of one or more defined areas within organized nursing services and had more than 5 staff nurse study participants. The nurse manager engaged in leadership and was responsible to a nurse executive. The nurse managers coordinated activities between defined areas, and provided clinical and administrative leadership and expertise. They facilitated an atmosphere of interactive management and the development of collegial relationships among staff nurses. The nurse managers had major responsibility for the implementation of the vision, mission, philosophy, core values, evidence-based practice, and standards of the organization within their defined areas of responsibility. The ability of nurse managers to enhance the practice environment was critical to the recruitment and retention of registered nurses (ANA, 2009). Throughout the research project, the nurse manager who engaged in leadership was also referred to as nurse leader.

Registered nurse $(R N)$ - an individual who had successfully completed the National Council Licensure Examination (NCLEX) for registered nurses and was licensed by the State of Kentucky to practice as a registered nurse (ANA, 2009). The RN was a graduate of an associate degree, baccalaureate, or master's degree nursing program. The staff nurse completed nursing orientation, worked in their area for a minimum of 90 days and more than two shifts per month and had enough contact with their nurse manager to respond to questions about their nurse manager leadership behavior. The nurse manager engaged in leadership, and those toward whom leadership was directed was called staff nurse. 


\section{CHAPTER IV}

\section{METHODOLOGY}

Chapter four describes the research design and methodology used to conduct the descriptive correlational study. A descriptive correlational design examines relationships that exist in a situation (Burns \& Grove, 2009). This study examined the interrelationships between nurse manager leader behaviors perceived by their staff nurses to the facets of staff nurse job satisfaction, to staff nurse overall job satisfaction, and the relationship between the facets of staff nurse job satisfaction and staff nurse overall job satisfaction in a hospital applying for Magnet status. The quantitative research design and research questions are presented, followed by the sample, method, instruments, procedure, data management, and data analysis. The chapter concludes with a summary.

The quantitative research approach was used for the research study. According to Cresswell (2008), survey research is probably the best method for collecting original data from a population that is too large to observe directly. The survey was the preferred type of quantitative research design for this study because it is economical as a means of data collection. It also allows for the ability to identify attributes of the specific population, and for the relatively simple collection of data. Survey research is frequently used in the social sciences and the standardized survey instruments assured that each participant in the study was presented the same data gathering technique (Babbie, 2001). Standardized quantitative surveys were the data gathering instruments used to determine which nurse leader behaviors were perceived by their staff nurses to be related to staff nurse job 
satisfaction. The use of standardized research instruments allowed for meaningful collection of comparable data and future replication of the study (Schwab \& Cummings, 1970).

\section{Population and Sample}

The sample for the study was staff nurses in a 490 bed non-profit acute care hospital in the southern United States. The hospital had over 500 registered nurses and 15 nurse managers. The staff nurse sample was defined as RNs who had completed nursing orientation and worked at least 90 days and more than two days per month on their current nursing unit. Nursing orientation is generally completed within 90 days and demonstrates that the staff nurse was practicing independently and had adequate interaction with their nurse manager to answer questions related to their nurse manager leadership behavior. The staff nurses were provided the definition of their nurse manager as having 24 hour a day and 7 day a week primary responsibility for the unit. To protect the anonymity of raters, MLQ data was not included in the study for nurse managers with less than 5 staff nurses participating in the study (Bass \& Avolio, 2004).

The sample was purposive due to its convenience, availability, and timeliness. The hospital site for the research project was conveniently located to the researcher and consisted of a large staff nurse sample size and adequate nurse manager pool. The hospital nursing administration supported the research study as it aligned with their mission to seek Magnet status.

\section{Sample size and power.}

The researcher believed that it would be reasonable to obtain a $50 \%$ or greater response rate to the survey. That would mean that approximately 250 or more persons would participate in the study. With a sample size of 250 , there would be sufficient 
statistical power to detect a moderate to large effect size with a type I error of .05 and a Type II error of .20. Thus, the study was planned to have sufficient power to detect the effects that were addressed in the proposed statistical analysis.

\section{Method}

The descriptive, correlation design used survey data to assess staff nurse perceptions of their nurse manager leadership behaviors and the relationship to the facets of staff nurse job satisfaction and staff nurse overall job satisfaction. The relationship between the facets of staff nurse job satisfaction and staff nurse overall job satisfaction were analyzed to determine what nurse manager leader behaviors were related to staff nurse job satisfaction.

The researcher met with the chief nursing officer $(\mathrm{CNO})$ and the Magnet Coordinator and obtained verbal agreement for the staff nurses to be invited to participate in the research study. The staff nurses attended monthly shared governance meetings. The researcher attended three shared governance meetings and explained the research project and data collection to increase the response rate. All materials for the staff nurses participation, such as cover letters, questionnaire including MLQ 5-X Short survey, aJDI/aJIG survey, and demographic items were prepared and delivered to the staff nurses during three of the shared governance monthly meetings. The staff nurses consented to participate by completing the survey. The cover letter to each study participant explained the purpose and relevance of the study, included the risks and benefits of participation and provisions regarding strict confidentiality and anonymity.

The researcher provided an envelope for the staff nurse to seal the questionnaire and place in a secure, closed collection box in the nursing administration office to ensure confidentiality and assure that nurse managers had no access to the surveys completed by 
their staff nurses. The consent to participate was the completed survey questionnaire. Refusal to participate in the research study was an option for the study participants and involved no penalty. A coding system preserved anonymity and was used for grouping the data. The return rate was monitored to improve the return rate. The staff nurses were eligible for one of two $\$ 50$ gift certificates once the study was completed by completing the survey and placing the survey in a sealed envelope and placing in a closed collection box in the nursing administration office.

\section{Instruments}

Three instruments were combined to collect data from the staff nurses. These instruments included a demographic questionnaire developed by the researcher, the Multifactor Leadership Questionnaire 5X Short (MLQ) and the Abridged Job Descriptive Index/Abridged Job in General (aJDI/aJIG). An individual who worked with designing layout of instruments was consulted to aid in putting all three instruments on one measurement tool to increase ease for completion by the staff nurses and thus increase response rate (see Appendices A-E for survey instruments and permissions).

\section{Demographic questionnaire.}

Shavelson (1996, p. 8) explained how demographic variables are used to describe the characteristics of the subjects and can "provide a picture" of the group membership. The demographic data were the independent variables used to identify factors that may influence facets of staff nurse job satisfaction and staff nurse overall job satisfaction that were independent of the nurse manager leadership behaviors.

Registered nurses have a wide range of individual and work related characteristics and these demographic data categories allowed for greater analyses across the subjects and their responses related to the MLQ and the aJDI/aJIG. A researcher- 
developed demographic questionnaire was utilized to collect characteristics of subjects and included variables such as age in five year increments, highest educational preparation (diploma in nursing, associate degree in nursing, baccalaureate degree in nursing, or master's degree in nursing), and background in nursing or higher degree in another field. Work-related characteristics such as staff nurses nurse manager, certifications, length of time in the current hospital in 5 year increments, length of time in the present position in 5 year increments, shift and days worked, and the predominate area of work was also collected. The questionnaire requested the staff nurse name and name of the manager for the purposes of future research involving the staff nurse overall job satisfaction and actual turnover and the self-reported leadership behaviors of the nurse manager compared to the staff nurse perception of their nurse manager.

\section{Multifactor Leadership Questionnaire (MLQ).}

The MLQ 5X Short form survey was used to answer the first and second research questions 1) What is the relationship between staff nurse perception of the nurse manager leadership behavior and the facets of staff nurse job satisfaction? 2) What is the relationship between the staff nurse perception of the nurse manager leadership behavior and the staff nurse overall job satisfaction?

The MLQ 5X Short was the classic form of the MLQ and was a 45-item selfreport questionnaire that identified and measured key leadership and effectiveness behaviors shown in prior research to be positively linked with individual and organizational success (Bass \& Avolio, 2004, p. 11). The MLQ contained 36 leadership items plus nine outcome items for a total of 45 items on the survey. The MLQ 5X Short rater forms were distributed to the staff nurses during three shared governance meetings and required at least five raters to protect anonymity and reduce inflation of the scores. 
The MLQ 5X Short rater form was used by staff nurses to measure their perception of their nurse manager leadership behaviors. Simple, clear instructions allowed respondents to complete the questionnaire without direct supervision. The approximate time to complete the MLQ portion of the survey was 15 minutes (Bass \& Avolio, 2004). The MLQ 5X Short form measured a Full Range of Leadership (Bass \& Avolio, 2004) behaviors through its 12 subscales and used a frequency rating with scoring that ranged from 0.0 (not at all), 1.0 (once in a while), 2.0 (sometimes), 3.0 (fairly often) to 4 (frequently, if not always). The frequency scale meant that a lower score exhibited less of a particular style (Bass \& Avolio, 2004, p. 9). The MLQ measured leader behaviors and outcomes of leadership. The MLQ subscales included: 1) transformational leadership (IIA = idealized attributes, IIB = idealized behaviors, IM = inspirational motivation, IS = intellectual stimulation, IC = individual consideration), 2) transactional leadership $(\mathrm{CR}=$ contingency reward, $\mathrm{MBEA}=$ active management-by-exception $)$, 3) passive avoidant (MBEP = passive management-by-exception, LF = laissez-faire), and 4) outcomes of leadership $(\mathrm{EE}=$ extra effort, $\mathrm{EFF}=$ effectiveness, and SAT $=$ satisfaction). The MLQ was not designed to label a leader as Transformational, Transactional, or Passive-avoidant. Averages were calculated and compared to norm tables (Bass \& Avolio, 2004) to identify leaders as "more transformational than the norm" or "less transactional than the norm".

One of the most popular reliability statistics in use today is Cronbach's coefficient alpha to determine the internal consistency or average correlation of items in a survey instrument to gauge its reliability. Cronbach's coefficient alpha of .80 or higher is considered to have high levels of reliability, in that the items consistently measure the 
same underlying construct. Cronbach's coefficient alpha for all of the MLQ subscales ranged from .69 to .83 (Bass \& Avolio, 2004, p. 69).

Table 3

Cronbach's Coefficient Alpha among the MLQ subscales

MLQ Factors Cronbach's coefficient alpha

\begin{tabular}{ll}
\hline IIA & .75 \\
IIB & .70 \\
IM & .83 \\
IS & .75 \\
IC & .77 \\
CR & .69 \\
MBEA & .75 \\
MBEP & .70 \\
LF & .71 \\
EE & .83 \\
EFF & .82 \\
SAT & .79 \\
\hline
\end{tabular}

The MLQ was developed by Avolio and Bass in the late 1980s as part of an empirical study to identify the most common leadership approaches and placed leadership behaviors on a continuum and defined more stages of leadership between the transactional and transformational leadership approaches. The MLQ measured the concepts of transactional and transformational leadership and was utilized in over 200 research studies within the past forty years (Bass \& Avolio, 2004).

The MLQ has well-established reliability and validity as a leadership instrument in both industrialized and service settings. Prior confirmatory factor analysis, the 
goodness of fit index, and reliability scores indicated that the MLQ is both a reliable and valid instrument for measuring transformational and transactional leadership characteristics (Bass \& Avolio, 2004). The results of the data indicated the leadership characteristics most frequently used and the predominant leadership style of the nurse managers as perceived by their staff nurses to be related to facets of job satisfaction and overall job satisfaction.

\section{Abridged Job Descriptive Index / Abridged Job in General (aJDI/aJIG).}

To answer the three research questions regarding facets of staff nurse job satisfaction and staff nurse overall job satisfaction, the researcher chose the Abridged Job Descriptive Index/Abridged Job in General (aJDI/aJIG). The Job Descriptive Index (JDI) was considered the premier instrument for assessing job satisfaction and addresses research questions one and three: 1) What is the relationship between the staff nurse perception of the nurse manager leadership behavior and the facets of staff nurse job satisfaction? 3) What is the relationship between the facets of staff nurse job satisfaction and staff nurse overall job satisfaction?

The JIG addressed research questions two and three: 2) What is the relationship between the staff nurse perception of the nurse manager leadership behavior and the staff nurse overall job satisfaction? 3) What is the relationship between the facets of staff nurse job satisfaction and staff nurse overall job satisfaction?

The JDI was a multi-faceted assessment of job satisfaction that had been extensively used in research and applied settings for over 40 years (Stanton \& Crossley, 2000). The original JDI was developed by Smith, Kendall, and Hulin (1969). The scale had been revised in 1985, 1997, and most recently in 2009 and came in both long 
(90 item) and short ("abridged" - 30 item) versions. The JDI included the five areas (facets) of job satisfaction that have been identified as important to organizations. In the aJDI, each facet (or subscale) was composed of 6 items (30 items total). The facets of job satisfaction were: work on present job; pay; opportunities for promotion; supervision; and coworkers. The aJIG scale measured overall satisfaction with the job and the aJIG was composed of 8 items (Brodke et al., 2009).

The JDI facet scales were designed to measure different aspects of the job and Brodke et al. (2009) explained the facet scores are measured separately and are not intended to be summed to reflect overall job satisfaction. The aJDI facet score was calculated for each respondent by summing the values for the items in each aJDI facet. The range of possible scores on each scale was 0 to 18 . Brodke et al. $(2009$, p. 24) explained the neutral point (the middle range of possible scores) is used to identify scores well above the neutral point to indicate satisfaction, while those well below the neutral point to indicate dissatisfaction. The higher satisfaction for each facet is indicated by scores well above 9 (the neutral point). The lower satisfaction for each facet is indicated by scores well below 9 (the neutral point).

The JDI instrument had established validity and reliability (Schwab \& Cummings, 1970; Smith, et al., 1969). A meta-analysis of the measurement properties of the JDI found that content, criterion-related and convergent validity were well established meaning that correlates were as expected with turnover and other job satisfaction measures. Each facet of the JDI and the JIG measured a distinct aspect of job satisfaction. The JDI facets were distinct from each other and from the JIG. Measures for facets of staff nurse job satisfaction, utilizing the aJDI, and measures for staff nurse overall job satisfaction, utilizing the aJIG, allowed the researcher to examine the facets of 
staff nurse job satisfaction and staff nurse overall job satisfaction as separate constructs related to the staff nurse perception of their nurse manager leader behaviors (Brodke et al., 2009). Cronbach's coefficient alpha for all of the JDI facets ranged from .88 to .92 (Brodke et al., 2009).

Table 4

Cronbach's Coefficient Alpha among the JDI facets and JIG

\begin{tabular}{lc}
\hline JDI Facets & Cronbach's coefficient alpha \\
\hline Work & .90 \\
Pay & .88 \\
Promotion & .91 \\
Supervision & .92 \\
CoWorkers & .92 \\
JIG & .92 \\
\hline
\end{tabular}

\section{Procedure}

Approval was obtained from the Human Subjects Review Board at University of Louisville and the hospital site. Only minimal risks were noted for the participants, including use of personal time and/or increased awareness/concern about answering personal questions related to the survey questions. The participants were assured through the consent form that participation was voluntary, data was kept confidential, and participation could be withdrawn at any time (see Appendix D for the preamble/consent forms).

The total number of all of the RNs that were employed at the hospital was available through the Human Resources department and included RNs employed as staff 
nurses. Staff nurses were provided a packet containing a cover letter, a preamble/consent form, the demographic questionnaire, the MLQ $5 X$ Short rater form, the abridged Job Descriptive Index/Abridged Job in General (aJDI/aJIG) survey, and a return envelope.

The distributed survey mode was chosen for the study due to the population to be surveyed was easily accessible. A professionally written cover briefly explained the study and was each letter was individually signed in blue ink (see Appendix E). The cover letter explained the use of the identification number and the coding system used for tracking the returned surveys. Return rates were monitored and follow up reminders were sent by email from nursing administration. Follow-up reminders and the use of self-addressed, stamped return envelopes improve response rates (Bass \& Avolio, 2004; Dillman et al., 2009). The return envelopes were labeled and respondents were given instructions to place the completed questionnaires in a closed collection box in the nursing administration office.

\section{Data Management and Analysis}

A data sheet was used for entering the data from the demographic, MLQ, and aJDI/aJIG survey instrument. All data were entered and cleaned by the researcher. Cleaning of the data included double checking all entries, noting and correcting errors. The Statistical Package for the Social Sciences (SPSS) version 19.0 was used for data analysis. All survey information is maintained in a secure location by the researcher.

The MLQ 5X Short form measured a full range of nurse manager leadership behaviors as perceived by their staff nurses. The rating scale for leadership items in the 12 subscales used a five point frequency rating. The rating scale ranged from $0=$ not at all, $1=$ once in a while, $2=$ sometimes, $3=$ fairly often, $4=$ frequently, if not always. Descriptive MLQ statistics for data included mean, standard deviation, and range of 
scores from $0=$ lowest to $4=$ highest. Due to the larger numbers of raters per leader, the mean and the range of ratings were carefully reviewed (Bass \& Avolio, 2004, p. 12).

The MLQ scoring key was used to group the 45 items by scale (IIA, IIB, IM, IS, IC, CR MBEA, MBEP, LF, EE, EFF, SAT). Averages were calculated for each respondent by summing the items in each scale and dividing by the total number of responses for that item. Blank answers were not included in the calculation and straight line responses were removed. The range of possible scores on each scale was $0-4$.

The SPSS automated scoring syntax was purchased for the aJDI/aJIG and included blank SPSS files for entering the participant's raw data. The instructions for the response to the survey items for the aJDI included: "Y" for "yes", "N" for "no", and "?" for "undecided". The data was cleaned by following the Job Descriptive Index and Job in General Reference Guide (Brodke, et al., 2009). The response options for the aJDI survey items were converted to numerical codes: "Y" was coded as 3, "N" was coded as 0 , and "?" was coded as 1 . One missing response per 5 item subscale was coded " 1 " and more than 1 missing response did not have a computed facet score for that participant. Straight line responses indicated unusable responses and the data for those individuals were removed. The aJDI scales were scored so that high values indicate high levels of satisfaction. Negatively worded items were identified and the scores were reversed: $3 \mathrm{~s}$ were changed to $0 \mathrm{~s}, 0 \mathrm{~s}$ were changed to $3 \mathrm{~s}$, and $1 \mathrm{~s}$ were not changed. The aJDI facet score was calculated for each respondent by summing the values for the items in each aJDI facet. The actual SPSS syntax files properly re-coded the data. Resources and support personnel were available for assistance at the JDI office and JDI Webpage. 
The study was designed to answer the following research questions:

1. What is the relationship between staff nurse perception of the nurse manager leadership behavior and the facets of staff nurse job satisfaction?

2. What is the relationship between the staff nurse perception of the nurse manager leadership behavior and the staff nurse overall job satisfaction?

3. What is the relationship between the facets of staff nurse job satisfaction and staff nurse overall job satisfaction?

\section{Statistical Analyses I Related to Research Questions}

The three research questions of the study were implied by the conceptual framework of the study. The first set of statistical analyses was designed to address the each research question.

1. What is the relationship between staff nurse perception of the nurse manager leadership behavior and the facets of staff nurse job satisfaction?

Pearson correlations were calculated between three MLQ leadership scores (transformational leadership, transactional leadership, passive-avoidant behavior) and staff nurse job satisfaction as measured by the satisfaction scores each of the aJDI facets.

2. What is the relationship between the staff nurse perception of the nurse manager leadership behavior and the staff nurse overall job satisfaction?

Pearson correlations were calculated between three MLQ leadership scores (transformational leadership, transactional leadership, passive-avoidant) and the staff nurse overall job satisfaction as measured by the global score on the aJIG.

3. What is the relationship between the facets of staff nurse job satisfaction and staff nurse overall job satisfaction? 
Pearson correlations were calculated between the facet satisfaction scores on the aJDI and the global score on the aJIG which measures overall job satisfaction.

\section{Statistical Analyses II Related to Mediation Analysis Implied by the}

\section{Conceptual Framework}

The conceptual framework of this study implies the possibility of mediation occurring. As can be seen in the framework, there are two influences of perceived nurse manager leadership behavior on the variable staff nurse overall job satisfaction. There is the direct effect of one variable on the other (the arrow in the lower right of the diagram). There is also the indirect effect of leadership behavior as mediated by staff nurse job satisfaction facets (the two arrows on the lower left of the diagram). The second set of statistical analyses will use multiple regression analysis to test mediation: i.e., to test if facets of job satisfaction mediate the effect of leadership behavior on overall job satisfaction or that leadership behavior directly affects overall job satisfaction without any mediation by facets of job satisfaction.

One regression equation will be calculated with leadership behavior as the predictor variable and job satisfaction the dependent variable. A significantly positive regression coefficient will be evidence that leadership behavior has a direct positive effect on the mediator job satisfaction. Table 5 shows the relationship among the variables. 
Table 5

Variables Used in this Study for Mediation Analysis

General Name of Variable Variables in This Study

Independent $(\mathrm{X}) \quad$ Leadership behavior

Mediator (M) Job satisfaction

Outcome (Y) Overall Job Satisfaction

A second multiple regression will be performed with leadership behavior entered as the first predictor variable and overall job satisfaction the dependent variable. A significant regression coefficient will be evidence that leadership behavior is positively associated with overall job satisfaction. This is the total effect of the independent variable (leadership behavior) on the outcome variable (overall job satisfaction) ignoring the mediator (job satisfaction).

In the second step of the hierarchical regression, the mediator variable $j o b$ satisfaction will be entered into the equation. The resulting regression will have two partial regression coefficients, estimating the effects of: (a) leadership behavior on overall job satisfaction, controlling for job satisfaction, and (b) job satisfaction on overall job satisfaction, controlling for leadership behavior.

\section{Mediation Analysis}

Procedures described by Berger (2004) will be used to perform the mediation analysis. Table 6 shows the regression coefficients that will be used for the analysis. 
Table 6

Source of Regression Coefficients for Mediation Analysis

\begin{tabular}{clcr}
\hline $\begin{array}{c}\text { Regression } \\
\text { coefficient }\end{array}$ & Effect of predictor variable on dependent variable & $\begin{array}{c}\text { Equation } \\
\text { Number }\end{array}$ & $\begin{array}{c}\text { Step of } \\
\text { equation }\end{array}$ \\
\hline a & Leadership behavior predicting Job satisfaction & 1 & 1 \\
c & Leadership behavior predicting Overall Job Satisfaction & 2 & 1 \\
c' & $\begin{array}{l}\text { Leadership behavior predicting Overall Job Satisfaction, } \\
\text { controlling for Job satisfaction }\end{array}$ & 2 & 2 \\
& Job satisfaction predicting Overall Job Satisfaction, & 2 & 2 \\
b & controlling for Leadership behavior & & \\
\end{tabular}

Note. Notation for regression coefficients was derived from Berger (2004).

If the regression analyses indicate that regression coefficients $a$ and $b$ shown in Table 6 are statistically significant, this will be evidence that mediation is occurring. If only regression coefficient $c$ is significant, then the effect of leadership behavior on overall job satisfaction is a direct effect, i.e., the effect of leadership behavior is not mediated by job satisfaction. These patterns of results are hypothetical, because the study may reveal no significant effects. The analyses described in Tables 5 and 6 will be performed three times, for: (a) MLQ leadership score on transformational leadership, (b) MLQ leadership score on transactional leadership, and (c) MLQ leadership score on passive-avoidant leadership behaviors.

\section{Summary of Statistical Analyses}

The proposed statistical analyses are summarized in Table 7. Shown in the table are the statistical procedures used and the independent and dependent variables employed in each test. 
Table 7

Summary of Proposed Statistical Analyses

\begin{tabular}{|c|c|c|c|}
\hline $\begin{array}{l}\text { Statistical } \\
\text { Analysis }\end{array}$ & $\begin{array}{l}\text { Statistical } \\
\text { Procedures }\end{array}$ & Independent Variable(s) & $\begin{array}{l}\text { Dependent } \\
\text { Variable(s) }\end{array}$ \\
\hline $\begin{array}{l}\text { Set I } \\
\text { Research } \\
\text { Question } 1\end{array}$ & $\begin{array}{l}\text { Three Pearson } \\
\text { correlations }\end{array}$ & $\begin{array}{l}\text { MLQ leadership scores on: } \\
\text { (a) transformational leadership, } \\
\text { (b) transactional leadership, } \\
\text { and } \\
\text { (c) passive-avoidant behavior. }\end{array}$ & $\begin{array}{l}\text { Staff nurse job } \\
\text { satisfaction as } \\
\text { measured by the } \\
\text { satisfaction facet } \\
\text { scores on the aJDI. }\end{array}$ \\
\hline $\begin{array}{l}\text { Research } \\
\text { Question } 2\end{array}$ & $\begin{array}{l}\text { Three Pearson } \\
\text { correlations }\end{array}$ & $\begin{array}{l}\text { MLQ leadership scores on: } \\
\text { (a) transformational leadership, } \\
\text { (b) transactional leadership, } \\
\text { and } \\
\text { (c) passive-avoidant behavior }\end{array}$ & $\begin{array}{l}\text { Staff nurse overall } \\
\text { job satisfaction as } \\
\text { measured by the } \\
\text { global score on the } \\
\text { aJIG. }\end{array}$ \\
\hline $\begin{array}{l}\text { Research } \\
\text { Question } 3\end{array}$ & $\begin{array}{l}\text { Pearson } \\
\text { correlations }\end{array}$ & $\begin{array}{l}\text { Facet job satisfaction scores on } \\
\text { the aJDI }\end{array}$ & $\begin{array}{l}\text { Score on the global } \\
\text { aJIG which indicates } \\
\text { overall job } \\
\text { satisfaction. }\end{array}$ \\
\hline \multirow[t]{2}{*}{ Set $\mathrm{II}^{\mathrm{a}}$} & $\begin{array}{l}\text { Multiple } \\
\text { regression } \\
\text { equation } 1\end{array}$ & MLQ Leadership behavior & Job satisfaction \\
\hline & $\begin{array}{l}\text { Multiple } \\
\text { regression } \\
\text { equation } 2\end{array}$ & $\begin{array}{l}\text { MLQ Leadership behavior Job } \\
\text { satisfaction }\end{array}$ & $\begin{array}{l}\text { Overall job } \\
\text { satisfaction }\end{array}$ \\
\hline
\end{tabular}

${ }^{a}$ For Set II analyses, there will be three separate analyses: for MLQ leadership scores on: (a) transformational leadership, (b) transactional leadership, and (c) passiveavoidant behavior.

\section{Summary}

In summary, this research was a correlational study because there was no treatment or intervention, data was obtained from a single group, and correlational statistical analyses was used to examine relationships between the variables (Burns \& Grove, 2009). The conceptual framework and transformational leadership model gave the foundation to answer the research questions regarding the independent variables 
including nurse manager leader behaviors and demographic variables to the dependent variables including staff nurse job satisfaction staff nurse overall job satisfaction. 


\section{CHAPTER V}

\section{RESULTS}

This descriptive correlational research study examined the relationships between the staff nurses' perception of their nurse manager leadership behavior and their job satisfaction in a hospital applying for Magnet recognition status. This chapter presents the results of the study.

\section{Procedures and Demographic Data}

The hospital site for the study was in the process of applying for Magnet status and reported there were about 500 staff nurses and 15 nurse managers employed in the facility. The 500 staff nurses were the target population for this study. Therefore, 500 staff nurses were invited to participate in the study. Individual packets were prepared that included a cover letter explaining the study, questionnaire including the MLQ-5X Short survey, aJDI/aJIG survey, and demographic survey. The consent to participate was the completed survey questionnaire. The individual packet included an envelope for the completed questionnaire to be sealed and placed in a closed collection box in the nursing administration office to ensure confidentiality and assure that nurse managers had no access to the surveys completed by their staff nurses. The researcher collected the closed collection box and replaced with another closed collection box during the data collection process. The researcher attended three Shared Governance meetings to discuss the research study and invite the staff nurses to participate in the study. Of the staff nurses, 
115 returned the survey during the two month data collection and following email reminders from the nursing administration personnel (23.0\% return rate).

Table 8 provides demographic information regarding age, clinical experience and academic preparation of the sample. The greatest percentage of subjects fell in the age ranges of $26-30(21.7 \%)$ and $41-45(15.7 \%)$. This was followed by the age ranges $51-55$ (12.2\%) and 56-60 (10.4\%). 5.2\% were over age 60. Data from HRSA (2010) national survey data of registered nurses reported the average age of all RNs was 47.0 in 2008 . The average age of staff nurses in this study was 42 years. HRSA (2010) reported nearly $45 \%$ of RNs were 50 years of age or older in 2008 . This study found that $27.8 \%$ of staff RNs were older than 50 years. Other demographic data included $25.2 \%$ of the subjects had 6-10 years of clinical experience, $22.6 \%$ had 5 or less years of clinical experience, and $39.1 \%$ had more than 15 years of clinical experience. The primary type of academic preparation for nursing found 58.3\% held an Associate Degree in Nursing, 38.3\% held a Baccalaureate Degree in Nursing, and 3.5\% held a Masters Degree in Nursing as the highest educational preparation.

Table 8

Demographics including Age, Clinical Experience, and Academic Preparation $(n=115)$

Age 
Clinical Experience

Educational Preparation

$\begin{array}{ll}\text { AD in Nursing } & 67\end{array}$

58.3

BS in Nursing

44

38.3

MS in Nursing

Missing

In regards to employment, $33 \%$ were employed in the hospital between $6-10$ years followed by $29.6 \%$ employed for 5 or less years. Of the sample, $41.7 \%$ were employed in their present position for 5 or less years, followed by $28.7 \%$ employed in their present position for 6-10 years. Respondents indicated $41.7 \%$ of their primary work shift was 
$7 \mathrm{a}-7 \mathrm{p}$ and $30.4 \%$ reported their primary work shift was $7 \mathrm{p}-7 \mathrm{a}$. Full-time employment status was reported by $87.8 \%$ of the respondents and $3.5 \%$ of the respondents were parttime. (Table 9)

Table 9

Demographics including Length of Time in Current Hospital and Present Position,

Primary Work Shift, and Employment Status $(n=115)$

Length of Time in Current Hospital

5 or less

$11-15$

Missing

Length of Time in Present Position 
Primary Work Shift

$7 a-7 p$

Other

Employment Status

Full time

Part time

PRN

\section{Reliability of Scales Used in the Study}

For the scales used in the study, Cronbach's alpha internal consistency reliability coefficient was computed for the data obtained from participants in the study. Table 10 shows the alpha coefficients. With one exception, each of these exceeded the criterion of .70 that is used as the minimum acceptable value for research (Nunnally \& Bernstein, 1994). The one exception (the Job Descriptive Index work scale), was only .01 lower than the recommended minimum of .70 . 
Table 10

Cronbach's Alpha Internal Consistency Reliability Coefficients for Scales Used in the

Study $(n=115)$

Scale

Number of items

$\underline{\text { Cronbach's alpha coefficient }}$

MLQ scales

Transformational

20

.95

Transactional

8

.72

Passive-Avoidant

8

.91

Job Descriptive Index (aJDI) scales

Work

6

Pay

6

Promotion

6

Supervision

6

.75

Coworker

6

.78

Job in General (aJIG) scale

8

.86

Note. MLQ = Multifactor Leadership Questionnaire (5x-short). Job Descriptive Index (aJDI) scales were the abridged forms of the questionnaires. Job in General (aJIG) scale was the abridged form of the instrument.

\section{Results for Statistical Analyses Set I: Research Question 1}

It was originally planned to calculate three Pearson correlations for these analyses: for three MLQ leadership factors each correlated with job satisfaction as measured by the abridged Job Descriptive Index (aJDI). However, it was discovered that the technical guide to the instrument (Brodke et al., 2009) did not recommend using a 
single value for job satisfaction. Rather, it was advised that each job facet be treated separately. Consequently, 15 correlation coefficients were calculated: 3 leadership factors $\mathrm{x} 5$ job facets from the JDI.

Table 11 shows means and standard deviations for the variables used in the analysis. Table 12 shows the Pearson correlation coefficients. For the latter analyses, the five correlations involving each MLQ scale were treated as a unit. The Bonferroni correction (Stevens, 2009) was used to determine statistical significance in order to reduce the inflation of Type I errors.

As can be seen Table 12, transformational leadership behaviors were positively related to satisfaction with opportunities for promotion $(r=.396)$ and satisfaction with supervision $(r=.686)$. A similar pattern was evident for transactional leadership behaviors ( $r=.322$ for promotion and $r=.484$ for supervision). In contrast, passiveavoidant leadership behaviors were negatively associated with all facets of job satisfaction. This was especially evident for satisfaction with supervision $(r=-.664)$.

The staff nurses in this study worked in a hospital applying for Magnet status. The results indicated that staff nurses reported the strongest satisfaction with supervision with the nurse managers they perceived to have Transformational leadership behaviors and the $r^{2}=.47$ indicated that $47 \%$ of the variance in satisfaction with supervision was associated with Transformational leadership. The strongest dissatisfaction with supervision was with the nurse managers they perceived to have Passive-avoidant leadership behaviors and the $r^{2}=.44$ indicated that $44 \%$ of the variance in dissatisfaction with supervision was associated with Passive-avoidant leadership. The results of this correlational study demonstrated greater staff nurse job satisfaction with nurse managers 
they perceived to be transformational leaders compared to the dissatisfaction with nurse managers they perceived to be passive-avoidant.

Table 11

Results of Statistical Analyses Set I, Research Question I: Descriptive Statistics for Perceived Nurse Manager Leadership Behaviors and Facets of Staff Nurse Job Satisfaction $(n=115)$

$\underline{\text { Scale }}$ $\underline{M}$

MLQ scales

Transformational

Transactional

Passive-Avoidant

Job Descriptive Index (aJDI) scales

Work

Pay

Promotion

Supervision

Coworker

Note. MLQ = Multifactor Leadership Questionnaire (5x-short). Job Descriptive Index (aJDI) scales were the abridged forms of the questionnaires. 
Table 12

Results of Statistical Analyses Set I, Research Question I: Correlations between

Perceived Nurse Manager Leadership Behaviors and Facets of Staff Nurse Job

Satisfaction $(n=115)$

MLQ scale

Transformational Transactional Passive-avoidant

aJDI scale

Work

Pay

Promotion

Supervision

Coworker
.120

.142

$.396 * *$

$.686^{* *}$

.154
.141

.042

$.322 * *$

$.484 * *$

.116
$-.258^{*}$

$-.169$

$-.277^{*}$

$-.664 * *$

$-.314^{* *}$

${ }^{*} p<.05$ using the Bonferroni adjustment for five significance tests, ${ }^{* *} p<.01$

using the Bonferroni adjustment for five significance tests.

\section{Results for Statistical Analyses Set I: Research Question 2}

Research question 2 dealt with the possible relationships between each of the MLQ leadership factors and overall job satisfaction as measured by the score on the Job in General (aJIG) scale. Table 13 shows means and standard deviations for the variables used in the analysis. Table 14 shows the Pearson correlation coefficients. For the latter analyses, the Bonferroni correction (Stevens, 2009) was used to determine statistical significance in order to reduce the inflation of Type I errors.

As can be seen in Table 14, transformational leadership behavior was positively related to overall job satisfaction $(r=.296)$. In contrast, passive-avoidant leadership was 
negatively associated with overall job satisfaction $(r=-.413)$. The results indicated that staff nurses reported overall job satisfaction with Transformational leadership style and the $r^{2}=.087$ indicated that $9 \%$ of the variance in overall job satisfaction was associated with Transformational leadership. The strongest overall job dissatisfaction was with the nurse managers the staff nurses perceived to have Passive-avoidant and the $r^{2}=.17$ indicated that $17 \%$ of the variance in overall job satisfaction was associated with Passive-avoidant leadership. The results of this correlational study indicated that Transformational leadership has a medium relationship with positive overall staff nurse job satisfaction. Passive-avoidant leadership has a strong negative relationship with staff nurse job satisfaction, resulting in less overall job satisfaction.

Table 13

Results of Statistical Analyses Set I, Research Question 2: Descriptive Statistics for Perceived Nurse Manager Leadership Behaviors and Overall Nurse Job Satisfaction $(n=115)$

$\underline{\text { Scale }}$

$\underline{M}$

$\underline{S D}$

MLQ scales

Transformational .85

Transactional

2.26

.70

Passive-Avoidant

1.56

1.04

Job in General (aJIG) scale

18.30

6.76

Note. MLQ = Multifactor Leadership Questionnaire (5x-short). Job in General (aJIG) scale was the abridged form of the questionnaire. 
Table 14

Results of Statistical Analyses Set 1, Research Question 2: Correlations between

Perceived Nurse Manager Leadership Behaviors and Overall Staff Nurse Job

Satisfaction $(n=115)$

MLQ scale

Transformational Transactional Passive-avoidant

$\begin{array}{llll}\text { aJIG scale } & .296^{* *} & .219 & -.413^{* *}\end{array}$

${ }^{* *} p<.01$ using the Bonferroni adjustment for three significance tests.

Note. $\mathrm{MLQ}=$ Multifactor Leadership Questionnaire (5x-short). Job in General (aJIG) scale was the abridged form of the questionnaire.

\section{Results for Statistical Analyses Set I: Research Question 3}

Research question 3 dealt with the possible relationships between ratings of satisfaction with five job facets from the aJDI and overall job satisfaction as measured by the score on the Job in General (aJIG) scale. Table 15 shows means and standard deviations for the variables used in the analysis. Table 16 shows the Pearson correlation coefficients. For the latter analyses, the Bonferroni correction (Stevens, 2009) was used to determine statistical significance in order to reduce the inflation of Type I errors.

As can be seen in Table 16, all five job facets were significantly and positively associated with overall job satisfaction. The strongest relationship was between the aJDI facet work on present job and overall job satisfaction $(r=.684)$ and indicated that $47 \%$ of the variance in satisfaction with work on present job was associated with overall job satisfaction $\left(r^{2}=.468\right)$. 


\section{Table 15}

Results of Statistical Analyses Set I, Research Question 3: Descriptive Statistics for

Ratings of Five Job Facets and Overall Nurse Job Satisfaction $(n=115)$

$\underline{\text { Scale }}$

$\underline{M}$

$\underline{S D}$

Job Descriptive Index (aJDI) scales

Work

Pay

13.44

4.47

Promotion

6.95

5.54

Supervision

12.15

5.74

Coworker

14.71

4.33

Job in General (aJIG) scale

18.30

6.76

Note. Job Descriptive Index (aJDI) scales were the abridged forms of the questionnaires. Job in General (aJIG) scale was the abridged form of the questionnaire. 
Table 16

Results of Statistical Analyses Set I, Research Question 3: Correlations between Ratings of Five Job Facets and Overall Nurse Job Satisfaction $(n=115)$

\begin{tabular}{lccccr} 
& \multicolumn{5}{c}{ aJDI facets } \\
& Work & Pay & Promotion & Supervision & Co-worker \\
aJIG scale & $.684^{* *}$ & $.264^{*}$ & $.339^{* *}$ & $.470^{* *}$ & $.453^{* *}$ \\
& & & & & \\
\hline${ }^{*} p<.05$ using the Bonferroni adjustment for five significance tests, ${ }^{* *} p<.01$
\end{tabular}
using the Bonferroni adjustment for five significance tests.

Note. Job Descriptive Index (aJDI) scales were the abridged forms of the questionnaires. Job in General (aJIG) scale was the abridged form of the questionnaire.

\section{Results for Statistical Analyses Set II: Mediation Analysis}

Set II of the statistical analyses addressed the issue of mediation. Specifically, the question was addressed of whether the score for aJDI supervision mediated the influence of MLQ leadership behavior on overall job satisfaction as measured by the JIG.

\section{MLQ Transformational}

The first MLQ score that was used was MLQ transformational. Two multiple regression analyses were used for this research question, following procedures outlined by Berger (2004). Equation 1 had the predictor variable MLQ transformational predicting aJDI supervision. Equation 2 had two predictor variables: $M L Q$ transformational and aJDI supervision. The dependent variable was score on the $J I G$ scale. In the first step, the score on the $M L Q$ transformational scale was entered into the equation. In the second step the score on the aJDI supervision scale was entered. Thus, 
in the second step of the equation the dependent variable $J I G$ scale had two predictor variables: MLQ transformational and aJDI supervision.

The regression equations are summarized in Tables 17 and 18. Table 17 shows regression coefficients and accompanying statistics for both equations. Table 18 shows the unstandardized partial regression coefficients (betas) from the two equations that were used for the mediation analysis. Figure 2 shows the mediation model in graphic form. The beta coefficients from Table 18 are inserted into the model.

Path $c$ is the total effect of $M L Q$ transformational score on job satisfaction as measured by the score on the $J I G$ scale. This effect must be statistically significant for mediation analysis to proceed. In this case, the unstandardized partial regression coefficient was statistically significant, $\beta=.237, p<.05$, so mediation analysis was possible.

In order for mediation to occur, these conditions were necessary: (a) there must have been a significant relationship between the independent variable $M L Q$ transformational and the mediating variable aJDI supervision score, (b) there must have been a significant relationship between the mediating variable aJDI supervision score and the dependent variable $J I G$ scale (controlling for the independent variable $M L Q$ transformational), and (c) there must have been a non-significant relationship between the independent variable $M L Q$ transformational and the dependent variable $J I G$ scale (controlling for the mediating variable $a J D I$ supervision score). In other words, paths $a$ and $b$ should have been statistically significant, and path $c^{\prime}$ not statistically significant.

In this case, mediation did occur. As shown in Table 18 and Figure 2, path $a$ $(\beta=.667)$ and path $b(\beta=.486)$ were both statistically significant. In addition, path $c^{\prime}$ $(\beta=-.087)$ was not statistically significant. The mediation can be interpreted as follows. 
Transformational leadership behaviors (MLQ transformational) were related to overall job satisfaction (JIG scale) in an indirect manner. The effect was indirect, through the influence of the mediating variable satisfaction with supervision (aJDI supervision).

There was a positive association between transformational leadership behaviors ( $M L Q$ transformational) and satisfaction with supervision (aJDI supervision). In addition, there was positive association between satisfaction with supervision (aJDI supervision) and overall job satisfaction (JIG scale). Thus, the effect of transformational leadership behaviors on overall job satisfaction was through satisfaction with supervision.

Table 17

Regression Summaries for Mediation Analysis: MLQ Transformational and aJDI supervision Predicting JIG score

\begin{tabular}{|l|r|r|r|r|r|}
\hline $\begin{array}{l}\text { Equation } 1 \\
\text { Dependent variable: aJDI } \\
\text { supervision }\end{array}$ & \multicolumn{2}{|c|}{$\begin{array}{c}\text { Unstandardized } \\
\text { Coefficients }\end{array}$} & $\begin{array}{c}\text { Standardized } \\
\text { Coefficients }\end{array}$ & & \\
\cline { 1 - 6 } & \multicolumn{1}{c|}{$\mathrm{B}$} & \multicolumn{1}{c|}{ Std. Error } & \multicolumn{1}{c|}{ Beta } & \multicolumn{1}{c|}{ Sig. } \\
\hline (Constant) & 1.078 & 1.219 & & .884 & .379 \\
MLQ Transformational & 4.576 & .483 & .667 & 9.478 & .000 \\
\hline
\end{tabular}

\begin{tabular}{|c|c|c|c|c|c|}
\hline \multirow{2}{*}{$\begin{array}{l}\text { Equation } 2 \\
\text { Dependent variable: JIG }\end{array}$} & \multicolumn{2}{|c|}{$\begin{array}{c}\text { Unstandardized } \\
\text { Coefficients } \\
\end{array}$} & \multirow{2}{*}{$\begin{array}{c}\begin{array}{c}\text { Standardized } \\
\text { Coefficients }\end{array} \\
\text { Beta } \\
\end{array}$} & \multirow[b]{2}{*}{$\mathrm{t}$} & \multirow[b]{2}{*}{ Sig. } \\
\hline & $\mathrm{B}$ & Std. Error & & & \\
\hline Step 1 (Constant) & 13.118 & 1.963 & & 6.683 & .000 \\
\hline MLQ Transformational & 1.995 & .775 & .237 & 2.575 & .011 \\
\hline \multirow{3}{*}{$\begin{array}{l}\text { MLQ Transformational } \\
\text { aJDI supervision }\end{array}$} & 12.529 & 1.835 & & 6.827 & .000 \\
\hline & -.731 & .971 & -.087 & -.753 & .453 \\
\hline & .592 & .141 & .486 & 4.206 & .000 \\
\hline
\end{tabular}


Table 18

Regression Coefficients (Betas) Used to Test Mediation: MLQ Transformational and aJDI supervision Predicting JIG score

Regression

coefficient Effect of predictor variable on dependent variable

Step of

Equation equation

$.667^{* *}$ a $\quad$ MLQ transformational predicting aJDI supervision 1 . 1

$.237 *$ c $\quad$ MLQ transformational predicting JIG

$2 \quad 1$

-.087 c' MLQ transformational predicting JIG,

$2 \quad 2$

controlling for aJDI supervision

$.486^{* *} \mathrm{~b} \quad$ aJDI supervision predicting JIG,

2

2

$* \mathrm{p}<.05, * * \mathrm{p}<.01$

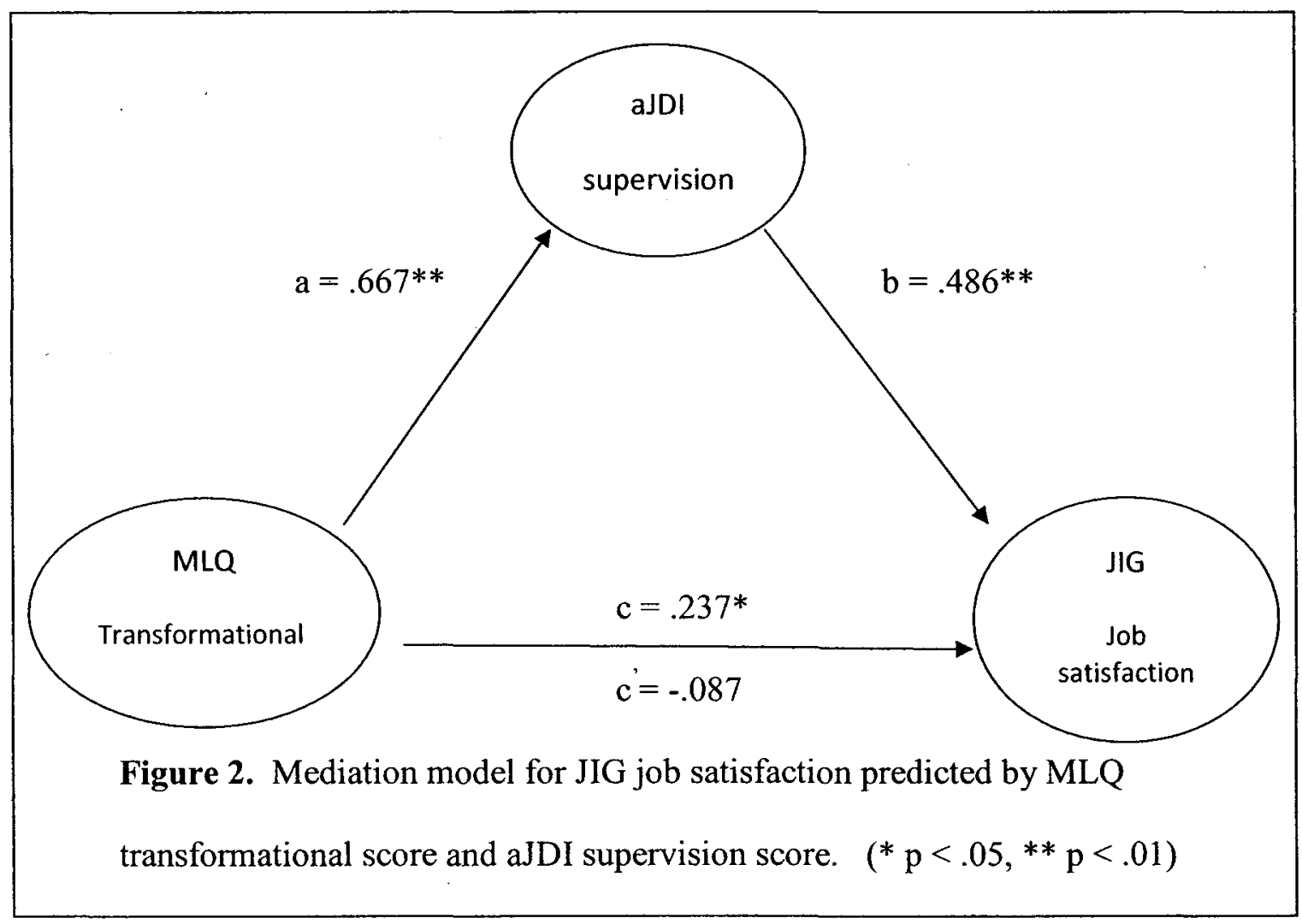




\section{MLQ Transactional}

A mediation analysis was attempted for the MLQ transactional score. Two multiple regression analyses were used for this research question. Equation 1 had the predictor variable $M L Q$ transactional predicting aJDI supervision. Equation 2 had two predictor variables: $M L Q$ transactional and aJDI supervision. The dependent variable was score on the $J I G$ scale. In the first step, the score on the MLQ transactional scale was entered into the equation. In the second step the score on the aJDI supervision scale was entered. The regression equations are summarized in Tables 19 and 20.

Path $c$ is the total effect of $M L Q$ transactional score on job satisfaction as measured by the score on the $J I G$ scale. This effect must be statistically significant for mediation analysis to proceed. In this case, the unstandardized partial regression coefficient was not statistically significant, $\beta=.157, p>.05$, so mediation analysis was not a productive activity. 
Table 19

Regression Summaries for Mediation Analysis: MLQ Transactional and aJDI supervision

Predicting JIG score

\begin{tabular}{|c|c|c|c|c|c|}
\hline \multirow{2}{*}{$\begin{array}{l}\text { Equation } 1 \\
\text { Dependent variable: aJDI supervision }\end{array}$} & \multicolumn{2}{|c|}{$\begin{array}{c}\text { Unstandardized } \\
\text { Coefficients } \\
\end{array}$} & \multirow{2}{*}{$\begin{array}{c}\begin{array}{c}\text { Standardized } \\
\text { Coefficients }\end{array} \\
\text { Beta } \\
\end{array}$} & \multirow[b]{2}{*}{$t$} & \multirow[b]{2}{*}{ Sig. } \\
\hline & $\mathrm{B}$ & Std. Error & & & \\
\hline (Constant) & 3.044 & 1.623 & & 1.876 & .063 \\
\hline MLQ Transactional & 3.973 & .690 & .478 & 5.759 & .000 \\
\hline
\end{tabular}

\begin{tabular}{|c|c|c|c|c|c|}
\hline \multirow{2}{*}{$\begin{array}{l}\text { Equation } 2 \\
\text { Dependent variable: JIG }\end{array}$} & \multicolumn{2}{|c|}{$\begin{array}{c}\text { Unstandardized } \\
\text { Coefficients } \\
\end{array}$} & \multirow{2}{*}{$\begin{array}{c}\begin{array}{c}\text { Standardized } \\
\text { Coefficients }\end{array} \\
\text { Beta } \\
\end{array}$} & \multirow[b]{2}{*}{$t$} & \multirow[b]{2}{*}{ Sig. } \\
\hline & $\mathrm{B}$ & Std. Error & & & \\
\hline Step 1 (Constant) & 14.261 & 2.261 & & 6.306 & .000 \\
\hline MLQ Transactional & 1.606 & .958 & .157 & 1.676 & .097 \\
\hline Step 2 (Constant) & 12.621 & 2.105 & & 5.996 & .000 \\
\hline MLQ Transactional & -.629 & 1.001 & -.062 & -.628 & .531 \\
\hline aJDI supervision & .557 & .119 & .457 & 4.666 & .000 \\
\hline
\end{tabular}


Table 20

Regression Coefficients (Betas) Used to Test Mediation: MLQ Transactional and aJDI supervision Predicting JIG score

Regression

$\underline{\text { coefficient }}$ Effect of predictor variable on dependent variable Equation equation

$\begin{array}{lllll}.478^{* *} & \text { a } & \text { MLQ transactional predicting aJDI supervision } & 1 & 1 \\ .157 & \text { c } & \text { MLQ transactional predicting JIG } & 2 & 1 \\ -.062 & \text { c' } & \begin{array}{l}\text { MLQ transactional predicting JIG, } \\ \text { controlling for aJDI supervision }\end{array} & 2 & 2 \\ .457 * * & \text { b } & \begin{array}{l}\text { aJDI supervision predicting JIG, } \\ \text { controlling for MLQ transactional }\end{array} & 2 & 2\end{array}$

$* * \mathrm{p}<.01$

\section{MLQ Passive-avoidant}

A mediation analysis was attempted for the MLQ passive avoidant score. As previously, two multiple regression analyses were used for this research question.

Equation 1 had the predictor variable $M L Q$ passive-avoidant predicting aJDI supervision. Equation 2 had two predictor variables: MLQ passive-avoidant and aJDI supervision. The dependent variable was score on the $J I G$ scale. In the first step, the score on the $M L Q$ passive-avoidant scale was entered into the equation. In the second step the score on the aJDI supervision scale was entered. The regression equations are summarized in Tables 21 and 22.

Path $c$ is the total effect of $M L Q$ passive-avoidant score on job satisfaction as measured by the score on the $J I G$ scale. The unstandardized partial regression coefficient 
was statistically significant, $\beta=.298, p<.01$, indicating that mediation analysis was possible.

Analysis revealed that mediation occurred. As shown in Table 22 and Figure 3, path $a(\beta=-.640)$ and path $b(\beta=.403)$ were both statistically significant. In addition, path $c^{\prime}(\beta=-.039)$ was not statistically significant. The mediation can be interpreted as follows. Passive-avoidant leadership behaviors (MLQ passive-avoidant) were related to overall job satisfaction (JIG scale) in an indirect manner. The effect was indirect, through the influence of the mediating variable satisfaction with supervision (aJDI supervision). There was a negative association between passive-avoidant leadership behaviors (MLQ Passive-avoidant) and satisfaction with supervision (aJDI supervision). In addition, there was positive association between satisfaction with supervision ( $a J D I$ supervision) and overall job satisfaction (JIG scale). Thus, the effect of passive-avoidant leadership behaviors on overall job satisfaction was through satisfaction with supervision. 
Table 21

Regression Summaries for Mediation Analysis: MLQ Passive-avoidant and aJDI supervision Predicting JIG score

\begin{tabular}{|c|c|c|c|c|c|}
\hline \multirow{2}{*}{$\begin{array}{l}\text { Equation } 1 \\
\text { Dependent variable: aJDI supervision }\end{array}$} & \multicolumn{2}{|c|}{$\begin{array}{c}\text { Unstandardized } \\
\text { Coefficients }\end{array}$} & \multirow{2}{*}{$\begin{array}{c}\begin{array}{c}\text { Standardized } \\
\text { Coefficients }\end{array} \\
\text { Beta } \\
\end{array}$} & & \multirow[b]{2}{*}{ Sig. } \\
\hline & $B$ & Std. Error & & & \\
\hline (Constant) & 17.554 & .759 & & 23.142 & .000 \\
\hline MLQ Passive-Avoidant & -3.569 & .404 & -.640 & -8.825 & .000 \\
\hline
\end{tabular}

\begin{tabular}{|c|c|c|c|c|c|}
\hline Equation 2 & \multicolumn{2}{|c|}{$\begin{array}{c}\text { Unstandardized } \\
\text { Coefficients } \\
\end{array}$} & \multirow{2}{*}{$\begin{array}{c}\text { Standardized } \\
\text { Coefficients } \\
\text { Beta } \\
\end{array}$} & \multirow[b]{2}{*}{$\mathrm{t}$} & \multirow[b]{2}{*}{ Sig. } \\
\hline Dependent variable: JIG & B & Std. Error & & & \\
\hline Step 1 (Constant) & 21.049 & 1.157 & & 18.196 & .000 \\
\hline MLQ Passive-Avoidant & -2.042 & .622 & -.298 & -3.284 & .001 \\
\hline Step 2 (Constant) & 12.408 & 2.651 & & 4.681 & .000 \\
\hline MLQ Passive-Avoidant & -.266 & .771 & -.039 & -.345 & .731 \\
\hline aJDI supervision & .491 & .137 & .403 & 3.582 & .001 \\
\hline
\end{tabular}


Table 22

Regression Coefficients (Betas) Used to Test Mediation: MLQ Passive-Avoidant and aJDI supervision Predicting JIG score

Regression coefficient

Effect of predictor variable on dependent variable

Equation $\begin{gathered}\text { Step of } \\ \text { equation }\end{gathered}$

$\begin{array}{llll}-.640^{* *} \text { a } & \text { MLQ Passive-avoidant predicting aJDI supervision } & 1 & 1\end{array}$

$-.298^{* *} \mathrm{c} \quad$ MLQ Passive-avoidant predicting JIG $\quad 2 \quad 1$

$\begin{array}{lllll}-.039 & \text { c' } & \text { MLQ Passive-avoidant predicting JIG, } & 2\end{array}$ controlling for aJDI supervision

$.403 * * \quad \mathrm{~b} \quad$ aJDI supervision predicting JIG,

2 controlling for MLQ Passive-avoidant

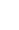

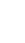




\section{Summary of Results for Research Questions 1 through 3 and Mediation Analysis}

Tables 23 and 24 show a summary of the results of the analyses. MLQ leadership factors were associated with both overall job satisfaction and satisfaction with specific job facets. Mediation analyses revealed that that the effects of MLQ transformational leadership behaviors and MLQ passive-avoidant leadership behaviors were mediated by ratings of the supervision job facet.

Table 23

Summary of Results for Research Questions 1 through 3 and Mediation Analyses

\begin{tabular}{|c|c|c|}
\hline $\begin{array}{l}\text { Research } \\
\text { question }\end{array}$ & Analysis performed & Results \\
\hline 1 & $\begin{array}{l}\text { Pearson correlation coefficients } \\
\text { between MLQ scores for } \\
\text { transformational, transactional, } \\
\text { and passive avoidant with five } \\
\text { job facets from the aJDI. }\end{array}$ & $\begin{array}{l}\text { MLQ transformational leadership was } \\
\text { positively related to satisfaction with: } \\
\text { (a) promotion, and (b) supervision. } \\
\text { MLQ transactional leadership was } \\
\text { positively related to satisfaction with: } \\
\text { (a) promotion, and (b) supervision. } \\
\text { MLQ passive-avoidant leadership was } \\
\text { negatively related to satisfaction with: } \\
\text { (a) work, (b) promotion, (c) supervision, } \\
\text { and (d) co-workers. }\end{array}$ \\
\hline 2 & $\begin{array}{l}\text { Pearson correlation coefficients } \\
\text { between MLQ scores for } \\
\text { transformational, transactional, } \\
\text { and passive avoidant with } \\
\text { overall job satisfaction as } \\
\text { measured by the JIG. }\end{array}$ & $\begin{array}{l}\text { MLQ transformational leadership was } \\
\text { positively related to overall job } \\
\text { satisfaction. } \\
\text { MLQ passive-avoidant leadership was } \\
\text { negatively related to overall job } \\
\text { satisfaction. }\end{array}$ \\
\hline 3 & $\begin{array}{l}\text { Pearson correlation coefficients } \\
\text { between five job facets from the } \\
\text { aJDI and overall job satisfaction } \\
\text { as measured by the JIG. }\end{array}$ & $\begin{array}{l}\text { Overall job satisfaction as measured by } \\
\text { the JIG was positively related to } \\
\text { satisfaction with: (a) work, (b) pay, (c) } \\
\text { promotion, (d) supervision, and (e) co- } \\
\text { workers. }\end{array}$ \\
\hline
\end{tabular}


Table 24

Summary of Results of Mediation Analyses

\begin{tabular}{|c|c|c|}
\hline $\begin{array}{c}\text { Mediation } \\
\text { Analysis }\end{array}$ & Analysis performed & Results \\
\hline 1 & $\begin{array}{l}\text { Two multiple regression equations } \\
\text { were calculated: } \\
\text { 1. Predictor variable } M L Q \\
\text { transformational predicting } \\
\text { aJDI supervision, } \\
\text { 2. Two predictor variables } M L Q \\
\text { transformational and aJDI } \\
\text { supervision predicting score } \\
\text { on the } J I G \text { scale. }\end{array}$ & $\begin{array}{l}\text { The effect of } M L Q \\
\text { transformational on } J I G \text { scale } \\
\text { score was mediated by the rating } \\
\text { of } a J D I \text { supervision. }\end{array}$ \\
\hline 2 & $\begin{array}{l}\text { Two multiple regression equations } \\
\text { were calculated: } \\
\text { 1. Predictor variable } M L Q \\
\text { transactional predicting aJDI } \\
\text { supervision, } \\
\text { 2. Two predictor variables } M L Q \\
\text { transactional and aJDI } \\
\text { supervision predicting score } \\
\text { on the } J I G \text { scale. }\end{array}$ & No mediation occurred. \\
\hline 3 & $\begin{array}{l}\text { Two multiple regression equations } \\
\text { were calculated: } \\
\text { 1. Predictor variable } M L Q \\
\text { passive-avoidant predicting } \\
\text { aJDI supervision, } \\
\text { 2. Two predictor variables } M L Q \\
\text { passive-avoidant and aJDI } \\
\text { supervision predicting score } \\
\text { on the } J I G \text { scale. }\end{array}$ & $\begin{array}{l}\text { The effect of } M L Q \text { passive- } \\
\text { avoidant on } J I G \text { scale score was } \\
\text { mediated by the rating of } a J D I \\
\text { supervision. }\end{array}$ \\
\hline
\end{tabular}




\section{Additional Statistical Analyses}

The mean and standard deviation for each leadership style was as follows: transformational $(M=2.39, S D=.85)$, transactional $(M=2.26, S D=.70)$, and passiveavoidant $(M=1.56, S D=1.04)$. Respondents' average score of 2.39 for Transformational leadership was at the $25^{\text {th }}$ percentile, meaning $25 \%$ of the normed population scored lower, and $75 \%$ scored higher than 2.39 . Respondents' average score of 2.26 for Transactional leadership was also at the $25^{\text {th }}$ percentile of the normed population. Respondents' average score of 1.56 for Passive-avoidant leadership was at the $80^{\text {th }}$ percentile, meaning that $80 \%$ of the normed population scored lower, and $20 \%$ scored higher than 1.56. These results indicate that the staff nurse respondents in the survey perceived their nurse leaders as less transformational and less transactional than the norm while perceiving their nurse leaders as more passive-avoidant than the norm.

A number of statistical comparisons were performed contrasting nurses who were employed a relatively small number of years with those who were employed for a longer period of time. These analyses were done because they highlighted differences between two groups that are likely to have different needs for supervision: the less experienced and the more experienced employee.

The first set of analyses focused on overall job satisfaction. The age of the staff nurses was grouped for comparisons and the results found no difference in staff nurses age $<26-30(n=31)$ and staff nurses age 31 and older $(n=82)(F(1,105)=0.03, p=.87)$. There was no difference in the comparisons of the staff nurses educational preparation for Associate Degree in Nursing $(n=67)$ and Baccalaureate Degree in Nursing $(n=44)$ $(F(1,103)=0.01, p=.93)$. However, the length of time in the current hospital was grouped for comparisons between staff nurses in the current hospital five-or-less years 
$(n=34,29.6 \%), 6-10$ years $(n=38,33 \%)$, and 11 -or-more years $(n=41,35.7 \%)$ and found a statistical difference between groups $(F(2,105)=3.11, p=.049$, partial eta squared $=.056$, medium effect size). Post hoc comparisons using the Tukey HSD test indicated that the mean score for the staff nurses in the current hospital five-or-less years $(M=16.41, S D=7.91)$ was significantly lower than the staff nurses in the current hospital 11-or-more $(M=20.13, S D=5.37)$. However, the staff nurses in the current hospital $6-10$ years $(M=18.74, S D=5.86)$ did not significantly differ from the five-orless years and the 11-or-more group.

Correlational statistics were used to examine the differences between staff nurses in the current hospital five-or-less years and staff nurses in the current hospital 11-ormore years on the correlations among nurse manager leadership behaviors and overall job satisfaction. Staff nurses in the current hospital five-or-less years had statistically significant positive correlations between job satisfaction and Transformational leadership behaviors $(r=.564, p=.001)$, and with Transactional leadership behaviors $(r=.419$, $p=.014)$. A negative correlation was found between job satisfaction and Passiveavoidant leadership behaviors $(r=-.687, p=.000)$. Staff nurses in the current hospital 11-or-more years had no statistically significant correlations between overall job satisfaction and the variables Transformational leadership $(r=.104, p=.523)$, Transactional leadership $(r=-.024, p=.882)$, and Passive-avoidant leadership $(r=-.085, p=.604)$

Further correlational analysis found staff nurses in the current hospital five-or-less years had the strongest correlations between the facet of job satisfaction with opportunities for promotion and all leadership behaviors: Transformational ( $r=.575$, 
$p=.000)$, Transactional $(r=.560, p=.001)$, and Passive-avoidant $(r=-.464, p=.006)$.

Staff nurses in the current hospital 11-or-more had the strongest correlations between the facet of job satisfaction with supervision and all leadership behaviors: Transformational $(r=.676, p=.000)$, Transactional $(r=.598, p=.001)$, and Passive-avoidant $(r=-.542$, $p=.000$ ). These results suggested that the overall job satisfaction of staff nurses employed in the hospital for five-or-less years was greatly influenced by leadership behaviors, but not for staff nurses employed in the hospital for 11-or-more years. The facets of job satisfaction differed for both groups - staff nurses employed in the hospital for five-or-less years had a greater relationship between leadership behaviors and satisfaction with opportunities for promotion while the staff nurses employed in the hospital for 11-or-more years had a greater relationship between leadership behaviors and satisfaction with supervision.

Correlational statistics were used to examine the differences between staff nurses in the current hospital five-or-less years and staff nurses in the current hospital 11-ormore years on the correlations among facets of job satisfaction and overall job satisfaction. Staff nurses in the current hospital five-or-less years had statistically significant strong positive correlations with the facets of satisfaction with work on present job $(r=.711, p=.000)$, supervision $(r=.717, p=.000)$, and coworkers $(r=.441$, $p=.009$ ), and a medium correlation with satisfaction with opportunities for promotion $(r=.324, p=.061)$. Staff nurses in the current hospital 11-or-more years had strong correlations between overall job satisfaction and the facets of satisfaction with work on present job $(r=.676, p=.000)$, and coworkers $(r=.407, p=.009)$. There was a medium correlation between overall job satisfaction and satisfaction with pay $(r=.360, p=.023)$. 
The groups of staff nurses employed five-or-less years and 11- or-more years accounted for $67 \%$ of the total sample. Further analysis of the differences between the two groups may provide additional insight. For example, $91.2 \%$ of the staff nurses employed in the current hospital for five-or-less years worked full time compared to $85.4 \%$ of the group employed for 11 -or-more years. Of the group of staff nurses employed in the current hospital for five-or-less years, $23.5 \%$ worked 7 AM to 7 PM shift compared to $46.3 \%$ of the group employed for 11 or more years. 


\section{CHAPTER VI}

\section{SUMMARY AND RECOMMENDATIONS}

This descriptive correlational study examined the relationship between the staff nurses' perception of their nurse manager leadership behavior with the facets of staff nurse job satisfaction and staff nurse overall job satisfaction in a hospital applying for Magnet Recognition status. The population consisted of Registered Nurses working as staff nurses in a 490 bed non-profit acute care hospital in the southern United States. This chapter includes a discussion of findings related to the research questions, implications and recommendations for nursing research, hospital and nursing executives, and human resource development (HRD).

\section{Conclusions}

Descriptive statistics were used to describe the sample of staff nurses. The demographic profile of the sample included the greatest percentage of staff nurses $(21.7 \%)$ were in the age group of 26-30 years of age followed by age group 41-45 (15.7\%). This study found that $27.8 \%$ of staff RNs were older than 50 years with an average age of 42 years. The Buerhaus, Staiger, and Auerbach report (as cited in AACN, 2011 ) projected the average age of RNs to 44.5 by 2012 and almost one quarter of the RN population being in their $50 \mathrm{~s}$. The respondents in this study were younger average age but greater percentage over 50 years of age than the Buerhaus et al. (2011) report.

The age groups $51-55(12.2 \%), 56-60(10.4 \%)$, and greater than 60 years of age $(5.2 \%)$ indicated that almost $28 \%$ of the sample will reach retirement age in the next 
decade. As noted previously, these findings are supported by the Buerhaus et al. (2009) explanation that a recent increase in employment for RNs increased the percentages of RNs in the workplace and had temporarily abated the nursing shortage, yet large shortages of nurses were expected to retire through the next decade once the health of the U.S. economy is restored (Mancino, 2009, p. 2). In addition to retiring nurses, the percentage of nurses under age thirty was found to be quite low at $26.9 \%$ of the sample and may impact those nurses with the potential for extended careers in nursing (Aiken et al., 2001). Hader et al. (2006) reported the largest majority of nurses who planned to retire were nurse managers followed by a large percentage of staff nurse employees. This study examined nurse manager leaders and it is important to consider they are the group reaching retirement age in the next decade. Therefore, succession planning for the nurse managers is of vital importance.

Studies show that nurse manager leader behaviors influence staff nurse job satisfaction (Blegen, 1993; Irvine \& Evans, 1995; Lashinger \& Finegan, 2005) and retention (Kettering-Murray, 2002; Kleinman (2004a); McGuire \& Kennerly (2006). With the aging staff nurse population and impending nurse shortage in the next decade, it is imperative that hospital executives understand the importance for nurse managers to analyze their leadership behaviors that most directly impact various facets of staff nurse job satisfaction and overall job satisfaction of staff nurses. Facets of job satisfaction in this study included satisfaction with work on present job, pay, opportunity for promotion, supervision, and coworkers. Overall job satisfaction was a global measure of job satisfaction. Overall job satisfaction and intent to depart are inversely correlated. Identifying nurse manager leader behaviors that are related to staff nurse overall job satisfaction may be a greater indicator of actual staff nurse turnover than identifying 
nurse manager leader behaviors that are related to facets of staff nurse job satisfaction (Brodke et al., 2009).

The research questions for the study were:

1. What is the relationship between staff nurse perception of the nurse manager leadership behavior and the facets of staff nurse job satisfaction?

2. What is the relationship between the staff nurse perception of the nurse manager leadership behavior and the staff nurse overall job satisfaction?

3. What is the relationship between facets of staff nurse job satisfaction and staff nurse overall job satisfaction?

Question 1: What is the relationship between staff nurse perception of the nurse manager leadership behavior and the facets of staff nurse job satisfaction?

The staff nurse perception of their nurse manager leadership style (transformational, transactional, and passive-avoidant) was measured by the MLQ 5X Short form developed by Bass and Avolio in the late 1980s (2004). Each facet of staff nurse job satisfaction (work, pay, promotion, supervision, and coworker) was measured by the aJDI. The facets of staff nurse job satisfaction were measured using the Abridged Job Descriptive Index (aJDI) developed by Smith, Kendall, and Hulin (1969) and revised most recently in 2009 .

Transformational leadership was defined by Bass and Avolio (2004) as "a process of influencing in which leaders change their associates' awareness of what is important, and move them to see themselves and the opportunities and challenges of their environment in a new way" (p. 95). Transactional leaders "display behaviors associated with constructive and corrective transactions (p. 96). Passive/avoidant behavior was described as "another form of management-by-exception leadership that is more passive 
and reactive and does not respond to situations and problems systematically" (p. 97). The strongest relationship was between Transformational leadership style and staff nurse satisfaction with supervision $(r=.686, p<.01)$ followed by the strong negative relationship between Passive-avoidant leadership style and staff nurse satisfaction with supervision $(r=-.664, p<.01)$. The staff nurses in this study worked in a hospital applying for Magnet status. Magnet status hospitals strive for and are recognized for Transformational leadership. Passive-avoidant leadership is contrary to the vision of Magnet hospitals (ANCC Magnet Recognition Program, n.d.).

The results of the study found that staff nurses had higher satisfaction regarding coworkers, work on present job, pay, and supervision and the least satisfaction with opportunities for promotion. The higher satisfaction reported by staff nurses with the coworkers, work itself, pay, and supervision was not surprising for this facility in the process of applying for Magnet status. Magnet hospitals are recognized for excellence in nursing services (ANCC Magnet Recognition Program, n.d.). Further research examining the greater dissatisfaction with opportunities for promotion may offer additional insight.

Question 2: What is the relationship between the staff nurse perception of the nurse manager leadership behavior and the staff nurse overall job satisfaction?

Overall job satisfaction was measured using the Abridged Job in General (aJIG). The Job in General (JIG) evaluated overall job satisfaction and was the best predictor of intent to quit (Brodke et al., 2009). The JIG (Job in General) was developed by Smith, Kendall, and Hulin (1969) and measured overall satisfaction with the job and reflected individuals' general feelings toward their jobs. The JIG was used in conjunction with the JDI but differs from the JDI in respect to being more global, more evaluative, and using a 
longer time frame. For the staff nurses in this study, there was a positive relationship between overall job satisfaction and Transformational leadership behaviors. The Dunham-Taylor (2000) study of 1,115 staff nurses in the United States also found as nurse executives were more transformational, they achieved higher staff nurse job satisfaction.

The MLQ measured leader behaviors and outcomes of leadership. The outcomes of leadership are not leadership styles but are results of leadership behavior. The MLQ contained 36 leadership items plus nine outcome items for a total of 45 items on the survey. Research in the social sciences indicates that leadership styles and behaviors can have an influence on performance and outcomes. Kleinman (2004A, 2004b) and Rad and Yarmohammadian (2006) indicated the importance of describing the relationship between the effects of leadership in the health care environment and how that relates to outcomes such as job satisfaction and retention. Using norms published by the MLQ, the results indicated that the staff nurse respondents in the survey perceived their nurse leaders as less transformational and less transactional than the norm while perceiving their nurse leaders as more passive-avoidant than the norm. These findings raise concerns, in light of the fact that Magnet status hospitals are philosophically committed to behaviors consistent with transformational leadership.

Question 3: What is the relationship between facets of staff nurse job satisfaction and staff nurse overall job satisfaction?

Facets of staff nurse job satisfaction was measured with the aJDI and staff nurse overall job satisfaction was measured with the aJIG. "The JDI measures five principal facets of job satisfaction that have been identified as important across numerous 
organizations. The JIG reflects individuals general feelings toward their jobs, encompassing all aspects of job satisfaction" (Brodke et al., 2009, p. 11) and was constructed to reflect the global, long-term evaluation of the job (p. 45) and can be used as an indicator of employee intent to depart.

All five facets of staff nurse job satisfaction were positively associated with overall job satisfaction. The strongest relationship was between the job facet satisfaction with work on present job and overall job satisfaction. The Dunham-Taylor (2000) study of 1,115 staff nurses in the United States also found as nurse executives were more transformational, they achieved higher staff nurse job satisfaction and higher work group effectiveness. The November 2, 2003 IOM report, Keeping Patients Safe: Transforming the Work Environment of Nurses, focused primarily on the work environment of nurses. The report urged attention to be paid to all organizational components regarding 1) transformational leadership and evidence-based management, 2) maximize workforce capability, and 3) create and sustain a culture of safety (IOM, 2004). The results of this study support staff nurse job satisfaction with work on present job. The low response rate of the respondents in the study, indicate further study is needed to understand the workforce engagement with evidence-based management and research activities in this hospital in the process of applying for Magnet status.

Mediation analysis was performed to address whether the facet of staff nurse job satisfaction with supervision mediated the Influence of MLQ Transformational, Transactional, and Passive-avoidant leadership. The analysis found that Transformational leadership behavior on overall job satisfaction was through satisfaction with supervision. Mediation analysis was not a productive activity for the MLQ transactional score because there was not a statistically significant total effect of the 
MLQ transactional score on job satisfaction. There was a negative association between passive-avoidant leadership behaviors and satisfaction with supervision. Mediation analysis for the MLQ passive-avoidant score revealed that mediation occurred. The effect of passive-avoidant leadership behaviors on overall job satisfaction was through dissatisfaction with supervision. The mediator effects mean that the relationships between leadership behaviors and overall job satisfaction are significantly related to the degree the staff nurse is satisfied with the job facet of satisfaction with supervision.

The mean and standard deviation for the aJIG were calculated $(M=18.30, S D=$ 6.76). The aJIG median was 21 and the mode was 24 with 41 respondents reporting the highest level of overall satisfaction. This indicated that staff nurses had moderately high overall job satisfaction. The moderately high overall job satisfaction reported by staff nurses may indicate less intent to depart in this facility that is in the process of applying for Magnet status. Magnet hospitals are recognized for excellence in nursing service indicated by high staff nurse job satisfaction and retention (ANCC Magnet Recognition Program, n.d.).

Demographic data found that $22.6 \%$ of the staff nurses had 5 or less years of clinical experience and $39.1 \%$ had more than 15 years of clinical experience and there was a statistical difference between these groups. Staff nurses with 5 or less years of clinical experience had strong relationships with Transformational leadership style while staff nurses with 11 and more years did not have a significant relationship with any leadership style. The groups also differed with regard to the facets of job satisfaction and overall job satisfaction. The 5 or less years of clinical experience related more job satisfaction with opportunities for promotion and the 11 and more years related more job satisfaction with supervision. These results suggest that overall job satisfaction for staff 
nurses employed in the hospital for 5 years or less was greatly influenced by leadership behaviors but not for staff nurses employed in the hospital for 11 or more years.

\section{Limitations}

The researcher notes some limitations of the study that may affect the ability to generalize the findings. Limitations of the study which may affect the ability to generalize findings included the following: the study design, and the use of distributed surveys. Additionally, the use of reported data related to nurse manager leader behaviors based on perception of the staff nurse and not actual leadership behaviors; the sample population was limited to staff nurses at a non-profit acute care hospital in the southern United States applying for Magnet status and may not apply to for-profit or hospitals in other geographical locations; and the study criteria excluded private hospitals, home care agencies, and urgent care facilities may be considered limitations.

This survey study had a low response rate. It fell considerably short of the recommended minimum response rate of $50 \%$ for survey research. It is impossible to precisely estimate what the results of the study had been if a more representative group of nurses had completed the questionnaires. The new ANCC (n.d.) model for Magnet included an evidence-based dimension focused on empirical outcomes. The new knowledge, innovations, and improvements component included an increased focus on evidence-based practice (EBP). The low response rate for this study may indicate future challenges if the hospital has not developed a plan for meeting the Magnet designation expectations for research and EBP (Ingersoll, Witzel, Berry \& Qualls, 2010).

Staff nurse perceptions and self-reported data do have limitations but the use of self-reporting to collect data has been supported by research (Goffin \& Gellatly, 2001). The self-report format was viewed as an appropriate means of collecting data to examine 
the staff nurses' perception of their nurse manager leadership behaviors and their job satisfaction.

The descriptive correlational design does not imply causation; however, this design was appropriate for the purpose and research questions of this study. Since hospitals are challenged to understand factors related to staff nurse retention in the context of the nursing slowdown (Huselid, 1995; Mancino, 2008); Mancino, 2009) and nurse manager leadership is a major influence with staff nurse job satisfaction, this research study provides a basis for further research. The more leadership behaviors of nurse managers are studied, the more nurse managers and nursing executives can target strategies to influence staff nurses' job satisfaction and retention.

\section{Implications}

The results of this study have direct implications for hospital executives, the nursing profession, and human resource development in the process of applying for Magnet Recognition status. The Institute of Medicine (IOM), in collaboration with The Robert Wood Johnson Foundation (RWJF), released a report on October 5, 2010, The Future of Nursing: Leading Change, Advancing Health, calling for the transformation of the nursing profession. One of the key recommendations presented in the report calls for nurses to "take responsibility for their personal and professional growth by developing leadership competencies and exercising these competencies across all care settings" (Institute of Medicine [IOM], 2010, p. 3).

Force 14 of the Forces of Magnetism discusses the use of clinical ladders as part

of the professional development program for achieving Magnet status (ANCC, n.d.) and continued professional growth is an essential element of Magnet status hospitals. The clinical ladder encourages nurses to take responsibility for their professional growth 
within the facility to improve staff nurse job satisfaction and retention, and offers nurses an opportunity to advance with pay and status. Transformational leadership begins with hospital executives being "proactive and striving for higher levels of individual, group and organizational development and innovation" (Bass \& Avolio, 2004, p. 95) by motivating employees to do more than is required and gaining commitment through their vision and confidence toward improvements in the organization (McNeese-Smith, 1997; Porter-O Grady, 2003). Hospital executives face challenges to recruit and retain clinical nurses (Force, 2005) and are in a position to identify problems and support improvement processes.

Transformation begins with top management changing their own priorities and ways of thinking to realign behavior and beliefs (Bartlett \& Ghoshal, 1995) throughout the organization. Organizational culture changes with the implementation of shared decision making (Porter-O'Grady \& Malloch, 2007). This is evident by the nurse leaders who created environments for increased nursing autonomy and resulted in improved staff nurse job satisfaction and reduced intent to leave the organization (Watters, 2009).

The rapidly changing healthcare system brings inevitable changes with it. The application process for Magnet status is a change process. The change process has similarities to problem solving techniques and to the nursing process. The nursing process includes: assessment, identification of possible nursing diagnoses, selection of nursing diagnosis, development of a plan, implementation of plan, evaluation and reassessment. The change process is similar to the nursing process and includes: recognition that a change is needed; collect data, identification of problem to be solved, selection of one of possible alternatives, development of plan, implementation of plan, evaluation of effects of change, and stabilization of change in place (Zerwekh \& 
Garneau, 2012). Results from this study suggest that further needs assessment may reveal gaps in promotion opportunities, shared decision making, lack of transformational leadership behaviors and too many passive-avoidant leader behaviors.

A needs assessment may identify reasons for low transformational nurse manager leadership behaviors and high passive-avoidant behaviors. Periodic measurement of nurse manager leadership behaviors that are related to the leadership facets and subscales is indicated along with 360 degree feedback for nurse managers to allow the nurse manager to monitor their employee satisfaction and take initiatives to improve it. Hospital executives can utilize performance improvement processes such as Six Sigma's DMAIC (define, measure, analyze, improve, and control) to develop a plan to target improvement in transformational leadership of their nurse managers. The hospital site for this research study uses the Six Sigma methodology approach for process improvement projects. The Six Sigma approach for improving nurse managers' transformational leadership skills begins with defining the problem, data collection, analyzing the data, making improvements, and putting controls in place to prevent returning to the status quo.

This research project identified the problem that the staff nurse respondents perceived their nurse leaders as less transformational than the norm. This is a problem because Magnet status hospitals strive for nursing excellence through transformational leadership. The results of the data provided statistical support of the problem and are a benchmark for measurement after improvements are initiated. The statistical analysis revealed the staff nurses demonstrated greater staff nurse job satisfaction with nurse managers they perceived to be transformational leaders and facets of satisfaction with promotion and supervision. This study indicates an improvement in nurse manager 
transformational leader behaviors may improve staff nurse job satisfaction with the facets of satisfaction with promotion and supervision.

Human resource development (HRD) has important functions in the hospital related to hiring new nurses and providing appropriate orientation, competency training, and ongoing education. Nurse administrators are expected to provide leadership in human resource development and management (ANA, 2009). The problem in many hospitals is that nurse managers often have little formal leadership training and learn on the job mostly through trial and error (Advisory Board Company, 2002; Sherman et al., 2007). Staff nurses are often promoted into leadership positions as a result of their excellent clinical skills and tenure and may not have the necessary skills or training for leadership roles.

The aging nurse manager population and their eventual turnover, makes it imperative to hire competent nurse manager leaders for the future success of the organization. If the selection of managers is made from within the organization, the criteria must include more than the candidate"s technical skills and capabilities and tenure history. In evaluating applicants, selection formats may include performance appraisals and potential assessment centers; merit systems; psychological, intelligence, and motivation tests; interviews; and coworker evaluations (Rowland \& Rowland, 1997). These selection measures have been shown to have validity in predicting performance (Schmidt \& Hunter, 1998).

Nurse managers are the direct link between nursing administration and staff nurses (Taunton, Boyle, Woods, Hansen, \& Bott, 1997) and have great influence. This study demonstrated that transformational leadership of nurse managers was positively related to facets of staff nurse job satisfaction and staff nurse overall job satisfaction. The 
study identified that transformation leadership behaviors as perceived by staff nurses were below the norm. In contrast, passive-avoidant leader behaviors (management-byexception passive and laissez-faire) are more passive and reactive and have a negative effect on desired outcomes. This study demonstrated that nurse managers exhibited more passive-avoidant behaviors than the norm.

It is worth noting that while transactional leadership behaviors of nurse managers were related to facets of job satisfaction with promotion and supervision, there was not a significant relationship between transactional leadership behaviors of nurse managers and staff nurse overall job satisfaction. This finding contrasts with suggestions by Bass and Avolio (2004) that transactional leadership was a positive form of leadership and that good managers exhibited both transformational and transactional types of leader behaviors. Reasons for the current study's finding that transactional leadership was not related to overall job satisfaction may include the role expectations for nurse managers and the cultural norms of the hospital. Informal observation of the nursing profession and hospital norms suggests that nurse managers are expected to continuously exhibit transactional leadership behaviors. Nurse managers exhibit transactional leader behaviors (constructive and corrective) with staff nurses by defining expectations and promoting performance to achieve the goals related to policies and procedures, evidence based practices and outcomes, and rules and regulations.

Recommendations for improving nurse manager transformational leadership behaviors include having administrative personnel collaborate with the human resource development and education departments to develop a formal leadership development training program for nurse managers that targets transformational leadership skills. The development and implementation of a leadership development program must have the 
same organizational commitment as any other strategic initiative. Hospital executives must support a leadership development program that is relevant, well defined, and has adequate resources for real behavior change (Rowland \& Rowland, 1997).

The MLQ offers a leader form questionnaire for nurse managers to complete that identifies nurse managers' full range of leadership behaviors. The Full Range of Leadership (Bass \& Avolio, 2004) behaviors were identified in a continuum found in four dimensions and 12 subscales: 1) transformational leadership (idealized attributes, idealized behaviors, inspirational motivation, intellectual stimulation, individual consideration, 2) transactional leadership (contingency reward, active management-byexception, 3) passive avoidant (passive management-by-exception, laissez-faire), and 4) outcomes of leadership (extra effort, effectiveness, and satisfaction). The MLQ was not designed to label a leader as Transformational, Transactional, or Passive-avoidant. This study calculated the averages and compared to norm tables (Bass \& Avolio, 2004) to identify leaders as "more transformational than the norm" or "less transactional than the norm".

The results of the nurse managers' MLQ leader questionnaires would offer insight for planning the nurse managers' transformational leadership skill building and competency. The staff nurses in this study reported their perception of their nurse leadership behaviors. The results offered insights related to the MLQ subscales that identified the leadership behaviors of the nurse managers. Understanding the nurse managers' leader behaviors is critical to planning and implementing an evidence-based leadership development program. Once the leadership training has been completed, competency with transformational leadership behaviors should be demonstrated.

Performance evaluation should be documented and ongoing competency monitored and 
measured through performance evaluations and additional MLQ leader and staff nurse rate questionnaires to maintain control and continued improvement of the process. The 360 feedback helps nurse managers' transition to a more transformational leadership style. Absence of real behavior change indicates a failure of the leadership development program (Rowland \& Rowland, 1997).

Transformational leadership theory (Bass, 1985; Bennis \& Nanus, 1985; and Burns, 1978) assumed that people followed a person who inspired them, a person with vision and passion could achieve great things, and enthusiasm and energy got things done. Recommendations for elements of a formal leadership training program are presented in James Kouzes and Barry Posner in The Leadership Challenge (2003). The transformational leadership model is described and includes five fundamental practices of an effective leadership style: 1) model the way, 2) inspire a shared vision, 3) challenge the process, 4) enable others to act, and 5) encourage the heart. The Leadership Practices Inventory and conceptual framework was developed through a triangulation of qualitative and quantitative research methods and studies that include interviews and written case studies from their personal-best leadership experiences (Kouzes \& Posner, 2002). The fundamental practices and behaviors can lead health care systems into the future along with a transformational leadership style (Jooste, 2004).

The nursing profession is guided by the ANA Scope and Standards of Practice (2009, p. 3) "to understand and embrace the competencies of nursing leadership" and "be aware of and exemplify leadership skills and traits." Clinical competency is imperative in a hospital setting and extensive competencies and evaluation tools are in place. Leadership development programs and competencies must include the skills that are necessary to address the complexities within the healthcare environment and not just 
address the technical skills (Graver \& Kilpatrick, 20078; Wooten \& Crane, 2003). The results of this study support the importance of hospitals applying for Magnet status to develop more transformational leadership behaviors in their nurse managers and reduce the influence of the negative passive-avoidant leader behaviors.

The Magnet Recognition program includes Transformational leadership as one of their five model components (ANCC, n.d.). Transformational leadership is a process of "influencing in which leaders change their associates' awareness of what is important, and move them to see themselves and the opportunities and challenges of their environment in a new way" (Bass \& Avolio, 2004, pg. 95). Passive-avoidant leadership produces negative outcomes with staff nurse job satisfaction. The MLQ measures a fullrange of leadership styles and allows for both leader (nurse manager) and rater (staff nurse) questionnaires. McGuire and Kennerly (2006) and Brown and Reilly (2009) conducted studies that show managers perceive their leadership behaviors different than those who reported to them. Nurse managers can identify their passive-avoidant behaviors through completing the MLQ leader questionnaire. Once the nurse managers understand their leader behaviors they can develop more positive transformational leadership skills and behaviors through training and performance improvement strategies while reducing the negative passive-avoidant behaviors.

Hospitals desire to recruit qualified staff nurses and retain them within their organization. The link between the nursing shortage and staff nurse retention is significant because staff nurses have more opportunity to seek other employment during times of nursing shortage with their increased demand. The work of Anthony et al., (2005); Irvine \& Evans (1995); and Rad \& Yarmohammadian (2006) validated the significant role that nurse managers have on the staff nurse job satisfaction and Kettering- 
Murray (2002), Kleinman (2004a), and McGuire \& Kennerly (2006) identified direct links between leader behavior and staff nurse retention. Retention is a critical issue for acute care hospitals (Huselid, 1995; Mancino, 2008; Mancino, 2009). Improving nurse manager transformational leadership behaviors can have an impact on staff nurse job satisfaction. The cost of recruitment and training are substantial and these results demonstrate the positive impact that transformational leadership behaviors have with staff nurse overall job satisfaction. Of significance from this study is the strong negative impact that passive-avoidant leadership has with overall job satisfaction and as an indicator for increased nurse departure from the facility.

\section{Recommendations}

The topic of the current and projected nursing shortage has been widely reported in the literature. Previous studies identified nursing leadership as a factor influencing staff nurse satisfaction and retention. More research is needed to identify the leadership behaviors of nurse managers that influence facets of staff nurse job satisfaction and staff nurse overall job satisfaction. Efforts to develop nurse manager leadership competencies and performance evaluation tools require empirical data. Many nurse managers are promoted into leadership roles from their clinical experience and tenure and may not be good leaders. Future studies should include analysis of the specific 4 dimensions of the MLQ and the 12 subscales: 1) transformational leadership (idealized attributes, idealized behaviors, inspirational motivation, intellectual stimulation, individual consideration,

2) transactional leadership (contingency reward, active management-by-exception, 3) passive avoidant (passive management-by-exception, laissez-faire), and 4) outcomes of leadership (extra effort, effectiveness, and satisfaction). 
It would be of interest to explore the nurse managers' perception of their leadership behaviors as compared to the staff nurses' perception of those nurse managers. This may offer possible explanations for the difference in various groups of staff nurses' job satisfaction. For example, why do staff nurses with 5 or less years of clinical experience report higher job satisfaction with nurse managers with Transformational leadership style and staff nurses with 11 or more years report no significant relationship with their nurse manager leadership style.

Another recommendation for research would be to examine the correlation between staff nurses employed in their position for 5 or less years and actual turnover. This study found that $41.7 \%$ of the staff nurses reported being in their present position for 5 or less years. This indicates that nurses may be mobile within the facility and could be an indicator of intent to depart the facility. The hospital site for the study was in the process of applying for Magnet Recognition status. Magnet Recognition status is sought by hospitals to demonstrate excellent outcomes in both patient care as well as the ability to attract and retain nurses (Brady-Schwartz, 2005; Hader, Saver \& Steltzer, 2006; Prater, 2009; Taylor, 2005; Upenieks, 2003a).

Further research is suggested to examine the staff nurses' perception of their nurse manager leadership behaviors and staff nurse intent to depart. Retention of staff nurses is critical for hospitals especially during and with impending nursing shortages. Hospital executives, nursing personnel, and human resource development are directly involved with recruitment and retention strategies. The JDI measures overall job satisfaction that is inversely correlated with intent to depart - it is not a direct measure of intent to depart. The Theory of Reasoned Action (TRA) assumed that self-reported intentions or plans were the best predictors of behavior (Sheppard et al., 1988). Many researchers studying 
turnover used turnover intentions as the most immediate and most accurate predictor of actual employee turnover (Van Bruekelen, Van Der Vlist, \& Steensma, 2004; Cotton \& Tuttle, 1986). Studies with specific intent to depart measures and qualitative data may provide additional insight with nurse manager leadership behaviors and staff nurse job intent to depart and actual turnover.

\section{Summary}

Sellgren et al. (2006) found leadership behaviors that were suitable for health care organizations had been poorly explored. Describing the perception of staff nurses' perception of their nurse manager leader behaviors in this study gave additional insight into how nurse manager leader behavior is related to facets of staff nurse job satisfaction and staff nurse overall job satisfaction. Taunton et al. (1997) identified manager leadership behaviors as the "target for intervention most likely to improve retention of hospital staff nurses" (p. 224). As supported by the findings of this study, transformational leadership behaviors of nurse managers is related to facets of staff nurses' satisfaction and overall job satisfaction and can result in developing quality nurse manager leadership training programs and improve staff nurse job satisfaction and retention. 


\section{REFERENCES}

Advisory Board Company. (2002). Annual report. Competing for talent: Recovering America's Hospital Workforce. Washington, DC: Author.

Aiken, L. H., Clarke, S. P., Sloane, D. M., Sochalski, J. A., Busse, R., Clarke, H., et al. (2001). Nurses' report on hospital care in five countries. Health Affairs, 20, 43-53.

Aiken, L. H., Havens, D., \& Sloane, D. (2000). The Magnet nursing services recognition program: A comparison of two groups of Magnet hospitals. American Journal of Nursing [AJN], 100, 26-36.

Albrecht, S. (2005). Leadership climate in the public sector: Feelings matter too! International Journal of Public Administration, 28, 397-416.

Alimo-Metcalfe, B., Alban-Metcalfe, J., Bradley, M., Mariathasan, J., \& Samele, C. (2008). The impact of engaging leadership on performance, attitudes to work and wellbeing at work: A longitudinal study. Journal of Health Organization and Management, 22, 586-598.

American Association of Colleges of Nursing [AACN]. (1999). Faculty shortages intensify nation's nursing deficit [AACN Issue Bulletin]. Retrieved from http://www.aacn.nche.edu/publications/issues/IB499WB.htm American Association of Colleges of Nursing [AACN]. (2005). Nursing faculty shortage [Fact sheet]. Retrieved from www.aacn.nche.edu/Media/Factsheets/facultyshortage.htm 
American Association of Colleges of Nursing [AACN]. (2010). Nursing shortage [Fact sheet]. Retrieved from http://www.aacn.nche.edu/media/factsheets/nursingshortage.htm American Association of Colleges of Nursing [AACN]. (2011). Nursing shortage [Fact sheet]. Retrieved from http://www.aacn.nche.edu/media/factsheets/nursingshortage.htm American Hospital Association [AHA]. (2002). In our hands: How hospital leaders can build a thriving workforce. Chicago: Author.

American Hospital Association [AHA]. (2007). The 2007 state of American's hospitals: Taking the pulse, findings from the 2007 AHA survey of hospital leaders.

Chicago: American Hospital Association.

American Hospital Association [AHA]. (2010). Resource center: Fast facts on US hospitals. Retrieved from http:/www.aha.org/aha/resource-center/Statistics-and-Studies/fast-facts.html American Nurses Association [ANA]. (2002). Nursing's agenda for the future. Washington, DC: Author.

American Nurses Association [ANA]. (2009). ANA nursing administration: Scope and standards of practice. Silver Spring, MD: American Nurses Association. American Nurses Credentialing Center [ANCC]. (n.d.). Magnet recognition program. $A$ new model for ANCC's Magnet recognition program. Retrieved from http://www1.va.gov/nursing/docs/ANCC_NewMagnetModel.pdf American Nurses Credentialing Center [ANCC]. (2010). AACN: Find a Magnet facility. Retrieved from http://www.nursecredentialing.org/Magnet?FindaMagnetFacility.aspx 
Anderson, B., Manno, M., O’Connor, P., \& Gallagher, E. (2010). Listening to nursing leaders: Using national database of nursing quality indicators data to study excellence in nursing leadership. Journal of Nursing Administration, 40, 182-187.

Anthony, M., Standing, T., Glick, J., Duffy, M., Paschall, F., Sauer, M., et al. (2005). Leadership and nurse retention: the pivotal role of nurse managers. Journal of Nursing Administration, 35, 146-155.

Atencio, B. L., Cohen, J., \& Gorenberg, B. (2003). Nurse retention: Is it worth it? Nursing Economics, 21, 262-299.

Babbie, E. R. (2001). The practice of social research. (9th ed.). Belmont, CA: Wadsworth.

Babin, B. J. \& Boles, J. S. (1996). The effects of perceived co-worker involvement and supervisor support on service provider role stress, performance and job satisfaction. Journal of Retailing, 72, 57-75.

Baldrige National Quality Program. 2003 Award Winner. Retrieved from http://www.nist.gov/public_affairs/baldrige2003/Baptist_3.3.04.pdf

Barrett, A., \& Beeson, J. (2002). Developing business leaders for 2010. New York, NY: Conference Board.

Bartlett, C. A., \& Ghoshal, S. (1995). Changing the role of top management: Beyond strategy to purpose. Harvard Business Review, 72(6), 79-84.

Bass, B. M. (1981). Stogdill's handbook of leadership: A survey of theory and research. New York: The Free Press.

Bass, B. M. (1990). Bass \& Stogdill's handbook of leadership. (3rd ed.). New York: Simon \& Schuster. 
Bass, B. M. (1999). Two decades of research and development in transformational leadership. European Journal of Work and Organizational Psychology, 8, $9-32$.

Bass, B., \& Avolio, B. (2004). MLQ multifactor leadership questionnaire. (3rd ed.). Redwood City, CA: MindGarden, Inc.

Bateman, T. S. \& Organ, D. W. (1983). Job satisfaction and the good soldier: The relationship between affect and employee "citizenship". Academy of Management Journal, 26, 587-595.

Bedeian, A. G., Ferris G. R., \& Kacmar, K. M. (1992). Age, tenure, and job satisfaction: A tale of two perspectives. Journal of Vocational Behavior, 40, 33-48.

Bedeian, A.G., Kemery, E.R., \& Pizzolatto, A.B. (1991). Career commitment and expected utility of present job as predictors of turnover intentions and turnover behavior. Journal of Vocational Behavior, 39, 331-343.

Bennis, W. G., \& Nanus, B. (1985). Leaders: The strategies for taking charge. New York: Harper \& Row.

Benson, S. G., \& Dundis, S. P. (2003). Understanding and motivating health care employees: Integrating Maslow's hierarchy of needs, training and technology. Journal of Nursing Management, 11, 315-320.

Berger, D. E. (2004). Using regression analysis. In J. S. Wholey, H. P. Hatry, \& K. E. Newcomer (Eds.), Handbook of practical program evaluation (2nd ed.) (pp. 479505). San Francisco: Jossey-Bass.

Bernardin, H. J. (2010). Human resource management: An experiential approach. (5th ed.). Boston: McGraw-Hill. 
Blegen, M. A. (1993). Nurses' job satisfaction: A meta-analysis of related variables. Nursing Research, 42, 36-41.

Blendon, R. J., Schoen, C., Donelan, K., Osborn, R., DesRoches, C. M., Scoles, K., et al. (2001). Physicians' views on quality of care: A five-country comparison, Health Affairs, 20, 233-243.

Brady-Schwartz, D. (2005). Further evidence on the Magnet recognition program. Journal of Nursing Administration, 35, 397-403.

Brodke, M., Sliter, M., Balzer, W., Gillespie, J., Gillespie, M., Gopalkrishnan, P., et al. (2009). The job descriptive index and job in general: 2009 revision quick reference guide. Bowling Green, $\mathrm{OH}$ : Bowling Green State University.

Brown, F. W., \& Reilly, M. D. (2009). The Myers-Briggs type indicator and transformational leadership. Journal of Management Development, 28, 916-932.

Buchan, J. (1999). Still attractive after all these years? Magnet hospitals in a changing health care environment. Journal of Advanced Nursing, 30, 100-108.

Buckingham, J., \& Coffman, C. (1999). First Break All the Rules. NewYork: Simon and Schuster.

Buerhaus, P., Auerbach, D., \& Staiger, D. (2009). The recent surge in nurse employment: Causes and implications. Health Affairs, 28, 657-668.

Buerhaus, P., Donelan, K., Ulrich, B., Norman, L., \& Dittus, R. (2006). State of the registered nurse workforce in the United States. Nursing Economics, 24, 6-12.

Burke, R. (2006). Why leaders fail: exploring the darkside. International Journal of Manpower, 27, 91-100.

Burns, J. M. (1978). Leadership. New York: Harper and Row. 
Burns, N., \& Grove, S. K. (2009). The practice of nursing research: Appraisal, synthesis, and generation of evidence. (6th ed.). St. Louis, MO: Saunders Elsevier.

Calhoun, J. (2008). Development of an interprofessional competency model for healthcare leadership. Journal of Healthcare Management, 53, 375-391.

Changing Minds. (2009). Leadership theories. Retrieved from http://changingminds.org/disciplines/leadership/theories/leadership_theories.htm

Charmel, P. (2009). Changing the face of healthcare. Retrieved from http://www.griffinhealth.org/AboutGriffin/Mission.aspx

Cohen, J. (1988). Statistical power analysis for the behavioral sciences. (2nd ed.). Lawrence Erlbaum Associates: United States.

Corser, W. D. (1995). First-line managers: What do nurses expect? Nursing Management, $26,32-36$.

Cotton, J. L. \& Tuttle, J. M. (1986). Employee turnover: A meta-analysis and review with implications for research. Academy of Management Review, 11, 55-70.

Cropanzano, R., \& Mitchell, M. S. (2005). Social exchange theory: An interdisciplinary review. Journal of Management, 31, 874-900.

Cresswell, J. W. (2008). Educational research: Planning, conducting, and evaluating quantitative and qualitative research (3rd ed.). New Jersey: Pearson Prentice Hall.

Crook, T. R., Ketchen, D. J., Combs, J. G., \& Todd, S. Y. (2008). Strategic resources and performance: A meta-analysis. Journal of Management, 29, 1141-1154.

Cullen, K. (1999). Strong leaders strengthen retention: Skilled nurse leaders give nurses the autonomy they need to stay satisfied and stay put. Nursing Management, 30, $27-28$. 
Deming, W. E. (1993). The new economics for industry, government, education. Cambridge: Massachusetts Institute of Technology.

Dillman, D. A., Smyth, J. D., \& Christian, L. M. (2009). Internet, mail, and mixed-mode surveys: The tailored design method. (3rd ed.). Hoboken, New Jersey: John Wiley \& Sons.

Dooley, C. R. (1945). The training within industry report, 1940-1945. Washington, DC: War Manpower Commission Bureau of Training, Training within Industry Service.

Dunham-Taylor, J. (2000). Nurse executive transformational leadership found in participative organizations. Journal of Nursing Administration, 30, 241-50.

Emerson, R. M. (1976). Social exchange theory. Annual Review of Sociology, 2, 335-362.

Fang, D., \& Tracy, C. (2010). Special survey on vacant faculty positions for academic year 2009-2010. American Association of Colleges of Nursing [ANCC]. Retrieved from http://www.aacn.nche.edu/IDS/pdf/vacancy09.pdf

Foong-Loke, C. (2001). Leadership behaviors: Effects on job satisfaction, productivity, and organizational commitment. Journal of Nursing Management, 9, 191-200.

Force, M. (2005). The relationship between effective nurse managers and nursing retention. Journal of Nursing Administration, 35, 336-341.

Gandossy, R., \& Guarnieri, R. (2008). Can you measure leadership? MIT Sloan Management Review, Fall, 65-69.

Gettler, L. (2003). Jay Conger: Why chief executives fail. Retrieved from Management Today http://www.aim.com.au/resources/article_jconger.html 
Glickman, W., Baggett, K., Krubert, C., Peterson, E., \& Schulman, K. (2007). Promoting quality: The health-care organization from a management perspective. International Journal of Quality Health Care, 19, 341-348.

Goffin, R. D. \& Gellatly, I. R. (2001). A multi-rater assessment of organizational commitment: Are self-report measures biased? Journal of Organizational Behavior, 22, 437-451.

Graber, D. \& Kilpatrick, A. (2008). Establishing values-based leadership and value systems in healthcare organizations. Journal of Health and Human Services Administration, 31, 179-197.

Graeff, C. L. (1997). Evolution of situational leadership theory: A critical review. The Leadership Quarterly, 8, 153-170.

Greguras, G., \& Ford, M. (2006). An examination of the multidimensionality of supervisor and subordinate perceptions of leader-member exchange. Journal of Occupational and Organizational Psychology, 79, 433-465.

Griffeth, R. W., Hom, P. W., \& Gaertner, S. (2000). A meta-analysis of antecedents and correlates of employee turnover: Update, moderator tests, and research implications for the next millennium. Journal of Management, 26, 463-488.

Hader, R., Saver, C., \& Steltzer, T. (2006). No time to lose: Results from nursing management's exclusive aging workforce survey. Nursing Management, 37, $23-29,48$.

Hellman, C. M. (1997). Job satisfaction and intent to leave. Journal of Social Psychology, $137,677-689$.

Herzberg, F. (1987). One more time: How do you motivate employees? Harvard Business Review, Sept/Oct, 87-99. 
House, R. J. (1996). Path-goal theory of leadership: Lessons, legacy, and a reformulated theory. Leadership Quarterly, 7, 323-352.

House, R. J. \& Wigdor, L. A. (1967). Herzberg's dual-factor theory of job satisfaction and motivation: A review of the evidence and a criticism. Personnel Psychology, 369-389.

Huselid, M. (1995). The impact of human resource management practices on turnover, productivity, and corporate financial performance. Academy of Management Journal, 38, 635-872.

Ingersoll, G. L., Witzel, P. A., Berry, C., and Qualls, B. (2010). Meeting Magnet research and evidence-based practice expectations through hospital-based research centers. Nursing Economics, 28(4), 226-235.

Institute of Medicine (IOM). (1999). To err is human: Building a safer health system. Retrieved from http://www.iom.edu/Reports/1999/To-Err-is-Human-Building-ASafer-Health-System.aspx

Institute of Medicine (IOM). (2001). Crossing the quality chasm: A new health system for the 21st century. Retrieved from http:/www.iom.edu/Reports/2001/Crossing-theQuality-Chasm-A-New-Health-System-for-the-21st-Century.aspx

Institute of Medicine (IOM). (2003). Health professions education: A bridge to quality. Retrieved from http://www.iom.edu/Reports/2003/Health-Professions-EducationA-Bridge-to-Quality.aspx

Institute of Medicine (IOM). (2004). Keeping patients safe: Transforming the work environment of nurses. Washington, DC: Author.

Institute of Medicine (IOM). (2010). The future of nursing: Leading change, advancing health. Retrieved from http://www.iom.edu/nursing 
Irvine, D., \& Evans, M. (1995). Job satisfaction and turnover among nurses: Integrating research findings across studies. Nursing Research, 44, 246-252.

Jago, A. G. (1982). Leadership: Perspective in theory and research. Management Science, $28,315-336$.

James, D. (2003). Back to the future - Enduring traits in leadership. Retrieved from Management Today http://www.aim.com.au/DisplayStory.asp?ID=462

Jones, C. (2004). The costs of nurse turnover, part 1: An economic perspective. Journal of Nursing Administration, 34, 562-570.

Jones, C. (2008). Revisiting nurse turnover costs. The Journal of Nursing Administration. $38,11-18$.

Jones, C., \& Gates, M. (2007). The costs and benefits of nurse turnover: A business case for nurse retention. OJIN: The Online Journal of Issues in Nursing, 12.

Jooste, K. (2004). Leadership: A new perspective. Journal of Nursing Management, 12, 217-223.

Judge, T. A., Bono, J. E., Ilies, R., \& Gerhardt, M. W. (2002). Personality and leadership: A qualitative and quantitative review. Journal of Applied Psychology, 87, $765-780$.

Kerfoot, K. (2000). The leader as a retention specialist. Nursing Economics, 18, 216-218.

Kettering-Murray, M. (2002). The nursing shortage: Past, present, and future. Journal of Nursing Administration, 32, 79-83.

Kleinman, C. (2004a). Leadership: A key strategy in staff nurse retention. Journal of Continuing Education in Nursing, 35, 128-132. 
Kleinman, C. (2004b). The relationship between managerial leadership behaviors and staff nurse retention, $82,2-9$.

Koltko-Rivera, M. E. (2006). Rediscovering the later version of Maslow's hierarchy of needs: Self-transcendence and opportunities for theory, research, and unification. Review of General Psychology, 10, 302-317.

Kotter, J. P. (1988). The leadership factor. New York: The Free Press.

Kouzes, J. M., \& Posner, B. Z. (2002). The leadership practices inventory: Theory and evidence behind the five practices of exemplary leaders. Retrieved from http://media.wiley.com/assets/463/74/lc_jb_appendix.pdf

Kouzes, J. M., \& Posner, B. Z. (2003). The Leadership Challenge (3rd ed.). San Francisco, CA: Jossey-Bass

Kovner, C., Brewer, C., Fairchild, S., Poornima, S., Kim, H., \& Djukic, M. (2007). Newly licensed RNs: Characteristics, work attitudes, and intentions to work. American Journal of Nursing, 107, 58-70.

Kovner, C., Brewer, C., Wu, Y., Cheng, Y., \& Suzuki, M. (2006). Factors associated with work satisfaction of registered nurses. Journal of Nursing Scholarship, 38, $71-79$.

Kramer, M. (1990). The Magnet hospitals: Excellence revisited. Journal of Nursing Administration, 20, 35-44.

Kramer, M., \& Schmalenberg, C. (1988a). Magnet hospitals: Institutions of excellence part 1. Journal of Nursing Administration, 18, 13-24.

Kramer, M., \& Schmalenberg, C. (1988b). Magnet hospitals: Institutions of excellence part 2. Journal of Nursing Administration, 18, 11-19. 
Kramer, M. \& Schmalenberg, C. (1991). Job satisfaction and retention insights for the '90s part 2. Nursing, 21, 51-55.

Kramer, M., \& Schmalenberg, C. (2003). Magnet hospital nurses describe control over nursing practice, $25,434-452$.

Kramer, M., \& Schmalenberg, C. (2005) Best quality patient care - A historical perspective on Magnet hospitals. Nursing Administration Quarterly, 29 , 275-287.

Laschinger, H., \& Finegan, J. (2005). Using empowerment to build trust and respect in the workplace: A strategy for addressing the nursing shortage. Nursing Economics, 23, 6-13.

Lashinger, H., Finegan, J., \& Wilk, P. (2009). Context matters: The impact of unit leadership and empowerment on nurses' organizational commitment. Journal of Nursing Administration, 39, 228-235.

Laschinger, H., Purdy, N., \& Almost, J. (2007). The impact of leader-member exchange quality, empowerment, and core self-evaluation on nurse manager's job satisfaction. Journal of Nursing Administration, 37, 221-229.

Laschinger, H., Wong, C., McMahon, L., \& Kaufmann, C. (1999). Leader behavior impact on staff nurse empowerment, job tension, and work effectiveness. Journal of Nursing Administration, 29, 28-39.

Lasky, S., Datnow, A., Stringfield, S., \& Sundell, K. (2007). Diverse populations and school effectiveness and improvement in the USA. In T. Townsend (Ed.), International handbook of school effectiveness and improvement, 557-579.

Dordrecht, The Netherlands: Springer. 
Lewis, C., \& Matthews, J. (1998). Magnet program designates exceptional nursing services. American Journal of Nursing, 98, 51-52.

Luthans, F. (2005). Organizational Behavior. Boston, MA: McGraw-Hill Irwin.

Maag, M. (2006). A conceptual framework for a clinical nurse leader program. Journal of Professional Nursing, 22, 367-72.

Malloch, K., \& Porter-O'Grady. (2009). The Quantum Leader: Applications for the new world of work. Sudbury, MA: Jones and Bartlett.

Mancino, D. (2008). The nursing shortage: Predictions and predicaments. Dean's Notes. $30,1-2$.

Mancino, D. (2009). Entry level positions for new graduates: Real-time dilemma requires real-time solutions. Dean's Notes, 31, 1-3.

Marriner-Tomey, A. (1993). Transformational leadership in nursing. St. Louis: Mosby.

Martin, C. (2004). Turn on the staying power. Nursing Management, 35, 21-26.

Maslow, A. H. (1943). A theory of human motivation. Psychological Review, 50, 370-396.

McGregor, D. M. (1960/1985). The human side of enterprise. New York: NY: McGrawHill.

McGuire, E., \& Kennerly, S. (2006). Nurse managers as transformational and transactional leaders. Nurse Economics, 24, 179-185.

McNeese-Smith, D. (1995). Job satisfaction, productivity, and organizational commitment. Journal of Nursing Administration, 25, 17-26.

McNeese-Smith, D. (1997). The influence of manager behavior on nurses' job satisfaction, productivity, and commitment. Journal of Nursing Administration, $27,47-55$. 
Medley, F. \& Larochelle, D. R. (1995). Transformational leadership and job satisfaction. Nursing Management, 26, 64JJ-64NN.

Moye, M., \& Henkin, A. (2006). Exploring associations between employee empowerment and interpersonal trust in managers. Journal of Management Development, 25, 101-117.

National Association for Healthcare Quality (NAHQ). (2006). Lean six sigma in healthcare. Journal for Healthcare Quality. Retrieved from http://www.nahq.org/journal/ce/article.html?article_id=250

Neill, M., \& Saunders, N. (2008). Servant leadership: Enhancing quality of care and staff satisfaction. Journal of Nursing Administration, 38. 395-400.

Northouse, P. G. (2010). Leadership theory and practice. (5th ed). Los Angeles: SAGE. Nunnally, J. C., \& Bernstein, I. H. (1994). Psychometric theory (3rd ed.). New York: McGraw-Hill.

Nursing Solutions, Inc (NSI). (2009). 2009 national healthcare and RN retention report. Retrieved from http:/www.nsinursingsolutions.com/Files/assets/library/retentioninstitute/NationalHealthcareRNRetentionReport2009.pdf

O'Reilly, M. (2007). Change and change again - Nurse leaders in the new millennium Retrieved from http://cme.medscape.com/viewarticle/568013

Pfeffer, J. (1977). The ambiguity of leadership. The Academy of Management Review, 2, 104-112.

Picker-Rotem, L., Schneider, A., Wasserzub, S., \& Zelker, R. (2008). Nursing leaders of tomorrow: A peer selection process. Journal of Nursing Management, 16, 915-920. 
Popper, M. (2004). Leadership as relationship. Journal for the Theory of Social Behavior, $34,107-125$.

Porter-O'Grady, T. (1999). Quantum leadership: New roles for a new age. Journal of Nursing Administration, 29, 37-42.

Porter-O'Grady. T. (2003). A different age for leadership: Part I. Journal of Nursing Administration, 33(2), 105-110.

Porter-O'Grady, T. \& Malloch, K. (2007). Managing for success in healthcare. St. Louis, MO: Mosby Elsevier.

Porter-O'Grady, T. \& Malloch, K. (2007). Quantum leadership: A resource for health care innovation, (2nd ed.) Boston, Mass: Jones \& Bartlett.

Prater, M. (2009). Nursing at Memorial: A Magnet hospital. Retrieved from https://www.memorialmedical.com/CareerCenter/Nursing/

Purvanova, R., Bono, J. \& Dzieweczynski, J. (2006). Transformational leadership, job characteristics, and organizational citizenship performance. Human Performance, $19,1-22$

Rad, A. \& Yarmohammadian, M. (2006). A study of relationship between managers' leadership style and employees' job satisfaction. Journal of Leadership in Health Services, 19, 11-28.

Randolph, P. (2010). What happened to the nursing shortage? Leader to Leader, Spring 2010

Rearick, E. (2007). Enhancing success in transition service coordinators: Use of transformational leadership. Professional Case Management, 12, 283-287.

Robbins, B., \& Davidhizar, R. (2007). Transformational leadership in healthcare today. The Health Care Manager, 26, 234-239. 
Robert Wood Johnson Foundation (RWJF). (2007). Multiple factors affect job satisfaction of hospital RNs. RWJF Research Highlight, 22, 1-2.

Roussel, L. (2006). Management and leadership for nurse administrators. (4th ed.). Boston: Jones and Bartlett.

Rowland, H. \& Rowland, B. (1997). Nursing administration handbook. (4th ed.). Gaithersburg, MD: Aspen.

Schmidt, F. L., \& Hunter, J. E. (1998). The validity and utility of selection methods in personnel psychology: Practical and theoretical implications of 85 years of research findings. Psychological Bulletin, 124, 262-275.

Schwab, D. P. \& Cummings, L. L. (1970). Theories of performance and satisfaction: A review. Industrial Relations: A Journal of Economy and Society, 9, 408-430.

Sellgren, S., Ekvall, G., \& Tomson, G. (2006). Leadership styles in nursing management: Preferred and perceived. Journal of Nursing Management, 14, 348-355.

Senge, P. (1990). The fifth discipline: The art and practice of the learning organization. New York: Doubleday.

Shamir, B., House, R. J., \& Arthur, M. B. (1993). The motivational effects of charismatic leadership: A self-concept based theory. Organizational Science, 4, 577-594.

Shavelson, R. J. (1996). Statistical Reasoning for the Behavioral Sciences (3rd ed.). Boston: Allyn and Bacon, Inc.

Sheppard, B. H., Hartwick, J., \& Warshaw, P. R. (1988). The theory of reasoned action: A meta-analysis of past research with recommendations for modifications and future research. Journal of Consumer Research, 15, 325-343.

Sherman, R. O., Bishop, M., Eggenberger, T., \& Karden, R. (2007). Development of a leadership competency model. Journal of Nursing Administration, 37, 85-94. 
Skytt, B., Ljunggren, B., \& Carlsson, M. (2007). Reasons to leave: The motives of firstline nurse managers' for leaving their posts. Journal of Nursing Management, 15, 294-302.

Smith, P. C., Kendall, L. M., \& Hulin, C. L. (1969). The measurement of satisfaction in work and retirement. Chicago: Rand McNally.

Sosik, J., Potosky, D., \& Jung, D. (2002). Adaptive self-regulation: Meeting others' expectations of leadership and performance. The Journal of Social Psychology, $142,211-232$.

Stanton, J. \& Crossley, C. (Eds.). (2000). Electronic resources for the JDI and JIG. Bowling Green, OH: Bowling Green State University.

Steel, R. P. (2002). Turnover theory at the empirical interface: Problems of fit and function. Academy of Management Review, 27, 346-360.

Stefl, M. (2008). Common competencies for all healthcare managers: The healthcare leadership alliance model. Journal of Healthcare Management, 53, 360-374.

Stevens, J. (2009). Applied multivariate statistics for the social sciences (5th ed.). New York: Routledge.

Stogdill, R. M. (1974). Stogdill's handbook of leadership: A survey of theory and research. New York: The Free Press.

Studer, Q. (2004). The value of employee retention. Healthcare Financial Management. Retrieved from http://findarticles.com/p/articles/mi_m3257/is_1_58/ai_n6068612/ 
Sullivan, J., Bretschneider, J., McCausland, M. (2003). Designing a leadership development program for nurse managers: an evidence-driven approach. Journal of Nursing Administration, 33, 544-549.

Swanson, R. A. \& Holton III, E. F. (2001). Foundations of human resource development. San Francisco: Berrett-Kohnler.

Swenson, C. (2008). Next Generation Workforce. Nursing Economics, 26, 64-65.

Taunton, R., Boyle, D., Woods, C., Hansen, H., \& Bott, J. (1997). Manager leadership and retention of hospital staff nurses. Western Journal of Nursing Research, 19, 205-226.

Taylor, N. (2005). The Magnetic Pull. Nursing Management, 36(7), 45-57.

Taylor, R. B. (2003). Leadership is a Learned Skill. Family Practice Management, 10, $43-48$.

Tett, R. P. \& Meyer, J. P. (1993). Job satisfaction, organizational commitment, turnover intention, and turnover: Path analyses based on meta-analytic findings. Personnel Psychology, 46, 259-275.

Thomas, K. W. (2000). Intrinsic motivation at work: Building energy and commitment. San Francisco: Berrett-Koehler.

Tietjen, M. A. \& Myers R. M. (1998). Motivation and job satisfaction. Management Decision, 36, 226-231.

Ulrich, B., Buerhaus, P., Donelan, K., Norman, L., \& Dittus, R. (2005). How RNs view the work environment: Results of a national survey of registered nurses. Journal of Nursing Administration, 35, 389-396. 
Upenieks, V. (2003a). The interrelationship of organizational characteristics of Magnet hospitals, nursing leadership, and nursing job satisfaction. Health Care Manager, 22, 83-98.

Upenieks, V. (2003b). What constitutes effective leadership? Perceptions of Magnet and non Magnet nurse leaders. Journal of Nursing Administration, 33, 456-467.

U.S. Department of Health and Human Services, Health Resources and Services Administration [HRSA]. (2010). The registered nurse population: Initial findings from the 2008 national sample survey of registered nurses. Retrieved from http://bhpr.hrsa.gov/healthworkforce/rnsurvey/initialfindings2008.pdf

U.S. Department of Labor, Bureau of Labor Statistics [BLS]. (2009). Employment projects: Occupations with the largest job growth. Retrieved from http://www.bls.gov/emp/ep_table_104.htm

U.S. Department of Labor, Bureau of Labor Statistics [BLS]. (2010). Regional and state unemployment - 2009 annual averages. Retrieved from http://www.bls.gov/news.release/pdf/srgune.pdf

Vahey, D., Aiken, L., Sloane, D., Clarke, S., \& Vargas, D. (2004). Nurse burnout and patient satisfaction. Medical Care. 42, 57-66.

Van Breukelen, W., Van Der Vlist R., \& Steensma, H. (2004). Voluntary employee turnover: Combining variables from the traditional turnover literature with the theory of planned behavior. Journal of Organizational Behavior, 25, 893-914.

Vance, C., \& Larson, E. (2002). Leadership research in business and health care. Journal of Nursing Scholarship, 34, 165-171.

Ventegodt, S., Merrick, J. \& Anderson, N. J. (2003). Quality of life theory III: Maslow revisited. The Scientific World Journal, 3, 1050-1057. 
Vroom, V. H. \& Yetton, P. W. (1973). Leadership and decision-making. Pittsburg: University of Pittsburg Press

Wagner, C. (2007). Organizational commitment as a predictor variable in nursing turnover research: Literature review. Journal of Advanced Nursing, 60, 235247.doi:10.111/j.1365-2648.2007.04421.x

Watters, S. (2009). Shared leadership: Taking flight. Journal of Nursing Administration, $39,26-29$.

Webb, K. (2007). Motivating peak performance: Leadership behaviors that stimulate employee motivation and performance. Christian Higher Education, 6, 53-71.

Westlund, S. G. \& Hannon, J. C. (2008). Retaining talent: Assessing job satisfaction facets most significantly related to software developer turnover intentions. Journal of Information Technology Management, 19, 1-15.

Wooten, L., \& Crane, P. (2003). Nurses as implementers of organizational culture. Nursing Economics, 21, 275-279.

Yang, Y. (2009). An investigation of group interaction functioning stimulated by transformational leadership on employee intrinsic and extrinsic job satisfaction: An extension of the resource-based theory perspective. Social Behavior and Personality, 37, 1259-1278.

Yukl, G. A. (1989). Leadership in organizations. (2nd ed.). Englewood Cliffs, NJ: Prentice Hall.

Zerwekh, J. \& Garneau, A. Z. (2012). Nursing today: Transition and trends. (7th ed.) St. Louis, MO: Elsevier Saunders 


\section{APPENDIX A}

INSTRUMENT INCLUDING MULTIFACTOR LEADERSHIP QUESTIONNAIRE (MLQ), ABRIDGED JOB DESCRIPTIVE INDEX/ABRIDGED JOB IN GENERAL (AJDI/AJIG) SURVEY, AND DEMOGRAPHIC QUESTIONNAIRE 
Page 1

Survey Instruments (modified document for dissertation)

Multifactor Leadership Questionnaire (5x-Short)

This questionnaire is to describe the leadership style of your nurse manager as you perceive it. Please answer all items on this answer sheet. If an item is irrelevant, or if you are unsure or do not know the answer, leave the answer blank.

Forty-five descriptive statements are listed below. Judge how frequently each statement fits your nurse manager.

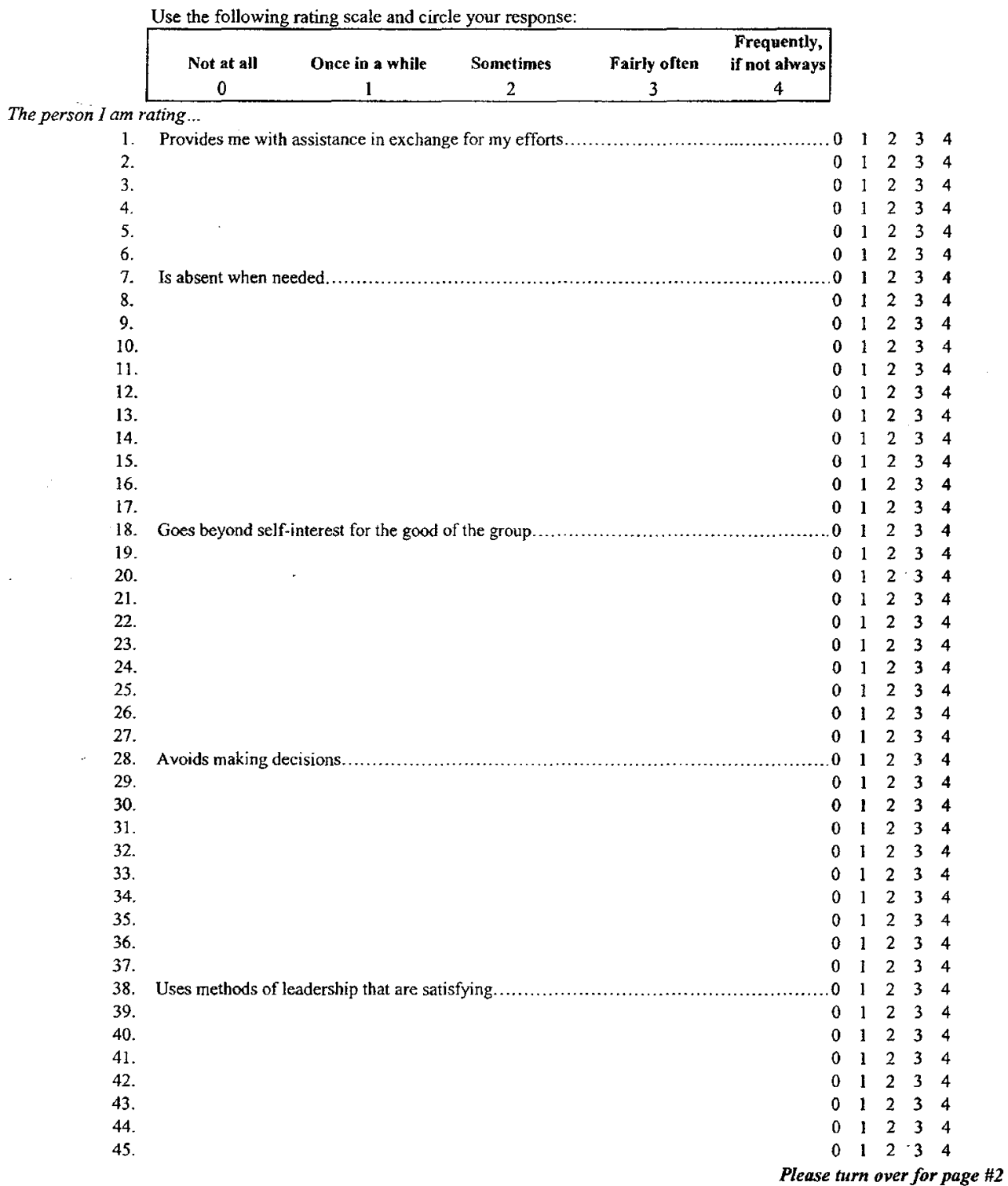


Page 2

Abridged Job Descriptive Index / Abridged Job in General Scale (Bowling Green State University, 2009)

Work on Present Job: Think of the work you do at present. How well does each of the following words or phrases describe your work? In the blank beside each word or phrase below, write

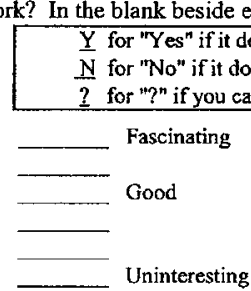

Pay: Think of the pay you get now. How well does each of the following words or phrases describe your present pay? In the blank beside each word or phrase below, write

\begin{tabular}{c}
$\begin{array}{c}\mathrm{Y} \text { for "Yes" if it describes your pay } \\
\mathrm{N} \text { for "No" if it does not describe it } \\
\text { for "?" if you cannot decide }\end{array}$ \\
\hline \\
\hline$\square$ Barely live on income \\
$\square$ Cell paid \\
\hline.$\quad$ Comfortable
\end{tabular}

Opportunities for Promotion: Think of the opportunities for promotion that you have now. How well does each of the following words or phrases describe these? In the blank beside each word or phrase below, write

\begin{tabular}{c}
$\begin{array}{c}\underline{Y} \text { for "Yes" if it describes your opport } \\
\underline{N} \text { for "No" if it does not describe them } \\
\text { for "?" if you cannot decide }\end{array}$ \\
\hline Good opportunities for promotion \\
$\square$ Dead-end job \\
$\square \quad$ Fairly good chance for promotion
\end{tabular}

Supervision: Think of the kind of supervision that you get on your job. How well does each of the following words or phrases describe this? In the blank beside each word or phrase below, write

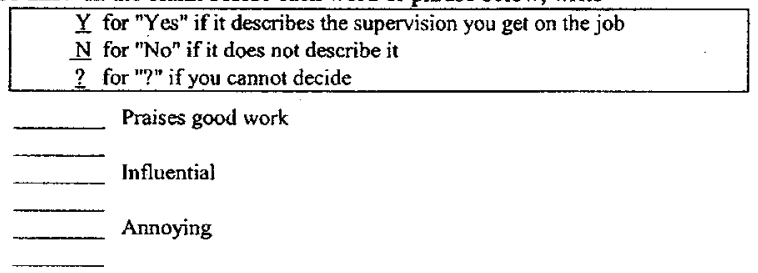

People on Your Present Job: Think of the majority of people with whom you work or meet in connection with your work. How well does each of the following words or phrases describe these people? In the blank beside each word or phrase below, write

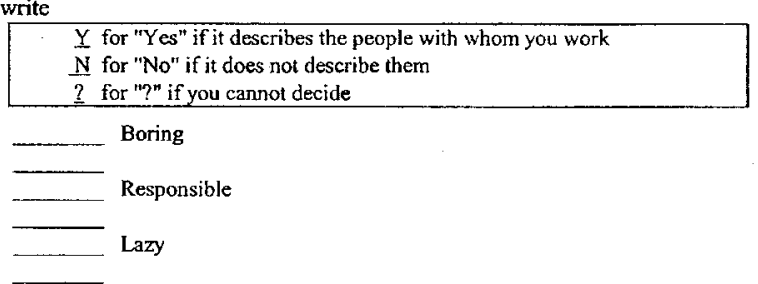


Page 3

Job in General: Think of your job in general. All in all, what is it like most of the time? In the blank beside each word or phrase below, write

$\begin{gathered}\frac{Y}{N} \text { for "Yes" if it describes your job } \\ \frac{N}{2} \text { for "No" if it does not describe it } \\ \square \text { Good cannot decide }\end{gathered}$
$\square$ Getter than most
$\square$ Makes me content
$\square$ Enjoyable

\section{Demographics}

\begin{tabular}{|c|c|c|c|c|c|}
\hline \multicolumn{3}{|c|}{ 1. What is your age? } & \multirow[b]{2}{*}{$36-40$} & \multirow[b]{2}{*}{7} & \multirow[b]{2}{*}{$-51-55$} \\
\hline & $<26$ & 4 & & & \\
\hline & $26-30$ & 5 & $41-45$ & 8 & $56-60$ \\
\hline & & 6 & $46-50$ & 9 & $>60$ \\
\hline
\end{tabular}

3. What is your highest nursing educational preparation.

1 ___ diploma in nursing

2 _ associate degree in nursing

3 _ baccalaureate degree in nursing

4 master's degree in nursing

5. Length of time in the current hospital?

$\begin{array}{lll}1 & <5 & 4 \\ 2 & 6-10 & 5\end{array}-\begin{aligned} & 16-20 \\ & 21-25\end{aligned}$

$\begin{array}{ll}2 \\ 3\end{array}-\begin{array}{ll}6-10 & 5 \\ 11-15 & 6\end{array}-\begin{aligned} & 21-25 \\ & >25\end{aligned}$

7. What is your primary shift of work?

$1 \quad 7 \mathrm{a}-7 \mathrm{p}$

$2 \longrightarrow 7 \mathrm{p}-7 \mathrm{a}$

3 other
2. Years of clinical experience.

$1<5 \quad 4 \ldots 16-20$

$2-6-10 \quad 5-21-25$

$3-11-15 \quad 6->25$
4. 1 background in nursing
2 higher degree in another field
3 certifications

The following information is optional. Information provided will be used for future research.

Print your name

Print your nurse manager name:

8. Indicate status:

Full-time 2

$6>25$

\begin{tabular}{|c|c|c|c|}
\hline \multicolumn{4}{|c|}{ Length of time in the present position? } \\
\hline 1 & $<5$ & 4 & $16 \cdot 20$ \\
\hline & $6-10$ & 5 & $21-25$ \\
\hline & $11-15$ & 6 & $>25$ \\
\hline
\end{tabular}

9. What is your predominate area/unit of work? (please list)

PRN

Thank you for taking the time to participate in this study. 


\section{APPENDIX B}

PERMISSION FOR USE OF THE MLQ QUESTIONNAIRE 


\section{mind garden}

www.mindgarden.com

To whom it may concern,

This letter is to grant permission for the above named person to use the following copyright material;

Instrument: Multifactor Leadership Questionnaire

Authors: Bruce Avolio and Bernard Bass

Copyright: 1995 by Bruce Avolio and Bernard Bass

for his/her thesis research.

Five sample items from this instrument may be reproduced for inchusion in a proposal, thesis, or dissertation.

The entire instrument may not be inchuded or reproduced at any time in any other published material.

Sincerely,

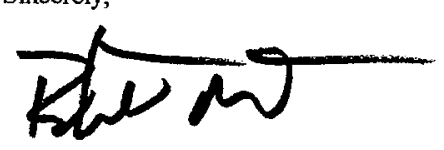

Robert Most

Mind Garden, Inc.

www.mindgarden.com

(c) 1995 Bruce Avolio and Bernard Bass. All Rights Reserved. Published by Mind Garden, Inc., www.mindgarden.com 


\section{APPENDIX C}

PERMISSION TO USE ABRIDGED JOB DESCRIPTIVE INDEX / ABRIDGED JOB IN GENERAL (AJDI - AJIG) 


\section{Bormann, Lorraine}

$\begin{array}{ll}\text { From: } & \text { JDI Research Assistance [joi ra@bgsu.edu] } \\ \text { Sent: } & \text { Monday, September 13,2010 7:21 PM } \\ \text { To: } & \text { Bormann, Lorraine } \\ \text { Subject: } & \text { JDI Order } \\ \text { Attachments: } & \text { 6363_Bormann.pdf; JDIJIG_QRG.pdt, SmithKendallHulin 1969.pdf; aJIGblank.sav, AJDI } \\ & \text { 06-2010.SPS; AJDiblank.sav; AJIG 06-2010.SPS }\end{array}$

Hi Lorraine,

Thanks for your recent order of JDI products from Bowling Green State University. The documents that you ordered are attached to this email.

-6363 Bormann.pdf is a copy of your receipt for this purchase

- JDIJIG_QRG.pdf is the Quick Reference Guide for the JDI/JIG

- SmithKendallHulin1969.pdf is the book Measurement of Satisfaction in Work and Retirement

There are four files for the SPSS automated scoring

- AlGblank.sav and ADDIblank.sav are blank SPSS files into which you will enter people's raw score data. AJDI data will need to be entered into AJDIblank.sav and AIG data will need to be entered into AJIGblank.sav. When entering in the raw data use the following format: yes $=1$, no $=2$, and $?=3$.

-AJIG 06 2010.SPS and AJDI O6 2010 are the actual syntax files that will properly re-code your data. The AlG file will re-code your AIG data, and the AJDI file will recode your AJDI data. Feel free to ask questions when you get to this stage in your research.

If I can be of further assistance, please let me know.

Best regards,

Chris

Christopher Lake

Job Descriptive Index (JDI) Office

Department of Psychology

Bowling Green State University

Bowling Green, $\mathrm{OH} 43403$

Tel: 419.372 .8247

Fax: 419.372 .6013

JDI Webpage 


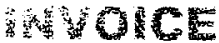

\section{JDI Office}

Bowling Green State University

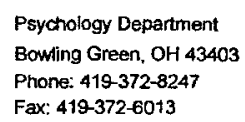


APPENDIX D

PREAMBLE/CONSENT FORM 
The Relationship Between Staff Nurse Perception of Nurse Manager Leadership Behavior and Staff Nurse Job Satisfaction in a Hospital Applying for Magnet Status

January 28, 2011

\section{Dear Staff Nurse:}

You are being invited to participate in a research study by answering the attached survey about the relationship between staff nurse perception of nurse manager leadership behavior and staff nurse job satisfaction in a hospital applying for magnet status. There are no known risks for your participation in this research study. The information collected may not benefit you directly. The information learned in this study may be helpful to others. The information you provide will be analyzed for the completion of the doctoral dissertation of Lorraine Bormann. Your completed survey data will be stored at the office of the Department of Educational Leadership, Foundations, and Human Resource Education. The survey will take approximately 20 minutes to complete.

Individuals from the Department of Educational Leadership, Foundations, and Human Resource Education, the Institutional Review Board (IRB), the Human Subjects Protection Program Office (HSPPO), and other regulatory agencies may inspect these records. In all other respects, however, the data will be held in confidence to the extent permitted by law. Should the data be published, your identity will not be disclosed.

Taking part in this study is voluntary. By completing this survey you agree to take part in this research study. You do not have to answer any questions that make you uncomfortable. You may choose not to take part at all. If you decide to be in this study you may stop taking part at any time. If you decide not to be in this study or if you stop taking part at any time, you will not lose any benefits for which you may qualify.

If you have any questions, concerns, or complaints about the research study, please contact: Susan Lasky, PhD (502) 852-0634 or Lorraine Bormann (270) 745-3690.

If you have any questions about your rights as a research subject, you may call the Human Subjects Protection Program Office at (502) 852-5188. You can discuss any questions about your rights as a research subject, in private, with a member of the Institutional Review Board (IRB). You may also call this number if you have other questions about the research, and you cannot reach the research staff, or want to talk to someone else. The IRB is an independent committee made up of people from the University community, staff of the institutions, as well as people from the community not connected with these institutions. The IRB has reviewed this research study.

If you have concerns or complaints about the research or research staff and you do not wish to give your name, you may call 1-877-852-1167. This is a 24 hour hot line answered by people who do not work at the University of Louisville.

Sincerely,

Susan G. Lasky, PhD

Lorraine Bormann 


\section{APPENDIX E}

\section{COVER LETTER}


January 14,2011

Dear Staff Nurse:

As a Registered Nurse, I know you are probably very interested in the nursing shortage,

Magnet hospitals, and staff nurse retention. I am currently working on my dissertation entitled:

"The Relationship Between Staff Nurse Perception of Nurse Manager Leadership Behavior and Staff Nurse Job Satisfaction in a Hospital Applying for Magnet Status". I plan to examine your staff nurse perception of your nurse manager's leadership behaviors and your job satisfaction.

You were selected to participate in this study because you are a staff nurse in an acute care hospital that is in the process of applying for Magnet Recognition status. I would greatly appreciate you laking the time to participate in this study by completing the survey, sealing it in the enclosed envelope, and placing it in the closed box located in nursing administration.

Enclosed you will find an informed consent form explaining the purpose, procedures, risks, and benefits of the study. You will also find a brief survey inclusive of the three instruments for this study. You are asked to write your name and your nurse manager name on the survey but this information is optional. This information is for future research related to staff nurse intent to depart and actual turnover and for nurse manager seff-reported leadership behaviors compared to staff nurse perception of nurse manager leadership behaviors. All names will be converted to numerical code for data analysis and interpretation of the findings in the study.

I think the findings from this study could have significant implications for nursing research and hope that all staff nurses take the time to participate. Your completed and submitted survey gives your implied consent for participation and will qualify you for a drawing for one of two $\$ 50$ gift cards.

Thank you in advance for your time and participation in the study.

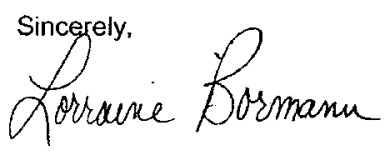

Lorraine Bormann 
APPENDIX F

PERMISSION TO USE LEADERSHIP TABLE 


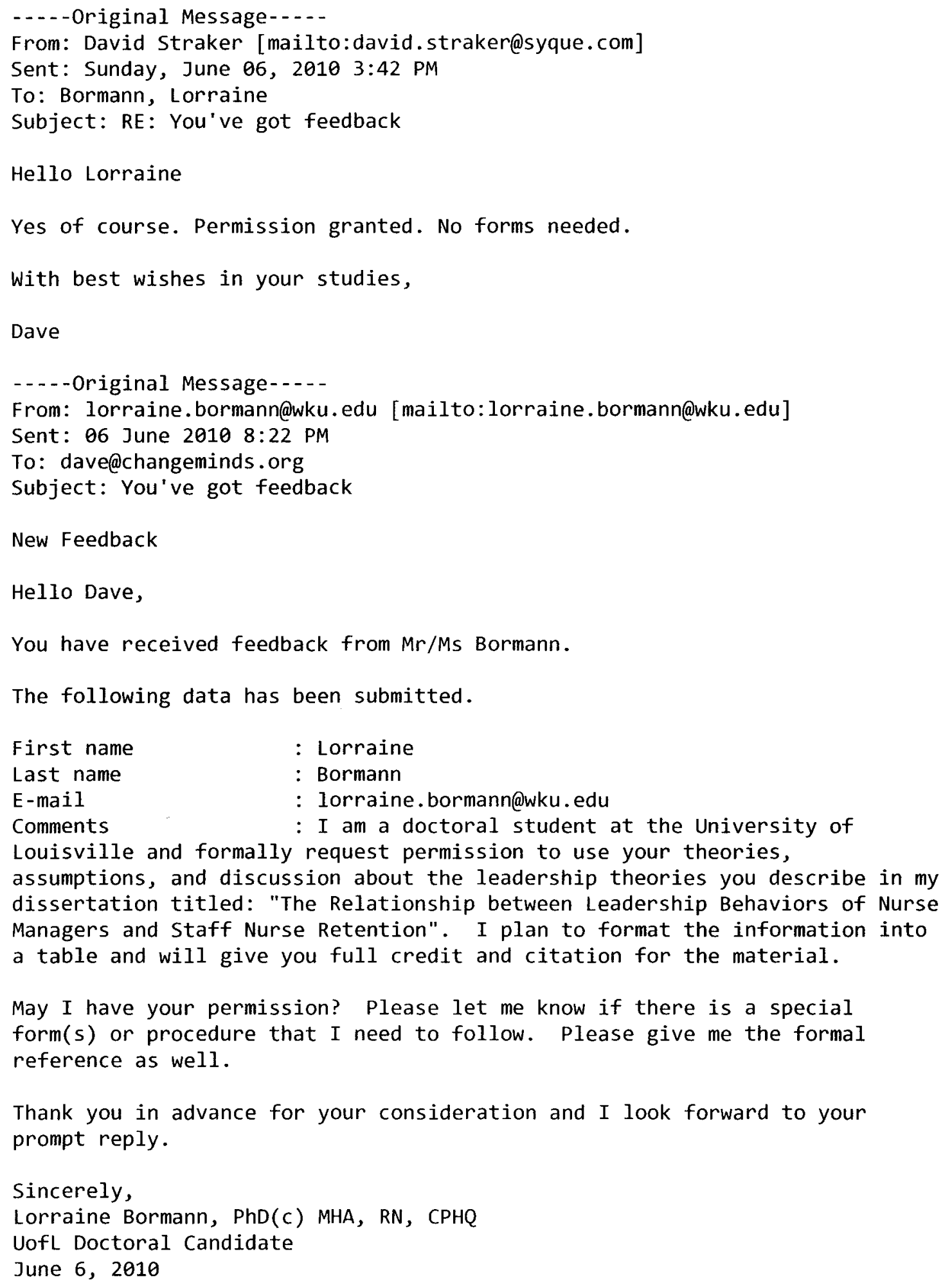




\section{CURRICULUM VITAE}

\section{Lorraine B. Bormann, RN, MHA, CPHQ}

Address: $\quad 242$ Bowie Avenue

Bowling Green, KY 42101

\section{Professional License:}

- Licensed as a Registered Nurse in the State of Kentucky.

\section{Certification:}

- Certified Professional in Healthcare Quality

- Graduate Leadership Studies Certificate

\section{Education:}

- 2008-Present: Doctoral student. (ABD) University of Louisville.

- M.H.A.

Western Kentucky University, 2003.

- B.S.

Western Kentucky University, 2001.

- A.S.N.

Western Kentucky University, 1978.

\section{Current Employment Status:}

- Instructor in the School of Nursing at Western Kentucky University.

\section{Professional Membership:}

- KNA (Kentucky Nurses Association)

- ANA (American Nurses Association)

- AONE (American Organization of Nurse Executives)

- ACHE (American College Healthcare Executives)

- Sigma Theta Tau International - Kappa Theta Tau

- Golden Key International Honour Society

- Eta Sigma Gamma (Honorary Society for Public Education)

- Gamma Beta Phi (Collegiate Honor and Service Organization)

- Harvard School of Public Health Nurses' Study I \& II 